DANIELLA ZANETTI BUCCI

\title{
AÇÃO DO IFN- $\gamma$ SOBRE AS CÉLULAS NÃO LEUCOCITÁRIAS (CÉLULAS ESTRUTURAIS) NA INFECÇÃO PELOS PROTOZOÁRIOS TRYPANOSOMA CRUZI E PLASMODIUM
}

Dissertação apresentada ao Programa de Pós-Graduação em Ciências Biomédicas do Instituto de Ciências Biomédicas da Universidade de São Paulo, para obtenção do Título de Mestre em Imunologia.

São Paulo

2009 


\section{AÇÃO DO IFN- $\gamma$ SOBRE AS CÉLULAS NÃO LEUCOCITÁRIAS (CÉLULAS ESTRUTURAIS) NA INFECÇÃO PELOS PROTOZOÁRIOS TRYPANOSOMA CRUZI E PLASMODIUM}

Dissertação apresentada ao Programa de Pós-Graduação em Ciências Biomédicas do Instituto de Ciências Biomédicas da Universidade de São Paulo, para obtenção do Título de Mestre em Imunologia.

Área de concentração: IMUNOLOGIA Orientador: JOSÉ MARIA ÁLVAREZ MOSIG

São Paulo 2009 
DADOS DE CATALOGAÇÃO NA PUBLICAÇÃO (CIP)

Serviço de Biblioteca e Informação Biomédica do

Instituto de Ciências Biomédicas da Universidade de São Paulo

(C) reprodução total

Bucci, Daniella Zanetti.

Ação do IFN $\gamma$ sobre as células não leucocitários Trypanosoma cruzi e Plasmodium / Daniella Zanetti Bucci. -- São Paulo, 2009.

Orientador: Jose Maria Alvarez Mosig.

Dissertação (Mestrado) - Universidade de São Paulo. Instituto de Ciências Biomédicas. Departamento de Imunologia. Área de concentração: Imunologia. Linha de pesquisa: Imunologia das Paraítoses.

Versão do título para o inglês: The efect on cell no Ifn leukocytes (structural cells) on infection by protozooan Trypanosoma cruzi and Plasmodium.

Descritores: 1. Quimerismo 2. Interferon gamma 3. Plasmodium 4. Trypanosoma cruzi I. Mosig, Jose Maria Alvarez II. Universidade de São Paulo. Instituto de Ciências Biomédicas. Programa de PósGraduação em Imunologia III. Título. 
Título da Dissertação:

Ação do IFN $\gamma$ sobre as células não leucocitários Trypanosoma cruzi e Plasmodium.

Orientador(a): $\quad$ Jose Maria Alvarez Mosig.

A Comissão Julgadora dos trabalhos de Defesa da Dissertação de Mestrado, em sessão pública realizada a .................., considerou
( ) Aprovado(a)
( ) Reprovado(a)

Examinador(a): Assinatura:

Nome:

Instituição:

Examinador(a): Assinatura:

Nome:

Instituição:

Presidente:

Assinatura:

Nome:

Instituição: 
Dedico a toda a minha familia: Líncoln, Ana, Alexandre, Patricia, Rodrigo, Maria Cristina e Yasmin, que sempre me apoiou e compreendeu minhas ausêncías aos almoços de domingo.

$\mathcal{A}$ minha sobrinha linda Yasmin, de quem sempre nos momentos dificeis eu me lembrava e ganhava o dia com seu sorrisinho lindo!!!

Em especial ao meu querido esposo, que apesar de todos os momentos dificeis esteve sempre ao meu lado incondicionalmente.

Ao Pepe que sofreu e cuidou de mím como se eu fosse sua filha, no momento em que fiquei hospitalizada. Estes momentos que ficaram marcados na minha vida não só pelo sofrimento, mas principalmete por ter me dado a oportunidade de confecer o amor de pessoas importantes em minha vida, como meu orientador. 
Aquele que, inocentemente, foi alvo de nosso estudo. Frágil e indefeso, porém, modelo importantíssímo para a evolução do conhecimento científíco.

$\mathcal{N} a ̃ o$ se justificam os meios para se chegarmos aos fins, mas é importante entender, que sua vida permitiu que pudéssemos adentrar um pouco mais na complexidade de uma doença negligenciada, que ainda assola milhares de individuos em todo o âmbito do globo terrestre 


\section{AGRADECIMENTOS}

Ao Prof. Dr. José Maria Alvarez Mosig (Pepe) pela cuidadosa orientação, paciência e dedicação.

À Profa. Dra. Maria Regina D'Império Lima pelas discussões, críticas, apoio e dedicação que em muito me auxiliaram no desenvolvimento desta tese.

Aos amigos e companheiros da velha guarda do laboratório: Rosa, Claudio, Pira, Claudinha, Ana Paula e Luizão, que me auxiliaram muito em meu caminho na pesquisa, se tornando mais que colegas de trabalho e sim amigos.

Ao Luizão, que representa mais que um amigo, um verdadeiro irmão, que me acompanhou desde minha iniciação científica, Às madrugadas no FACS, aos shopinhos no fim do dia e, principalmente, sempre me orientou que não se deve misturar "PEIXE COM VODKA".

A Sheyla, que apesar dos dias que não eram bons, é como uma irmãzinha.

A Claudinha que sempre soube como mostrar que o caminho estava errado, rir e ir às compras nos momentos de estresses.

Ao caro Rogério, sempre se esmerou em me auxiliar em todo o momento me ajudando a superar todos os obstáculos de cada experimento.

Ao caro amigo Sérgio, pelas conversas e auxílios sempre proveitosos.

Ao caro Claudio que me ensinou o valor da pesquisa e fez com que me apaixonasse por ela.

Aos amigos do laboratório: Christian, André, Fernando, Sandrinha (sempre muito amorosa), Henrique, Meire, Dani Piza, Danilo, Eduardo, Érika, Eliane, Bruno e Leandro que sempre estavam dispostos a ajudar e proporcionaram um convívio agradável e divertido. 
Aos Profs Gustavo e Rizzo pelo auxilio e sugestões no durante minha estadia no departamento.

Ao Paulo Albe pelo apoio e esmero técnico.

Agradeço a Sílvia, Regina de Lucca, Sueli, Dorival, Israel e todos os demais funcionários do biotério.

À Jô, Valéria, Eni e Amarildo por todo o apoio burocrático.

Aos amigos Nilton e Otácilio por com seu trabalho por permitirem garantirem a segurança

À Alessandra Comodaro, Andrea, Taciana e Giuliana pela amizade e companherismo. 


\section{RESUMO}

BUCCl, D. Z. Ação do ifn- $\gamma$ sobre as células não leucocitárias (células estruturais) na infecção pelos protozoários trypanosoma cruzi e plasmodium. $118 \mathrm{f}$. Dissertação (Mestrado em Imunologia) - Instituto de Ciências Biomédicas da Universidade de São Paulo, São Paulo, 2009.

O objetivo central desta dissertação de mestrado foi analisar se, pela sua resposta ao interferon- $\gamma$ (IFN $\gamma$ ), as células não leucocitárias contribuem ao controle dos protozoários Trypanosoma cruzi, Plasmodium chabaudi AS e Plasmodium berghei ANKA. O IFNy é uma citocina que promove a ativação de diversos tipos de leucócitos, a sua ação sobre as células mononucleares fagóciticas merece um destaque especial. Apesar de conhecermos os pormenores do papel desta citocina na ativação dos leucócitos, desconhecemos se o IFN $\gamma$ exerce ação ativadora sobre as células estruturais (não leucocitárias), ou seja, sobre as células não profissionais da resposta imune. A nossa hipótese de trabalho é que, no caso dos parasitas intracelulares, o IFN $\gamma$ poderia reforçar a ação sinalizadora e efetora das células estruturais infectadas. Por outro lado, em ambas as situações de parasitas intracelulares e extracelulares, o IFN $\gamma$, ao agir sobre diversas células estruturais, poderia induzir a produção de mediadores inflamatórios (citocinas, quimiocinas, etc) que contribuiriam direta ou indiretamente à remoção/controle do parasita. A nossa abordagem tem sido o estudo da infecção por estes protozoários em quimeras de medula óssea B6/IFN $\gamma$ RKO, nas quais as células não leucocitárias são deficientes em receptores para $\operatorname{IFN} \gamma$ e as células leucocitárias são normais. A análise por imunofluorescência de cortes histológicos mostrou uma alta expressão de IFN $\gamma R$ pelas células estruturais do coração dos animais $B 6$ e quimeras controle B6/B6, mas nenhuma expressão deste receptor nos cortes histológicos correspondentes de animais IFN $\gamma$ RKO e quimeras experimentais B6/IFN $\gamma$ RKO, apesar de grande parte dos leucócitos dos animais deste último grupo ter se tornado $\operatorname{IFN} \gamma \mathrm{R}^{+}$. Após infecção pelo $T$. cruzi, o coração e músculo esquelético dos animais quiméricos B6/IFN $\gamma \mathrm{RKO}$ mostraram maior carga parasitária e menor intensidade dos infiltrados 
inflamatórios do que aqueles dos animais quiméricos B6/B6, resultados que sugerem o envolvimento das células estruturais no controle do parasita e promoção do recrutamento leucocitário. $\mathrm{Na}$ infecção pelo Plasmodium chabaudi AS a análise comparativa dos grupos IFN $\gamma$ RKO e quimera B6/IFN $\gamma$ RKO mostrou que no início da infecção as curvas de parasitemia destes grupos são idênticas sugerindo que nesta fase da infecção a presença do IFN $\gamma \mathrm{R}$ nos leucócitos em pouco contribui na evolução da parasitemia. Por outro lado, a análise comparativa dos grupos quimera B6/IFN $\gamma$ RKO e quimera B6/B6 mostrou níveis mais elevados de parasitemia e maior índice de mortalidade nos animais B6/IFN $\gamma$ RKO, sugerindo que as células estruturais participam no controle do parasita através da sua resposta ao IFN $\gamma$. Entretanto, em uma experiência preliminar de infecção pelo Plasmodium berghei ANKA não observamos grandes diferenças entre os animais dos grupos B6/IFN $\gamma \mathrm{RKO}$ e B6/B6, não somente no que se refere à curva de parasitemias, como também na indução de morte precoce decorrente de malária cerebral.

Palavras-chave: Quimerismo. Interferon gama. Plasmodium. Trypanosoma cruzi. 


\section{ABSTRACT}

BUCCI, D. Z. Ação do ifn- $\gamma$ sobre as células não leucocitárias (células estruturais) na infecção pelos protozoários trypanosoma cruzi e plasmodium. $118 \mathrm{f}$. Dissertação (Mestrado em Imunologia) - Instituto de Ciências Biomédicas da Universidade de São Paulo, São Paulo, 2009.

The main purpose of our work was to analyze if by their response to Interferon- $\gamma$ (IFN- $\gamma$ ), the non-leucocyte cells are able to control Trypanosoma cruzi, Plasmodium chabaudi AS and Plasmodium berghei ANKA protozoans. IFN $\gamma$ was described as a cytokine that promote activation on different types of leucocytes, its action on mononuclear phagocytic cells is important. Despite the fact that this cytokine activate leucocytes, it is unknown whether IFN $\gamma$ activates the structural cells (non-leucocytes), that is, the non-professional cells of the immune response. Our hypotheses suggest that in the case of intracellular parasites, IFN $\gamma$ could help the infected structural cells by increasing their signaling and effect actions. In addition, during the response against intracellular and extracellular parasites, IFN $\gamma$ could induce the production of inflammatory mediators by these cells guaranteeing direct or indirectly the parasite clearance. In the present study, we analyzed the infection of different protozoans on bone marrow B6/IFN $\gamma$ RKO chimeras, in which the non-leukocyte cells are deficient in IFN $\gamma$ receptor and the leukocyte cells are normal. Immunofluorescence analyses of histological sections revealed a high expression of IFN $\gamma R$ on the structural cells from the heart of B6 and control chimeras B6/B6 animals, but non-expression of this receptor on histological sections from IFN $\gamma$ RKO and experimental chimeras B6/IFN $\gamma R K O$, despite the fact that a great part of leucocytes from the last group of animals express the receptor. After $T$. cruzi infection, the cardiac and skeletal muscle from B6/IFN $\gamma$ RKO chimera animals showed a huge amount of parasite and less infiltration inflammatory than B6/B6 animals, suggesting that the structural cells are involved in the parasite control and leukocyte recruitment. During Plasmodium chabaudi AS infection, comparative analyses from IFN $\gamma$ RKO and 
B6/IFN $\gamma R K O$ groups showed that parasitemia curves at the early phase are similar, suggesting that during this phase IFN $\gamma$ R expression on leukocytes are not important. On the other hand, parasitemia and mortality levels on B6/IFN $\gamma R K O$ and B6/B6 groups were higher than those on B6/IFN $\gamma R K O$ animals, determining that structural cells participate during the course of infection through their response to IFN $\gamma$. However, when B6/IFN $\gamma$ RKO and B6/B6 animals were infected with Plasmodium berghei ANKA no significantly difference was observed between these groups related to the course of parasitemia and cerebral malaria.

Keywords: Chimerism. Interferon gamma.Plasmodium. Trypanosoma cruzi. 


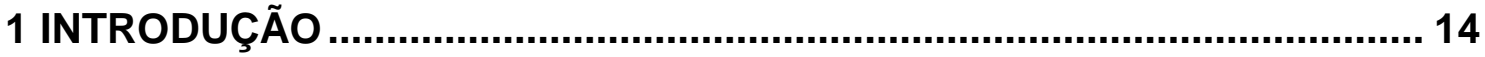

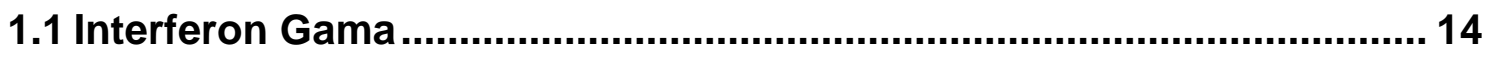

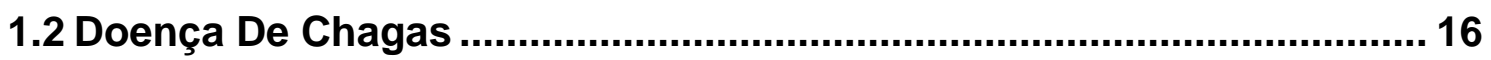

1.2.1 o Ciclo Evolutivo Do Trypanosoma Cruzi.......................................... 16

1.2.2 Mecanismos De Invasão Pelo T. Cruzi.............................................. 17

1.2.3 Mecanismos De Resistência À Infecção Do T. Cruzi Pelo Sistema

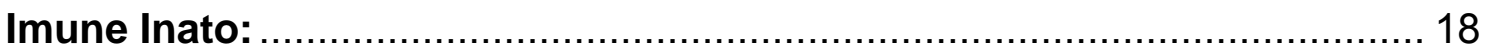

1.2.4 A Resposta Imune Humoral Ao T. Cruzi................................... 20

1.2.5 A Resposta Imune Celular Ao T. Cruzi ....................................... 20

1.2.6 Interferon Gama Na Resposta Ao T.Cruzi ................................ 22

1.2.7 Capacidade Efetora Das Células Não Leucocitárias Na Infecção Pelo T. Cruzi: Papel Do Ifn $\gamma$ Nas Populações Estruturais Do Coração, Musculatura Esquelética E Fígado ............................................................ 23

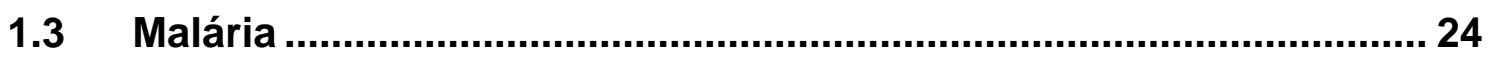

1.3.1 Ciclo Evolutivo Do Plasmódio................................................... 24

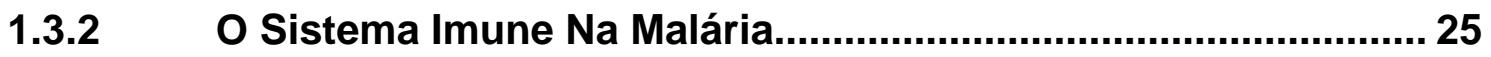

1.3.3 Atividade Imunológica No Baço Na Infecção Pelo Plasmodium 27

1.4.4 Malaria Cerebral $<0$

1.4.5 Interferon Gama Na Infecção Pelo Plasmodium ................................. 30

1.4.6 Capacidade Efetora Das Células Não Leucocitárias Na Infecção Pelo Plasmodium Chabaudi: Papel Do Ifn $\gamma R$ Nas Populações Estruturais Do Baço 32

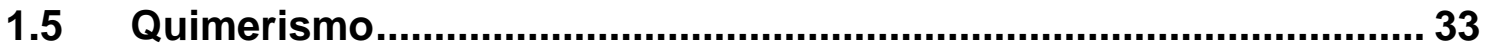

2 OBJETIVO

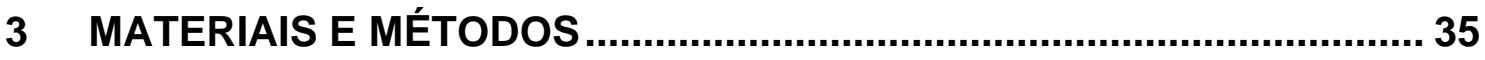

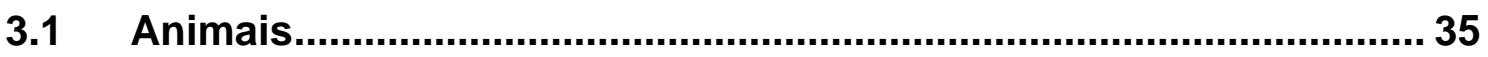

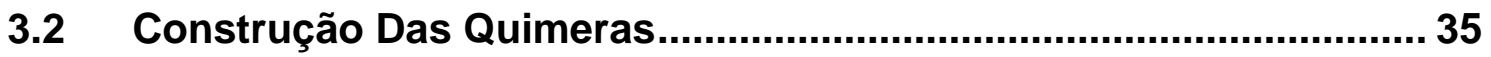

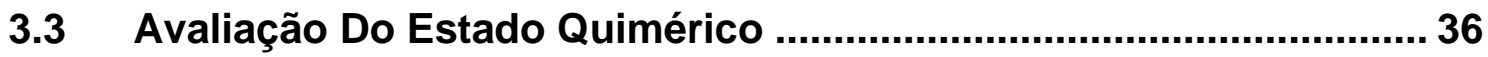


3.3.1 Análise Leucocitária da Expressão de Ifn $\gamma R$ por Citometria de Fluxo $\quad 36$

3.3.2 Análise De Quimerismo Tissular Por Imunofluorescência: Perfusão Dos Animais E Preparação Dos Cortes Congelados ................... 37

3.3.3 Processamento Dos Tecidos Congelados E Reação De

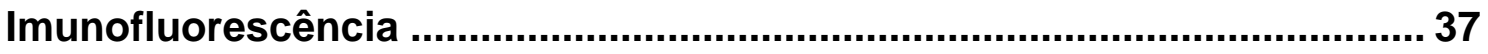

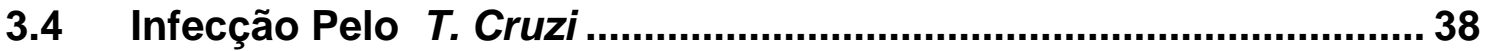

3.4.2 Desenho Experimental/ Infecção Pelo T. Cruzi........................... 38

3.4.3 Avaliação De Parasitemias E Carga Parasitária Local ............... 38

3.4.4 Análises Histopatológicas Na Infecção Pelo T. Cruzi Do

Coração, Fígado E Músculo Estriado Esquelético: ..................................... 39

3 .5 INFECÇÃO POR PARASITAS DO GÊNERO PLASMODIUM ................. 39

3.5.1 Avaliação De Parasitemias Na Infecção Pelo Plasmódio .................. 40

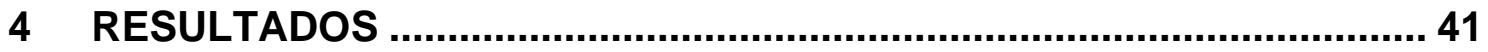

4.1 Quimerismo Por Células Egfp+ .................................................... 41

4.1.1 Análise Do Quimerismo Leucocitário Por Células Egfp+ ........ 41

4.1.2 Avaliação Da Concentração De Paraformaldeído Na Preservação Das Moléculas IfnүR E Egfp .............................................. 43

4.1.3 Imunofluorescência Tissular De Animais Egfp.......................... 44

4.1.4 Expressâo De Ifn $\gamma R$ No Coração Avaliada Por Imunofluorescência ....................................................................................... 48

4.1.5 Expressao De Egfp E Ifn $\gamma R$ No Baço Das Quimeras Egfp/Ifn $\gamma R 52$

4.1.6 Expressao De Egfp E Ifn $\gamma R$ No Fígado Das Quimeras Egfp/Ifn $\gamma R$ 54

4.2 Infecção Por Trypanosoma Cruzi De Quimeras B6/Ifn $\gamma R$ E B6/B6 .. 58

4.2.1 Análise Da Reconstituição Das Quimeras ................................... 58

4.2.2 Infecção Pelo Trypanosoma Cruzi Da Cepa Sylvio X10/4......... 60

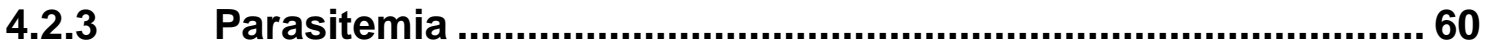

4.2.4 Análise Histopatológica Das Quimeras Infectadas Pelo T. Cruzi 61

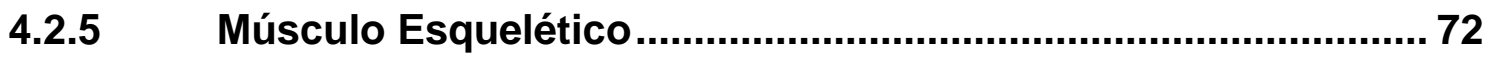

4.3 Infecção Pelo Plasmodium Berghei Anka Gfp .................................. 77 
4.3.1 Avaliação Do Estado Quimérico: Análise Por Citometria De Fluxo Da Expressão De Ifn $\gamma R$ Nos Leucócitos Do Sangue.......................... 77

4.3.2 Mortalidade Após Infecção Pelo Plasmodium Berghei AnkaGfp: Desenvolvimento De Malária Cerebral............................................... 78

4.3.3 Evolução Das Parasitemias Após Infecção Pelo P. Berghei Anka-Gfp 80

4.4 Construção Do Grupo Quimérico E Infecção Pelo Plasmodium

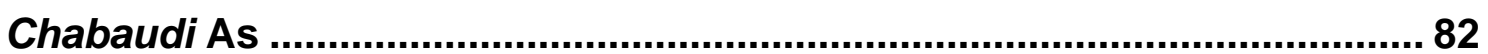

4.4.1 Análise Da Quimera............................................................... 82

4.4.2 Infecção Pelo Plasmodium Chabaudi As ................................ 83

4.4.3 Parasitemia ........................................................................... 84

5 DISCUSSÃO .................................................................................. 91

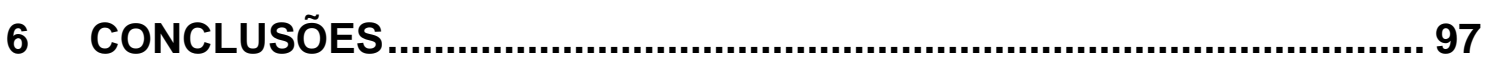

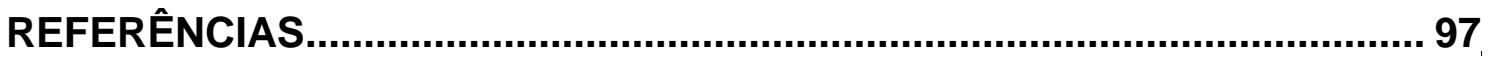




\section{INTRODUÇÃO}

\section{$1.1 \quad$ Interferon Gama}

O Interferon- $\gamma$ (IFN- $\gamma$ ) tem papel crucial na imunidade contra patógenos intracelulares e controle de tumor. Esta citocina é produzida predominantemente por células "natural killer" (NK), linfócitos "natural killer T" (NKT) e linfócitos $T \gamma \delta^{+}$, como parte da imunidade inata, e por linfócitos T CD4 ${ }^{+}$ Th1 e T CD8 ${ }^{+}$citotóxicos (CTL), como parte da resposta imune adquirida (JAMIE et al., 2007).

Durante a fase inicial da resposta imune inata, as células dendríticas e macrófagos ativados produzem grandes quantidades de IL-12. As principais atividades da IL-12 são estimular a produção de IFN $\gamma$ pelas células NK e promover a diferenciação de linfócitos $\mathrm{CD}^{+}$para o padrão funcional Th1, produtor de IFN $\gamma$.

Em relação à produção de IFN $\gamma$ pelas células NK, foi descrito que $30 \%$ destas células expressam CD28 em sua superfície quando estimuladas com LPS e que a interação de B7/CD28 atua como um sinal funcional na síntese de IFN $\gamma$ pelas células NK estimuladas. Apoiando estes achados, a co-estimulação de células NK com anticorpos anti-CD28 na presença de IL-12 resulta em um aumento significativo da produção de IFN $\gamma$ (VARMA, 2002).

Em forma análoga, o bloqueio in vivo da co-estimulação mediada por CD28 com anticorpos monoclonais anti-CD80 ou anti-CD86 inibe parcialmente a produção de IFN $\gamma$ por células NKT estimuladas com a-galactosilceramida, indicando a importância da interação de B7/CD28 na polarização funcional Th1 e Th2 de células NKT.

Pela sua vez, para que ocorra a ativação dos linfócitos $T$ convencionais pelas APCs, células dendríticas, macrófagos e linfócitos $B$, é necessária a interação de diversas moléculas de superfície. O primeiro sinal ocorre através da interação dos TCR, auxiliado pelas moléculas CD4 ou CD8, com peptídeos associados às moléculas de $\mathrm{MHCl}$ ou II, presentes nas APCs. O segundo sinal 
acontece após a interação entre a molécula B7 e a molécula CD28, sendo que via co-estimuladora B7/CD28 é particularmente relevante para a ativação de células T naive (IEZZI et al., 1998). Citocinas produzidas pelas APCs são também importantes para a ativação/diferenciação dos linfócitos T. Após a interação, linfócitos $\mathrm{TCD}^{+}{ }^{+}$se diferenciam em células Th1, Th2, Th3 e Th17. Os linfócitos Th1 fazem parte da imunidade celular e produzem, entre outras citocinas, o IFN $\gamma$ que além de ativar de macrófagos, interage com os linfócitos $B$ induzindo a produção de anticorpos lgG opsonizantes. Os linfócitos TCD8 ${ }^{+}$ efetores também são importantes partícipes da imunidade celular que se ativam por reconhecimento de peptídeos nas moléculas MHC classe I das APCs. Após expansão e diferenciação em células efetoras, os linfócitos T CD8 ${ }^{+}$ reconhecem células infectadas eliminando-as. A morte dessas células alvo se dá pela ação das perforinas e pela ação de granzimas, substâncias que ativam os mecanismos de apoptose induzindo a destruição do núcleo da célula reconhecida. No entanto, além da sua atividade citotóxica, os linfócitos TCD8 ${ }^{+}$ são também grandes secretores de IFN $\gamma$.

Em relação às funções desempenhadas sobre as células da imunidade inata, o IFN $\gamma$ é um potente ativador de macrófagos, estimulando a produção de NO e radicais de oxigênio por estas células e talvez por células dendríticas (BOGDAN et al., 2000). Mais ainda, o IFN $\gamma$ estimula o aumento da expressão de moléculas do MHC (classe I e II), moléculas de adesão, moléculas coestimuladoras (B7 e CD40) e receptores para a região $F c$ de anticorpos lgG (FcyR) na superfície de células apresentadoras de antígeno (APCs).

Alguns trabalhos sugerem que o IFN $\gamma$ tem um papel importante no controle de linfócitos, pois, em modelos de infecção bacteriana, a sua ausência determina proliferação exacerbada dos linfócitos TCD4 ${ }^{+}$(DALTON et al., 2000). Similarmente, camundongos IFN $\gamma \mathrm{KO}$ com encefalomielite autoimune experimental (EAE) apresentam um aumento na proliferação in vivo e in vitro de linfócitos TCD4 ${ }^{+}$(CHU et al., 2000). Em ambos os casos a expansão linfocitária esteve relacionada com uma diminuição na freqüência de células apoptóticas, sugerindo o envolvimento do IFN $\gamma$ na indução de apoptose destas células através da via independente de Fas (DALTON et al., 2000; RAFAELI et al., 2002). Por outro lado, a morte induzida por antígeno (AICD: "activation 
induced cell death") que depende da interação Fas/FasL é regulada parcialmente através de IFN $\gamma$ endógeno (SOBEK et al., 2002).

\subsection{Doença de Chagas}

\subsubsection{O Ciclo Evolutivo do Trypanosoma Cruzi}

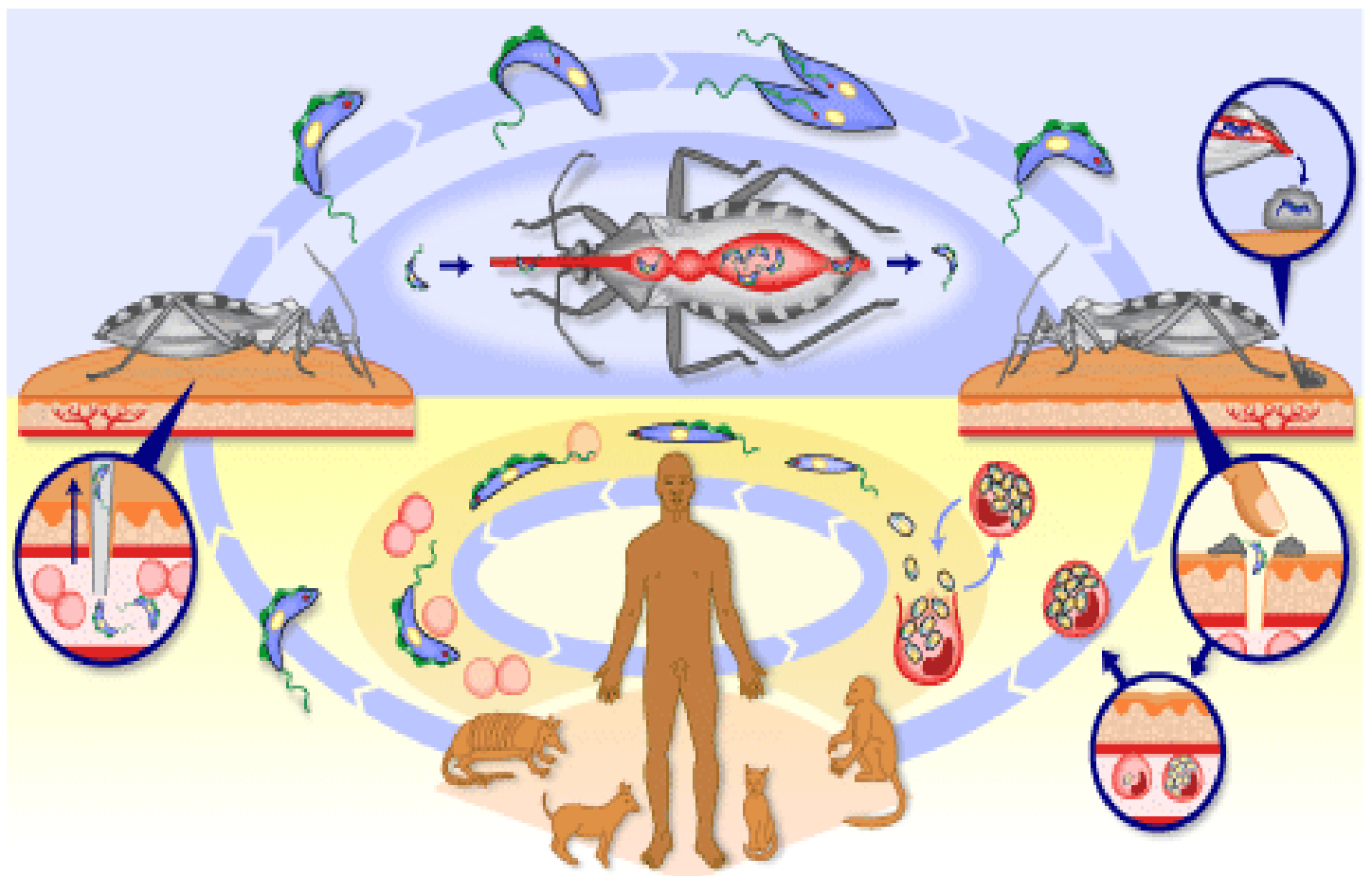

Figura 1: ciclo evolutivo do Trypanosoma cruzi; (WHO, 2008).

O Trypanosoma cruzi é um protozoário flagelado da família Trypanosomatidae, que causa a doença de Chagas, uma doença transmitida por vetor que têm alta prevalência na América Latina. A doença de Chagas é um importante problema de saúde pública nas regiões endêmicas, com 9-12 milhões de pessoas infectadas e outros 100 milhões com risco de adquiri-la (http://www.who.int/ctd/chagas/disease.htm). Durante o seu ciclo de vida, o $T$. cruzi alterna entre insetos vetores triatomíneos e mamíferos hospedeiros. $O$ inseto vetor, ao se alimentar do sangue do hospedeiro vertebrado, defeca nas 
proximidades da picada podendo transmitir através da pele lesada ou das mucosas íntegras as formas tripomastigotas metacíclicas infectantes que podem dar início à infecção. Os tripomastigotas metacíclicos invadem diferentes células do hospedeiro, principalmente fagócitos mononucleares, fibras musculares e fibroblastos. Ao penetrar no citoplasma destas células o parasita transforma-se na forma amastigota que se reproduz por divisão binária. Posteriormente, as amastigotas transformam-se em tripomastigotas que são liberadas, alcançando a circulação e disseminando a infecção. Os tripomastigotas sanguícolas podem ser ingeridos pelo inseto vetor onde, no lúmen do trato digestivo, transformam-se nas formas epimastigotas. Estas formas multiplicam-se no tubo digestivo do inseto, diferenciando-se na sua porção terminal em tripomastigotas metacíclicos que podem ser transmitidos ao hospedeiro vertebrado fechando assim, seu ciclo de vida (BRENER e ANDRADE; 1987; REY, 1991; RUPPERT e BARNES, 1994; WHO, 2008; MORTARA et al., 2008) (Figura 1).

\subsubsection{MECANISMOS DE INVASÃO PELO T. cruzi}

Os mecanismos utilizados pelas formas infectantes do Trypanosoma cruzi para invadir as células do hospedeiro ainda não estão totalmente esclarecidos. O parasita apresenta em sua membrana uma importante cisteínoprotease, a cruzipaína, que ativa a cascata das cininas promovendo uma sinalização celular que resulta em um aumento da penetração e colonização intracelular pelo T. cruzi. (LIMA et al., 2002; SCHARFSTEIN e LIMA, 2008 ). Estudos mostram que a habilidade do parasita em invadir células musculares humanas é influenciada pelo balanço entre cruzipaina e chagasina, um inibidor endógeno da papaína, assim como das cisteino proteases. Trabalhos indicam a participação de uma serina protease citosólica parasitária de 80 kD, oligopeptidase $B$, mas o seu papel ainda não está bem esclarescido (BURLEIGH,et al 1997; CALER et al., 1998). A trans-sialidase, enzima do parasita que promove a captação do ácido siálico a partir de substratos do 
hospedeiro, parece ser também importante no processo de invasão celular, uma vez que a penetração depende da presença de resíduos de ácido siálico na superfície do T. cruzi (COLLI, 1993, BURLEIGH e ANDREWS, 1995, FRANCHIN et al., 1997, TZELEPIS et al., 2008). Dependendo da célula hospedeira, a invasão requer TGF $\beta$ (MING e PEREIRA, 1995) ou do estímulo da célula hospedeira através de receptores ligados a proteína G (TARDIEUX etal, 1994, DOCAMPO e MORENO. 1996). O aumento da invasão celular pelo $T$. cruzi que acontece na presença de TGF- $\beta$, junto ao baixo nível de colonização na ausência de receptores para esta citocina, sugere um papel fundamental para o TGF- $\beta$ no processo de invasão (MING et al., 1995 ; MARTIM et al., 2007).

\subsubsection{MECANISMOS DE RESISTÊNCIA À INFECÇÃO DO T. cruzi PELO SISTEMA IMUNE INATO}

$\mathrm{Na}$ doença de Chagas os mecanismos da imunidade inata do hospedeiro não são eficazes no controle da infecção pelo parasito, necessitando da cooperação da imunidade adquirida (sistema linfocitário) para a destruição dos mesmos.

A invasão pelo $T$. cruzi ativa o sistema complemento, que não consegue efetivar com sucesso sua ação já que as formas tripomastigotas e amastigotas são resistentes à ação lítica deste sistema humoral. (BUDZKO et al., 1975; KIERSZENBAUM e HOWARD, 1976; KIERSZENBAUM e LIMA, 1983; KIPNIS et al., 1985). Apesar da ativação do complemento não prosseguir até a formação do complexo de ataque à membrana com a conseqüente lise do parasita, os tripomastigotas ficam recobertos de C3b e iC3B, auxiliando o parasita na penetração em células mononucleares fagocíticas que possuem receptores CR3 (KRETTLI e PONTES DE CARVALHO, 1979; TANOWITZ et al., 1992; BEUCHER e NORRIS, 2007). Assim, o sistema complemento parece ter uma função importante no controle do $T$. cruzi provavelmente devido à sua capacidade opsonizadora, uma vez que, animais depletados de C3 pelo 
tratamento com o CVF (fator de veneno de cobra) têm um agravamento da infecção (BUDZKO et al., 1975).

As células do Sistema Fagocítico Mononuclear (monócitos e macrófagos) são fundamentais no controle do parasita no sangue e nos tecidos. Entretanto, elas podem desempenhar um papel duplo na infecção pelo T. cruzi, ora servindo como células efetoras da resposta imune frente ao parasita, ora como células hospedeiras responsáveis pela multiplicação e diferenciação do mesmo (COHN, 1978; NOGUEIRA et al., 1982).. Por este fato, a fagocitose não parece ser um mecanismo suficientemente eficiente para a destruição dos parasitas, uma vez que, quando fagocitados, muitos conseguem passar para o citoplasma, onde diferenciam-se em amastigotas possibilitando a sua replicação (ALCANTARA e BRENER, 1978). Neste contexto, é importante resaltar que diferentes cepas de T. cruzi exibem graus diferentes de resistência à destruição pelos macrófagos. Por outro lado, a ação conjunta das células fagocíticas e linfócitos $T$ ativados, tornam os macrófagos elementos fundamentais no controle do parasita mediando a destruição intracelular destes (VITELLI-AVELLAR et al., 2006; SALES et al., 2008).

As células NK (Natural Killer) têm um papel importante na infecção pelo T. cruzi. Um aumento precoce e significante da atividade das células NK tem sido descrito em animais infectados com T. cruzi. (HATCHER e KUHN,1982) foram os primeiros a demonstrar em ensaios in vitro a participação efetiva das células NK na destruição de epimastigotas e tripomastigotas. Cardillo et al. (1996) sugeriram que nos estágios iniciais da infecção, as células NK, através da produção de IFN $\gamma$ promoveriam a ativação de macrófagos para a destruição intracelular do parasita. Assim, as células NK seriam as principais produtoras de IFN- $\gamma$ nesta fase da infecção, processo este provavelmente dependente da produção de IL-12 pelos macrófagos (ALIBERTI et al., 1996; GALVAO DA SILVA e DE ALMEIDA ABRAHAMSOHN, 2001). O aumento na atividade de células NK no início da infecção pode contribuir para a limitação da replicação do parasita até o estabelecimento da resposta imune específica (UNE et al., 2000). Desta forma, as células NK representam uma importante ponte entre a imunidade inata, que opera com limitada especificidade e eficiência, e a imunidade específica, caracterizada pela seleção clonal e a expansão de 
linfócitos específicos para o antígeno (KOS e ENGLEMAN, 1996; SALES et al., 2008; VITELLI-AVELLAR et al., 2006).

\subsubsection{A RESPOSTA IMUNE HUMORAL AO T. cruzi}

Os anticorpos específicos têm um papel fundamental na defesa do hospedeiro contra o $T$. cruzi pelo seu papel efetor frente às formas tripomastigotas circulantes e tissulares. Eles são em grande parte responsáveis pelo controle da parasitemia no fim da fase aguda e pela manutenção de baixos níveis de parasitas circulantes durante as fases indeterminada e crônica. A ação efetora dos anticorpos frente ao T. cruzi se dá ao promover a remoção do parasita do sangue por macrófagos e outras células do Sistema Fagocítico Mononuclear (SFM), processo que pode resultar na destruição dos parasitas intracelulares (ALCANTARA e BRENER, 1978). Os anticorpos permitem também a opsonização e destruição dos parasitas nos tecidos, mediada por polimorfonucleares (PMN) ou macrófagos (ALCANTARA e BRENER, 1978; KIPNIS et al., 1981), assim como a destruição dos parasitas nos tecidos por citotoxicidade dependente de anticorpos (ADCC) mediada por diversos elementos celulares tais como células NK, eosinófilos, neutrófilos e mastócitos (ABRAHAMSOHN e SILVA, 1977; KIERSZENBAUM e HAYES, 1980; KIPNIS et al., 1981; TAMBOURGI et al., 1989). Finalmente, os anticorpos auxiliam no controle do $T$. cruzi por plaquetas que destroem parasitas sanguícolas opsonizados por anticorpos e complemento (UMEKITA e MOTA, 1989).

\subsubsection{A RESPOSTA IMUNE CELULAR AO T. cruzi}

Os linfócitos T CD4 ${ }^{+}$e $\mathrm{CD}^{+}$são fundamentais no estabelecimento da resistência do hospedeiro ao $T$. cruzi. Isto foi demonstrado utilizando camundongos deficientes de células TCD4 ${ }^{+}, \mathrm{TCD}^{+}$ou ambas, que infectados 
pelo T. cruzi, revelaram uma suscetibilidade aumentada à infecção. Mais ainda, a depleção destas populações celulares induz nos animais infectados altos níveis de parasitemia e mortalidade (RUSSO et al., 1988; ARAUJO, 1989; TARLETON, 1990; TANOWITZ et al., 1992; ROTTENBERG et al., 1993; ROTTENBERG et al., 1995; RUSSO et al., 1996).

TARLETON (1990) demonstrou que animais depletados de células $\mathrm{TCD}^{+}$, previamente à infecção, tornavam-se altamente suscetíveis na fase aguda da doença. Quando essa depleção ocorria na fase crônica, os animais tinham índices de sobrevida e parasitemia semelhantes aos animais controle, sugerindo que as células $\mathrm{TCD}^{+}$são fundamentais no controle da infecção aguda, mas podem ser compensados por outros elementos efetores na fase crônica. Posteriormente, o papel dessas células na fase aguda foi confirmado, pelo mesmo autor, em animais deficientes de $\beta 2$-microglobulina que não possuem células TCD8 ${ }^{+}$(TARLETON et al., 1992).

As células $\mathrm{TCD}^{+}$poderiam destruir as células infectadas por um mecanismo dependente de perforinas. No entanto, Henriques-Pons et al. (2002) mostraram que camundongos deficientes para perforina quando infectados com parasitas da cepa $Y$ de T. cruzi desenvolvem os mesmos níveis de parasitemia que os animais selvagens (B6), demonstrando que esta molécula não desempenha um papel central no controle da infecção.

Embora seja a principal população linfocitária esplênica expandida na fase crônica (MARINHO et al., 1999) o papel na infecção das células TCD8 ${ }^{+}$ permanece controvertido. Leavey e Tarleton (2003) mostraram que no tecido muscular esquelético e cardíaco do camundongo infectado as células TCD8 ${ }^{+}$ têm sua capacidade efetora diminuída, evidenciada pelos baixos níveis de produção de IFN $\gamma$ e pela sua ineficiência em mediar citotoxicidade quando comparadas às células TCD8 ${ }^{+}$esplênicas.

Marinho et al., 2007, demonstraram a importância das células linfocitárias TCD4 ${ }^{+}$e TCD8 $^{+}$na infecção pelo $T$ cruzi Sylvio X10/4 utilizando camundongos deficientes em TCD4 ${ }^{+}$ou TCD $8^{+}$, onde os grupos experimentais apresentaram um aumento na mortalidade e na patologia nos tecidos, mas não apresentaram um aumento na parasitemia. 


\subsubsection{INTERFERON GAMA NA RESPOSTA AO T.cruzi}

O IFN- $\boldsymbol{\gamma}$ tem sido correlacionado com a resistência e o controle do parasita na fase aguda da infecção pelo T. cruzi (JAMES et al., 1982; PLATA et al., 1984; WIRTH et al., 1985; PLATA et al., 1987; REED, 1988; ABRAHAMSOHN e COFFMAN, 1996; ROMANHA et al., 2002). Diversos modelos têm mostrado que camundongos resistentes secretam altas quantidades de IFN- $\gamma$ enquanto que camundongos suscetíveis teriam uma secreção aumentada de IL-4 e IL-10 (SILVA et al., 1992; HOFT et al., 1993; MINOPRIO et al., 1993; REED et al., 1994).

O IFN- $\gamma$ está envolvido na ativação de macrófagos, induzindo-os a expressar moléculas de classe II do $\mathrm{CPH}$ e a secretar radicais de oxigênio e nitrogênio, ambos dotados de potente atividade microbicida (MUNOZFERNANDEZ et al., 1992). Tem sido relatado que o óxido nítrico produzido em animais infectados está relacionado à resistência e ao controle da parasitemia (GAZZINELLI et al., 1992; VESPA et al., 1994; SILVA et al., 2003).

O IFN- $\gamma$ está envolvido na mudança de classe de imunoglobulina para IgG2a e IgG3 (SNAPPER e PAUL, 1987; SNAPPER et al., 1992) e induz nos macrófagos aumento de expressão de receptores para a porção Fc de lgG (WILSON e FINBLOOM, 1992). Esta citocina contribui ainda à diferenciação de células $\mathrm{TCD}^{+} \mathrm{TH}_{0}$ na direção Th1, ao inibir a proliferação de células Th2 (PAUL e SEDER, 1994) e ao estimular a secreção de IL-12 por macrófagos ativados (KUBIN et al., 1994). Na infecção pelo T. cruzi, as células T sofrem supressão da produção de IL-2, mas não de IFN- $\gamma$ (NABORS e TARLETON, 1991), apesar das duas citocinas terem sido classificadas como do tipo Th1.

Sub-populações de linfócitos $T$, assim como as células NK, poderiam estar envolvidas na produção de IFN- $\gamma$. No início da infecção, previamente à ativação das células $T$, as células NK parecem ser as principais responsáveis pela produção desta citocina (CARDILLO et al., 1996), enquanto que mais adiante, as células $\mathrm{T} \mathrm{CD}^{+}$e $\mathrm{CD}^{+}$passariam a ter um papel proeminente. No entanto, em ensaios de dupla marcação com anticorpos para caracterizar in situ as populações produtoras desta citocina, Zhang e Tarleton, (1996) 
observaram que os maiores produtores de IFN- $\gamma$ no baço de animais infectados, são células com fenótipo TCRa $\beta^{+}$Thy $-1^{+}$CD4 ${ }^{-}$CD8 $8^{-}$. A importância destas células $T$ duplo negativas na imunidade frente ao parasita ainda não foi totalmente esclarecida (TARLETON, 1991).

Marinho et al., 2007, utilizando camundongos deficientes para IFN $\gamma$ identificou essa citocina como um fator crucial para o controle do parasita, demonstrando que sua ausência determina um aumento drástico do parasitismo tissular, presença de infiltrados leucocitários no músculo estriado cardíaco e esquelético e ainda uma lesão da medula espinhal e mortalidade.

\subsubsection{CAPACIDADE EFETORA DAS CÉLULAS NÃO LEUCOCITÁRIAS NA INFECÇÃO PELO T. CRUZI: PAPEL DO IFN $\gamma$ NAS POPULAÇÕES ESTRUTURAIS DO CORAÇÃO, MUSCULATURA ESQUELÉTICA E FÍGADO}

Enquanto que os leucócitos recrutados são fundamentais para o controle do $T$. cruzi no coração, desconhecemos se as populações não leucocitárias residentes (cardiomiócitos, fibroblastos, células endoteliais, etc.) desempenham alguma atividade efetora frente ao parasita. O eventual papel efector das populações estruturais é comumente ignorado, sendo consideradas exclusivamente alvo da infecção e/ou da destruição pela resposta imune. A atividade efetora das células estruturais poderia acontecer como conseqüência direta da sinalização pelo parasita, ou, indiretamente em resposta às citocinas (como o IFN $\gamma$ ) produzidas pelos leucócitos. Assim, existe a possibilidade do IFN $\gamma$ estimular nas células estruturais do coração a produção de óxido nítrico (CHANDRASEKAR et al., 2000) ou outras moléculas que venham interferir na proliferação intracelular do T. cruzi. Mais ainda, o IFN $\gamma$ poderia induzir nas células estruturais a produção de quimiocinas, como CXCL9/Mig, CXCL10/IP. 10 e CXCL11/ITAC (MACHADO et al., 2000) que determinem um aumento do recrutamento celular (FICHERA et al., 2004; CHANDRASEKAR et al., 1998) e, secundariamente, um maior controle do parasita. 


\subsection{MALÁRIA}

\subsubsection{CICLO EVOLUTIVO DO PLASMÓDIO}

A malária humana é causada por quatro espécies de Plasmodium: $0 P$. malarie, o $P$. ovale, o $P$. vivax e o $P$. falciparum, sendo o $P$. vivax e o $P$. falciparum as espécies mais comuns. Aproximadamente $40 \%$ da população mundial, na maior parte aquelas que vivem nas regiões mais pobres como África, Ásia e América Latina, estão expostas à malária.

Apesar dos esforços das autoridades de saúde, pelo menos 1 milhão de pessoas morrem todos os anos vítimas da malária. Noventa por cento das mortes ocorrem na África, principalmente em crianças com idade abaixo de cinco anos. Uma criança africana tem em média entre 1,6 e 5,4 episódios de febre decorrentes da malária por ano. Dados da Organização Mundial da Saúde mostram que a cada 30 segundos uma criança morre de malária (portal 10 Facts on Malaria, World Health Organization, 2007).

A infecção do hospedeiro vertebrado pelo plasmódio inicia-se com a inoculação do esporozoíto no momento da picada do mosquito Anopheles. Uma vez inoculados, os esporozoítas caem na corrente circulatória e penetram nas células hepáticas, onde se multiplicam por esquizogonia (esquizonte hepático), e finalmente diferenciam na forma merozoíta. Com a ruptura dos hepatócitos, alguns dos merozoítas, agora postos em liberdade, são englobados por células fagocitíticas e destruídos. Entretanto, outros parasitas conseguem invadir os eritrócitos, dando início ao ciclo eritrocítico. A fase eritrocítica do ciclo do plasmódio é a responsável pelos sintomas clínicos associados à doença, tais como: a febre, a anemia e a malária cerebral, muitas vezes fatal. Após sucessivas fases de esquizogonia, aparecem no ciclo eritrocítico os gametócitos. A infecção do mosquito ocorre com a ingestão de eritrócitos infectados por gametócitos, que se reproduzem de forma sexuada no intestino médio do mosquito, dando origem aos esporozoítas que atingem progressivamente as glândulas salivares. A simples presença de um indivíduo 
portador do plasmódio pode desencadear um surto de malária em qualquer região onde haja o mosquito transmissor da doença (Figura 2).

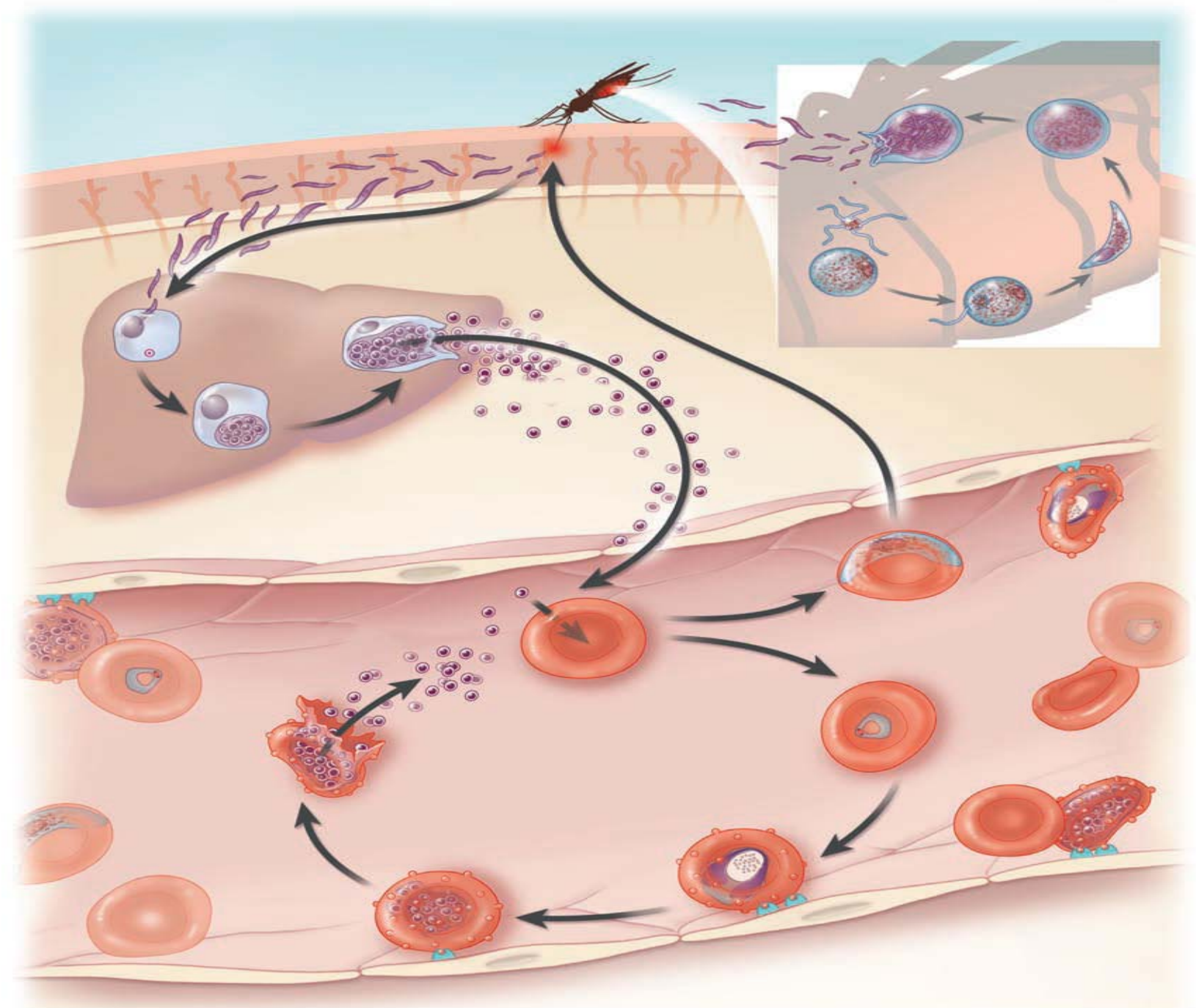

Figura 2: Ciclo do plasmódio; ROSENTHAL, PJ, 2008.

\subsubsection{O SISTEMA IMUNE NA MALÁRIA}

Sabendo que os parasitas inoculados pelo mosquito são capazes de alcançar os hepatócitos em 2-30 minutos, poucos mecanismos imunes efetores são realmente eficientes para detê-los neste momento (SAUL, 1987). Dessa forma os parasitas em desenvolvimento dentro dos hepatócitos são o melhor 
alvo para a resposta imune durante o estágio pré-eritrocítico (Hoffman et al., 1996), sendo esta proteção mediada principalmente por linfócitos T CD8 ${ }^{+}$ (HOFFMAN et al., 1996; GOOD et al., 1988; HAFALLA et al., 2006). Citocinas, como IFN- $\gamma$ e IL-12, e outros fatores (incluindo o óxido nítrico) também são descritos como importantes na proteção contra o estágio pré-eritrocítico da malária (HOFFMAN et al.,1996; SCHOFIELD et al., 1987; SEGUIN et al., 1994; DOOLAN e HOFFMAN, 1997; KLOTZ et al., 1995; SEDEGAH et al., 1994; HOFFMAN et al., 1997).

A capacidade do Plasmodium de se replicar em eritrócitos, células anucleadas e desprovidas de moléculas do $\mathrm{MHC}$, via de acesso ao reconhecimento pelos linfócitos $\mathrm{T}$, torna este parasita bastante particular. Assim, a dificuldade de reconhecimento dos parasitas que estão dentro dos eritrócitos faz com que, na fase eritrocítica da infecção, os mecanismos efetores do sistema imune atuem especialmente no compartimento extracelular, quando os merozoítas são liberados durante o rompimento dos eritrócitos, ou ainda, através do reconhecimento de antígenos variáveis codificados pelo parasita e que passam a ser expressos na superfície destas células, situações nas quais se tornam alvos da ação efetora dos anticorpos. A proteção desempenhada pelos anticorpos (resposta humoral) durante a infecção por malária é crucial, como mostrado em experimentos de transferência passiva de imunoglobulina de adultos protegidos para crianças não imunes, evidenciando o papel protetor dessas moléculas na malária humana causada pelo P.falciparum (COHEN et al., 1961; SABCHAREON et al., 1991). Vários trabalhos também apontam para o fato de que anticorpos naturalmente adquiridos contra antígenos expressos nas hemáceas infectadas ou contra antígenos da superfície dos merozoítas mostram-se diretamente associados à redução de morbidade em crianças infectadas por $P$. falciparum (MARSH et al., 1989; RILEY et al., 1992; TOLLE et al., 1993; AL-YAMAN et al., 1996; EGAN et al., 1996). Estudos confirmam a importância dos anticorpos também na proteção em modelos murinos, pois soros obtidos de camundongos que sobreviveram à infecção pelo $P$. yoelii, $P$. berghei ou $P$. chabaudi podem transferir proteção a recipientes não imunes (FREEMAN e PARISH,1981; FALANGA et al., 1984; JARRA et al., 1986; CAVINATO et al., 2001; ELIAS et al., 2005). 
Vários estudos demonstram que, em condições naturais, o estabelecimento de imunidade protetora capaz de prevenir contra as manifestações clínicas da malária em humanos ocorre somente após um longo período de exposição às picadas de mosquitos infectados (MAEGRAITH, 1974; GREENWOOD et al., 1987; BAIRD et al., 1991). Porém, nesta situação de "imunidade clínica" o que se observa é que a persistência da infecção é comum. Assim, mesmo não observada ao microscópio ótico, a parasitemia é mantida em baixos níveis que são necessários para o estabelecimento de uma imunidade duradoura, o que neste contexto implica apenas na proteção contra a doença, e não contra a infeç̧ão (TONGREN et al., 2004). Em um novo foco de epidemia na África, indivíduos de diferentes idades infectados pelo plasmódio foram acompanhados e foi verificado que parece haver a necessidade de apenas poucas infecções para a aquisição de imunidade contra a malária severa (BAIRD et al., 2003; KLEINSCHMIDT e SHARP, 2001). Uma possível interpretação para esses dados é a de que os mecanismos imunes efetores que protegem contra a malária severa são induzidos por antígenos relativamente conservados e/ou altamente imunogênicos, enquanto os mecanismos imunes efetores responsáveis pela eliminação do parasita reconhecem antígenos que são mais variáveis e menos imunogênicos.

\subsubsection{ATIVIDADE IMUNOLÓGICA NO BAÇO NA INFECÇÃO PELO Plasmodium}

Durante o ciclo eritrocítico é no sangue e no baço, o maior órgão linfóide do organismo, que se encontra em contato direto com o sistema circulatório, que a resposta imune contra o Plasmodium sp. é deflagrada.

O baço é considerado um local com alta capacidade fagocítica, o que está diretamente relacionado à grande quantidade de macrófagos presentes, além de ser um centro de proliferação de linfócitos e produção de anticorpos pela sua capacidade de iniciar a resposta imune aos microorganismos que circulam no sangue. Uma das principais funções do baço é garantir que apenas eritrócitos íntegros continuem circulando no sangue. Assim, durante o estágio 
eritrocítico do parasita, este órgão parece estar envolvido na eliminação de hemácias parasitadas, realizando intensa fagocitose. Além disso, a possibilidade do baço participar da remoção do parasitas através de mudanças na arquitetura dos vasos e polpa vermelha constitui uma possibilidade importante. Por outro lado, na infecção aguda pelo plasmódio o baço mostra uma forte resposta hematopoiética (ALVES et al., 1996; GRUN et al., 1985; YAP e STEVENSON, 1992) que visa compensar a inibição da eritropoiese que acontece na medula óssea (MAGGIO-PRICE et al., 1985; VILLEVAL et al., 1990).

A importância do baço como órgão central na proteção durante a infecção por malária, em modelos murinos, pôde ser comprovada pelo fato de animais esplenectomizados serem extremamente suscetíveis a várias espécies do Plasmodium (OSTER et al., 1980; GRUN et al., 1985; WEISS, 1989; YADAVA et al., 1996).

\subsubsection{MALARIA CEREBRAL}

Uma complicação grave da infecção pelo Plasmodium falciparum (em humanos) e pelo Plasmodium beghei ANKA (em camundongos C57BL/6) é a malária cerebral, uma síndrome clínicamente complexa de coma e encefalopatia potencialmente reversível, associada a uma alta taxa de mortalidade, que atinge crianças e adultos não imunes. Mais ainda, as pessoas que sofrem de malária cerebral e sobrevivem sofrem importantes seqüelas (BAGOT et al., 2002; COMBES et al., 2006, WASSMER et al., 2006).

Utilizando uma combinação de estudos clínicos e patológicos, ensaios in vitro e modelos animais, os estudos da fisiopatologia da malária cerebral têm focalizado a barreira hematoencefálica, principal interface entre o parênquima cerebral e a hemácia infectada que permanece dentro do espaço vascular. $\mathrm{Na}$ malária humana, a citoaderência de glóbulos vermelhos infectados ao endotélio vascular é considerada a principal causa de malária cerebral. O seqüestro das 
hemácias infectadas é mediado por diferentes receptores da superfície celular endotelial, principalmente ICAM-1 e CD36 (KAUL, 1998).

Em humanos e em modelos murinos de malária cerebral foi observada a infiltração de células efetoras linfocitárias citotóxicas $\left(\mathrm{TCD}^{+}\right)$que poderiam contribuir à patogênese das lesões através de citotoxicidade direta contra as células endoteliais. Citotoxicidade e apoptose de células endoteliais podem levar a uma ruptura da barreira hematoencefálica (PINO et al., 2005).

Os estudos funcionais da barreira hematoencefálica na malária cerebral têm mostrado redistribuição das células endoteliais na junção intercelular e ativação de proteínas sinalizadoras intracelulares, evidencias que apóiam sua gênese secundária ao seqüestro de hemácias parasitadas e à presença de leucócitos no seio da microvasculatura cerebral. Muitos aspectos deste processo são, entretanto, pouco conhecidos, tais como o aumento generalizado na permeabilidade da barreira hematoencefálica que leva ao edema cerebral, os efeitos dependentes e os efeitos independentes de aderência, a ativação das células endoteliais e células perivasculares e os danos cerebrais que resultam da diminuição do fluxo sanguíneo, hipóxia ou ação das toxinas do parasita (MEDANA e TURNER, 2006). Mais ainda, estudos em modelos experimentais murinos sugerem também o envolvimento das plaquetas na gênese da patologia (COMBES et al., 2006; WASSMER et al., 2006).

$\mathrm{Na}$ patogênese da malária cerebral, um dos primeiros eventos parece ser um leve aumento na permeabilidade da barreira hematoencefálica como conseqüência do dano ao endotélio vascular pelos linfócitos TCD8 ${ }^{+}$. Isto resulta em liberação para o parênquima cerebral de citocinas, antígenos do plasmódio e moléculas potencialmente nocivas, que resultam em ativação da microglia e apoptose de astrócitos. O papel da hipóxia na patogenia da malária cerebral está relacionado à obstrução vascular, alterações no metabolismo glicídico e hipóxia citopática. 


\subsubsection{INTERFERON GAMA NA INFECÇÃO PELO Plasmodium}

A resistência inata às bactérias e protozoários é criticamente dependente da ação do interferon gama (IFN $\gamma$ ). Esta citocina regula a expressão de uma série de 1200 genes que codificam a função efetora de eliminar patógenos a partir de células hospedeiras (BOEHM et al 1997; STARK et al 1997; EHRT et al., 2001).

A imunidade contra o Plasmodium abrange tanto uma resposta Th1 precoce com secreção de IFN $\gamma$ que induz ativação de macrófagos e produção de anticorpos opsonizantes (IgG2a) que favorecem a fagocitose de merozoitas e eritrócitos infectados, como uma resposta Th2 com produção de anticorpos neutralizantes (lgG1) de alta afinidade, capaz de impedir a invasão de novos eritrócitos pelos merozoitas (LONGHORNE et al., 1989; LONG et al., 1994). Durante a infecção primária se observa predomínio da resposta Th1, com produção exacerbada de IFN $\gamma$, óxido nítrico e IgG2a. A ativação policlonal do sistema imune auxilia o controle inicial da infecção, principalmente através da produção precoce de IFN $\gamma$ e, conseqüente ativação de macrófagos.

A produção de IFN $\gamma$ durante a fase inicial da infecção é requerida para o controle da fase aguda e sobrevivência de camundongos infectados pelo Plasmodium chabaudi ou pelo Plasmodium berghei (CLARK et al., 1987; van der HEYDE et al., 1997; YONETO et al., 1999). Trabalhos demonstrando infecções exacerbadas pelo Plasmodium chabaudi em camundongos tratados com anticorpos anti-IFN $\gamma$ (MEDING et al., 1990; STEVENSON et al., 1990) ou que não apresentam receptores para IFN $\gamma$ (IFN $\gamma$ R-KO) (FRAVE et al., 1997; TSUJl et al., 1995) apóiam o papel desta citocina no controle da infecção na fase aguda. A infecção pelo Plasmodium chabaudi AS de camudongos IFN $\gamma$ RKO sugere que durante as primeiras semanas de infecção o IFN $\gamma$ é crucial para o controle das formas sanguícolas do parasita (FRAVE et al., 1997). Assim enquanto os camundongos selvagens (B6) apresentam um único pico de parasitemia e resistem à malaria, 60\% dos animais deficientes morrem da doença, sendo que os sobreviventes desenvolvem um segundo pico de parasitemia antes de controlar a infecção. Em forma análoga, um aumento da parasitemia foi observado em camundongos IFN $\gamma \mathrm{R}-\mathrm{KO}$ infectados por 
Plasmodium yoeli e Plasmodium c. adami (TSUJl et al., 1995). Alterações nos níveis de anticorpos específicos ao parasita, bem como deficiência na produção de IL-12, TNFa e NO, foram correlacionadas com a incapacidade de camundongos IFN $\gamma$ R-KO sobreviverem à infecção primária pelo Plasmodium chabaudi AS (SU e STEVENSEN, 2000).

A suscetibilidade aumentada de camundongos IL-18KO à infecção pelo Plasmodium berghei, em comparação aos controles, sugere o envolvimento da IL-18 na proteção durante a fase eritrocítica através do aumento da produção de IFN $\gamma$ (SHING et al., 2002). Além disso, a ausência de IL-12 endógena determina aumento da parasitemia na fase aguda da infecção pelo Plasmodium chabaudi, que se acompanha de uma diminuição acentuada da produção de IFN $\gamma$ e anticorpos específicos IgG2a (SU e STEVENSEN, 2002).

Como indicado acima o IFN $\gamma$ e a IL-12 são mediadores essenciais na imunidade protetora durante a fase sanguínea da malária (FRAVE et al., 1997; STEVENSEN et al., 1995). Na infecção pelo Plasmodium chabaudi AS, evidencias experimentais sugerem que o IFN $\gamma$ sinergiza com o TNFa no controle da parasitemia e recrutamento de células mononucleares (TAYLORROBINSON et al., 1993; JACOBS et al., 1996).

Na infecção murina pelo Plasmodium berghei ANKA, várias citocinas pró e anti-inflamatórias influenciam a patogênese da malária cerebral (LOUISE et al., 2008). Em 1989, Grau et al., descreveram que o IFN $\gamma$ representa um elo importante na rede de citocinas que levam a inflamação dos vasos cerebrais, uma vez que a sua produção por células $\operatorname{TCD} 4^{+}$ativadas resulta em aumento da produção e da ação do TNF $\alpha$.

No modelo experimental murino, o IFN $\gamma$ está aparentemente envolvido na indução de ICAM-I pelo endotélio e na patologia microvascular que resulta na malária cerebral (RUDI et al., 1997). Na ausência da sinalização por esta citocina, a expressão de ICAM-1 e a produção local de TNF $\alpha$ são consideravelmente reduzidas. Utilizando camundongos knock-out (KO) para receptor de IFN- $\gamma$, Amani et al., em 2000 demonstraram a importância do IFN $\gamma$ na patogênese da malária cerebral experimental induzida pelo Plasmodium berghei ANKA. Estes autores observaram que os camundongos IFN $\gamma$ RKO não desenvolvem malária cerebral e não mostram seqüestro de parasitas ou 
leucócitos no cérebro, assim como não sofrem hemorragias. Desta forma, a diferença do que acontece nos animais WT, a resistência dos camundongos IFN $\gamma$ R-deficientes foi associada com a ausência de quaisquer aumentos de TNF- $\alpha$ e ICAM-1 no cérebro. Em outro trabalho, foi mostrado que o IFN $\gamma$ induz aumento da expressão pelas células endoteliais microvasculares de indoleamine 2,3-dioxigenase, enzima que potencializa a produção de uma série de metabólitos biologicamente ativos que podem ser considerados parte de uma resposta protetora do tecido contra os efeitos das citocinas e leucócitos (HUNT et al., 2006).

\subsubsection{CAPACIDADE EFETORA DAS CÉLULAS NÃO LEUCOCITÁRIAS NA INFECÇÃO PELO PLASMODIUM CHABAUDI: PAPEL DO IFN $\gamma$ R NAS POPULAÇÕES ESTRUTURAIS DO BAÇO}

$\mathrm{Na}$ infecção pelo plasmódio o baço é um órgão fundamental no controle do parasita. Expressão desta importância é o fato da infecção ser muito mais virulenta em animais esplenectomizados e em indivíduos que perderam o baço em decorrência de injuria traumática (DEMAR et al 2004; CONTAMIN et al., 2000; BACH et al., 2005). Nestes casos, a maior suscpetibilidade à malaria decorre principalmente do fato do baço ser um órgão linfóide fundamental para o desenvolvimento da resposta mune $T$ e $B$ frente às formas que circulam no sangue (ciclo intraeritrocítico). No entanto, este não parece ser o único motivo, acreditando-se que as mudanças vasculares que acontecem neste órgão possibilitam não somente a sensibilização do hospedeiro, mas a remoção dos parasitas pelas células do sistema fagocítico mononuclear (MPS).

Por outro lado, na infecção de camundongos IFNүKO pelo plasmódio A/S existe um aumento notável do primeiro pico de parasitemia, que progride em forma exponencial e frequentemente leva a morte dos animais (von der WEID et al., 1993) Desconhece-se qual o papel desempenhado pelo IFN $\gamma$ no controle deste primeiro pico, uma vez que anticorpos não parecem estar envolvidos no processo. 
Assim foi lançada a hipótese do IFN $\gamma$, além do seu envolvimento em muitos outros processos de defesa frente ao plasmódio, estar agindo direcionando, direta ou indiretamente, as modificações vasculares esplênicas supostamente envolvidas na remoção inicial do parasita.

\subsection{QUIMERISMO}

Estudos utilizando quimeras de células tronco derivadas de medula óssea têm sido usados para demonstrar a atividade dessas células tanto na reconstituição tecidual durante o reparo patológico quanto para demonstrar a importância de moléculas e células efetoras circulantes do sistema imune (ONOÉ et al., 1980; GENG L et al 1986; ASAHARA T et a.l, 1999; ZIEGELHOEFFER et al., 2004).

A medula óssea contém células precursoras capazes de se diferenciar em células hematopoiéticas e em diversas linhagens de células mesenquimais (PROCKOP, 1997). Desta forma, células tronco hematopoiéticas podem reconstituir toda a população circulante de células hematopoiéticas e células tronco mesenquimais podem diferenciar-se em osteócitos, condrócitos, adipócitos e fibroblastos. Os dois tipos de células troncos mantêm um elevado grau de plasticidade e são capazes de contribuir para regeneração de células progenitoras dos diferentes tecidos (ASAHARA et al., 1997; SHI Q et al., 1998; CHAMBERS, 1978). Em organismos adultos essas células têm sido usadas no estudo da constituição de novos tecidos sob condições fisiológicas e patológicas (ONOÉ et al., 1980; TRISCHIMAN,1982; ONOÉ et al., 1997). Assim, tem sido proposto que células tronco da medula óssea ou progenitoras endoteliais circulam no organismo adulto e podem ser recrutadas para incorporar sítios de neo-vascularização (RISAU, 1997; CARMELIET, 2000). 


\section{OBJETIVO}

Esta dissertação de mestrado visa avaliar se, em reposta ao IFN- $\gamma$, as células não leucocitárias (células estruturais) desempenham atividade efetora frente aos protozoários Trypanosoma cruzi, Plasmodium chabaudi AS e Plasmodium berghei ANKA eGFP.

Objetivo complementar deste trabalho é avaliar se há reconstituição de

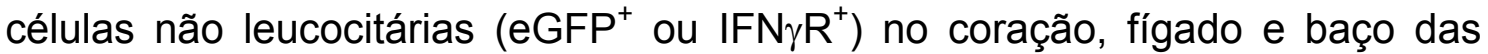
quimeras B6/IFN $\gamma$ RKO.

Através destas experiências pretendemos indagar:

Se na infecção pelo $T$. cruzi as células estruturais do coração, músculo esquelético e fígado respondem ao IFN $\gamma$ produzido pelos leucócitos contribuindo à atividade efetora local frente ao parasita.

Se na infecção pelo $P$. chabaudi as células estruturais do baço (células endoteliais dos vasos) respondem ao IFN $\gamma$ produzido pelos leucócitos determinado um aumento da atividade efetora local.

Se na infecção pelo $P$. berghei ANKA as células estruturais dos vasos respondem ao IFN $\gamma$ produzido pelos leucócitos determinado um aumento da atividade efetora no baço e/ou um aumento do quadro inflamatório cerebral. 


\section{MATERIAIS E MÉTODOS}

\subsection{ANIMAIS}

Foram utilizados camundongos machos de 6 a 8 semanas de idade da linhagem C57BL/6 (B6: "wild type"), IFN $\gamma$ R-KO ("Knock-out” em background C57BL/6) e eGFP ("background" C57BL/6), obtidos do Biotério de Animais Isogênicos do Departamento de Imunologia, ICB/USP. "eGFP" (do inglês "enhanced green fluorescent protein") é uma proteína fluorescente verde responsável pela bioluminescência verde das medusas Aequorea victoria, cujo gene foi incorporado ao genoma de camundongos selvagens C57BL/6 para transcrição intensificada por Masaru Okabe da Universidade de Osaka em 1997.

\subsection{CONSTRUÇÃO DAS QUIMERAS}

Para a construção das quimeras experimental e controle os camundongos machos IFN $\gamma$ R-KO e C57BL/6 foram irradiados com 1200 rads e transferidos via intraperitoneal, logo após a irradiação, com $20 \times 10^{6}$ células de medula óssea provenientes de camundongos machos C57BL/6 ou eGFP ("background" C57BL/6). Como controles não quiméricos, incluímos camundongos IFN $\gamma R-K O$ e C57BL/6 que não sofreram irradiação nem transferência celular.

As células da medula óssea foram obtidas do fêmur por suaves jatos de RPMI suplementado com 1\% SBF. Após centrifugação de 3000 rpm por 5 minutos, a suspensão foi ajustada para $1 \times 10^{8}$ células/ ml, em RPMI $1 \%$ SBF, e um volume de $200 \mu$ injetado via intraperitoneal em cada animal logo após a irradiação. Os animais irradiados e transferidos com células de medula, assim 
como os animais dos grupos controle, foram tratados por duas semanas com antibiótico (CIPRONIL- Farmabase) diluído em água.

\subsection{AVALIAÇÃO DO ESTADO QUIMÉRICO}

\subsubsection{ANÁLISE LEUCOCITÁRIA DA EXPRESSÃO DE IFN $\gamma$ R POR CITOMETRIA DE FLUXO}

De cada animal foram retirados $45 \mu \mathrm{l}$ de sangue periférico através de secção da cauda e diluídos em $100 \mu \mathrm{l}$ de PBS 1X heparinizado. Esta suspensão foi transferida para tubo Falcon e incubadas com $1 \mathrm{ml}$ de tampão de lise contendo TRIS e $\mathrm{NH} 4 \mathrm{Cl}(0,16 \mathrm{M})$ por 5 minutos, acondicionando os tubos no gelo para manter a viabilidade celular. Após a lise, as células foram lavadas por duas vezes acrescendo 9ml de RPMI completo e centrifugação a 1200 rpm.

Os leucócitos obtidos após a lise do sangue foram incubados com 0,25 $\mu \mathrm{l}$ de anticorpos monoclonais diluídos em PBS suplementado com 1\% SBF e 0,05\% azida sódica (Sigma-Aldrich), por 30 minutos a $4{ }^{\circ} \mathrm{C}$. Os anticorpos utilizados foram anti-B220, anti-CD3 e anti-IFN $\gamma$ R, conjugados respectivamente a Fluorescein Isothiocyanate (FITC), Cy-Chrome (CY) e Biotina. Após lavadas com PBS-SBF-azida, as células foram incubadas com estreptoavidina-PE (SA$\mathrm{PE}$ ) por 30 minutos, novamente lavadas com o mesmo tampão e analisadas em citômetro de fluxo (FACScalibur-Becton Dickinson). No caso de análise de células $\mathrm{eGFP}^{+}$, as incubações foram realizadas com anti-B220-Cy-chrome e anti-CD3-PE. As análises foram realizadas utilizando o software Cell Quest. Todos os anticorpos foram obtidos da PharMingen. 


\section{$\begin{array}{llll}\text { 3.3.2 ANÁLISE DE } & \text { QUIMERISMO } & \text { TISSULAR } & \text { POR }\end{array}$ IMUNOFLUORESCÊNCIA: PERFUSÃO DOS ANIMAIS E PREPARAÇÃO DOS CORTES CONGELADOS}

Os animais foram anestesiados com Xylazina (Rompum TM; 0,25 $\mathrm{mg} / \mathrm{animal}$ ) e clorhidrato de ketamina (Ketamina TM; $1,25 \mathrm{mg} / \mathrm{animal}$ ) e perfundidos por via transcardíaca com salina tamponada e paraformaldeído a 2-4\% em tampão fosfato 0,1 M (PBS; pH 7,4). Após 5 horas de fixação, os órgãos (coração, fígado e baço) foram transferidos para uma solução de sacarose a $30 \%$ em PBS para crioproteção.

Cortes dos diferentes órgãos congelados $(16 \mu \mathrm{m})$ foram obtidos (utilizando-se um micrótomo deslizante de congelação) e imediatamente coletados em lâminas gelatinizadas para posterior incubação com os devidos anticorpos para a técnica de imunofluorescência.

\subsubsection{PROCESSAMENTO DOS TECIDOS CONGELADOS E REAÇÃO DE IMUNOFLUORESCÊNCIA}

Após o corte do tecido, as lâminas foram lavadas 2 vezes por 10 minutos em Tampão PB 0,1M e separadas em dois grupos: a) lâminas que não receberam nenhum tratamento e que, após cobertas com solução de montagem, foram levadas ao microscópio de fluorescência; e b) lâminas lavadas em PBS 0,1M e incubadas overnight com anticorpo anti-IFN $\gamma \mathrm{R}$ (Santa Cruz), diluído a 1:200 em solução de Triton X-100 0,3\% em PBS 0,1M com 5$10 \%$ de soro normal de cabra. Após incubação, as lâminas foram lavadas em PBS $0,1 \mathrm{M}$ e incubadas por 2 horas com anticorpo secundário goat anti-rat IgG (PharMingen) marcado com ficoeritrina, diluído a 1:200 em solução de Triton $\mathrm{X}-100$ 0,3\%. Após lavados em PBS 0,1M, as lâminas foram incubadas por mais 15 minutos com Dapi (para marcação dos núcleos) e, após novo ciclo de 
lavados em PBS 0,1M, adicionadas com solução de montagem para leitura em microscópio de fluorescência.

\subsection{INFECÇÃO PELO T. cruzi}

\subsubsection{MANUTENÇÃO DA CEPA DE T. cruzi}

A cepa Sylvio (clone $\mathrm{X10/4}$ ) de T. cruzi foi originalmente obtida na Escola Paulista de Medicina (UNIFESP) e os parasitas mantidos por meio de passagens semanais em monocamadas de células LLC-MK2 (American Type Culture Collection - ATCC - CCL7.1).

\subsubsection{DESENHO EXPERIMENTALI INFECÇÃO PELO T. cruzi}

Os camundongos tanto dos grupos quiméricos, quanto dos grupos controles foram infectados via intraperitoneal com inóculo de $10^{6}$ T.cruzi da cepa Sylvio (clone X10/4) e sacrificados em diferentes dias de infecção. O sacrifício dos animais foi realizado por narcose em $\mathrm{CO}_{2}$.

\subsubsection{AVALIAÇÃO DE PARASITEMIAS E CARGA PARASITÁRIA LOCAL}

As parasitemias foram avaliadas pela observação microscópica de amostras de $5 \mu l$ de sangue, obtidas pela secção da cauda dos animais, segundo método descrito por Brener (1962).

A carga parasitária no coração, músculo esquelético e fígado foram avaliadas através da contagem do número de ninhos em 6 lâminas não contínuas de secções de tecidos, coradas com hematoxilina-eosina. 


\subsubsection{ANÁLISES HISTOPATOLÓGICAS NA INFECÇÃO PELO T. cruzi DO CORAÇÃO, FÍGADO E MÚSCULO ESTRIADO ESQUELÉTICO:}

Os animais dos diferentes grupos foram sacrificados em diferentes dias de infecção para análise do parasitismo tissular e do grau de patologia desenvolvida no coração, fígado e músculo estriado (quadríceps).

Após o sacrifício dos animais os órgãos foram coletados e fixados por $24 \mathrm{~h}$ em solução de formaldeído a $10 \%$, sendo posteriormente processados para inclusão em blocos de parafina. O coração foi cortado sagitalmente em duas partes, cada uma contendo as quatro cavidades. Seis cortes sagitais de $5 \mu \mathrm{m}$, não consecutivos, foram obtidos do coração, assim como do fígado e músculo estriado esquelético (quadríceps), corados por hematoxilina-eosina e posteriormente analisados na sua totalidade através de microscopia óptica (MARINHO et al., 2004).

Com exceção do tratamento antibiótico, nenhum dos grupos sofreu qualquer tipo de tratamento no período pós-infecção.

A intensidade do infiltrado inflamatório foi avaliada em forma semiquantitativa, onde: (0) nenhum, (1) suave, (2) moderado, (3) intenso e (4) severo.

\section{3 .5 INFECÇÃO POR PARASITAS DO GÊNERO Plasmodium}

Para avaliar o papel do IFN $\gamma$ sobre as células não leucocitárias na infecção por parasitas do gênero plasmódio, camundongos machos das linhagens C57BL/6 (B6) e IFN $\gamma \mathrm{R}-\mathrm{KO}$, assim como animais quiméricos B6/B6 e B6/IFN $\gamma$ R-KO foram infectados com eritrócitos infectados de $P$. Berghei ANKAGFP e $P$. chabaudi AS. Previamente à infecção, os grupos quiméricos experimental e controle foram avaliados por citometria de fluxo em relação à obtenção do estado quimérico na forma descrita acima. Logo após, os animais dos grupos quiméricos e controle foram infectados via intraperitoneal com $10^{6}$ 
eritrócitos parasitados por $P$. berghei ANKA-GFP, mantidos em repiques semanais em animais IFN $\gamma \mathrm{R}-\mathrm{KO}$, ou $10^{6}$ eritrócitos parasitados por $P$. chabaudi da cepa AS, mantidos em repiques semanais em camundongos C57BL/6, e acompanhados em sua parasitemia e morte.

\subsubsection{AVALIAÇÃO DE PARASITEMIAS NA INFECÇÃO PELO PLASMÓDIO}

As parasitemias foram monitoradas a partir do primeiro dia de infecção através de esfregaços sanguíneos corados por Giemsa e observados por microscopia. 


\section{RESULTADOS}

\subsection{QUIMERISMO POR CÉLULAS EGFP+}

\subsubsection{ANÁLISE DO QUIMERISMO LEUCOCITÁRIO POR CÉLULAS EGFP+}

Grupos quiméricos eGFP/B6 e eGFP/IFN $\gamma$ RKO foram construídos inoculando via i.p. células da medula óssea de animais eGFP ("background" C57BL/6) em animais C57BL/6 e IFN $\gamma R$ RKO irradiados com 1200 rads. Estes experimentos foram realizados com o objetivo de avaliarmos por imunofluorescência a reconstituição leucocitária, e ainda, para verificar se as células estruturais conseguem repopular ou não diferentes tecidos.

Foram realizadas duas análises de quimerismo para avaliarmos a efetividade da reconstituição leucocitária por células eGFP, 1 e 2 meses após a transferência da medula (Figura 3) Para a análise, que foi realizada por citometria de fluxo como citada acima, utilizamos leucócitos de sangue periférico de cada animal. A análise da freqüência de células $\mathrm{eGFP}^{+}$nas populações $\mathrm{T}\left(\mathrm{CD}^{+}\right)$e $\mathrm{B}\left(\mathrm{B} 220^{+}\right)$do sangue periférico mostrou que os animais das duas quimeras foram parcialmente reconstituídos pela medula de animais eGFPs (Figura 3). Em forma interessante, a reconstituição da população CD3 $^{+}$ por células $\mathrm{eGFP}^{+}$mostrou-se discretamente menor que a de células $\mathrm{B} 22 \mathrm{O}^{+}$ dos mesmos animais e foi mais intensa nas quimeras eGFP/IFN $\gamma$ RKO do que nas quimeras eGFP/B6.

Aos 5 meses da transferência das células da medula, e por ocasião do sacrifício dos animais, estudamos a freqüência de células $\mathrm{eGFP}^{+}$na medula óssea dos animais quiméricos, verificando-se uma reconstituição quase que completa de células $B$ e parcial de células $T$, mas com grande variabilidade individual (Figura 4). 
Em ambas as análises do sangue e medula óssea, a freqüência de células eGFP ${ }^{+}$nas quimeras eGFP/IFN $\gamma R K O$ e eGFP/B6 mostrou-se mais intensa na população das células B (B220+) do que nas células CD4+ (Figuras $3-4)$.

\section{Avaliaçäo do Estad o Quimérico}

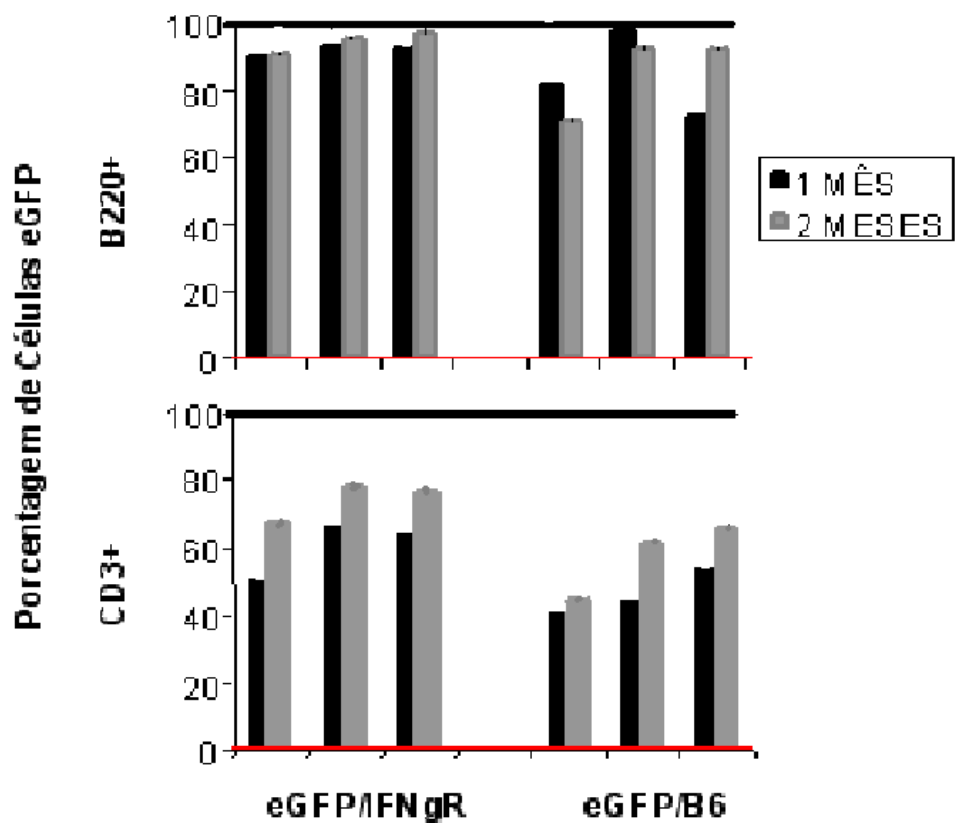

Figura 3. Análise por citometria de fluxo da reconstituição de animais quiméricos (eGFP/IFN $\gamma$ RKO e eGFP/B6) por células eGFP ${ }^{+}$, nas populações $\mathrm{B220}^{+}$e $\mathrm{CD}^{+}$ do sangue periférico aos 30 e 60 dias após a transferência de medula. A linha horizontal preta representa os animais controle B6 e a linha horizontal vermelha os animais controles IFN $\gamma$ RKO

\section{Avaliação da frequência de células eGFP na medula óssea após 5 meses de reconstituição}

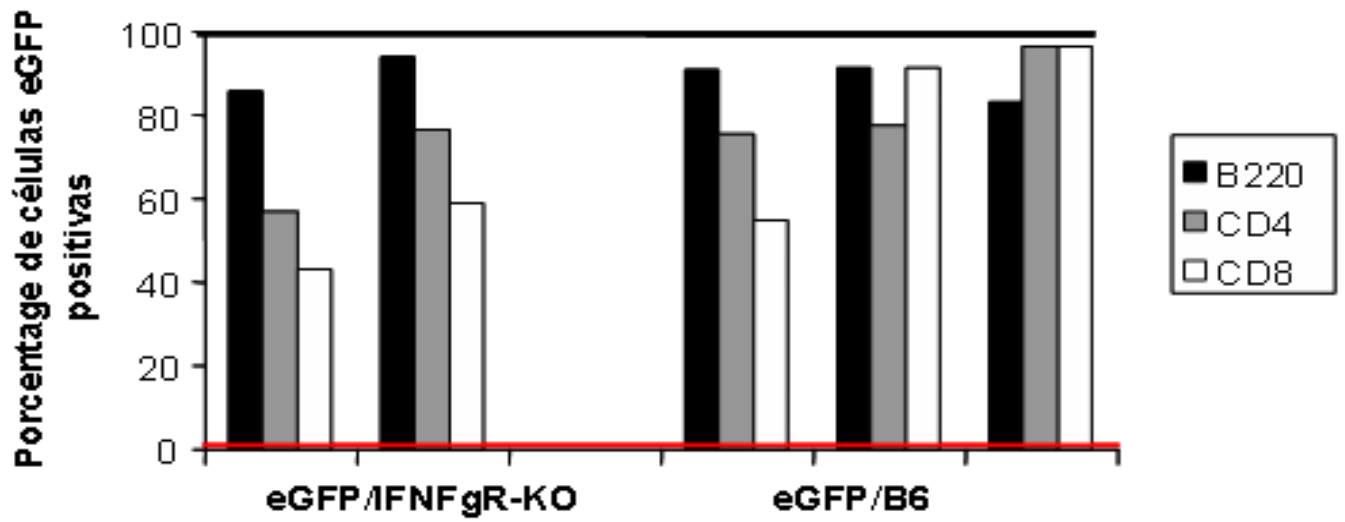

Figura 4. Análise por citometria de fluxo da reconstituição por células eGFP+ na medula óssea de animais quiméricos (eGFP/IFN RKO e eGFP/B6) após 5 meses de reconstituição, nas populações CD4+, CD8+ e B220+ . A linha horizontal preta representa os animais controle B6 e a linha horizontal vermelha os animais controles IFN RKO. 


\subsubsection{AVALIAÇÃO DA CONCENTRAÇÃO DE PARAFORMALDEÍDO NA PRESERVAÇÃO DAS MOLÉCULAS PIFN R E EGF}

Como a avaliação do quimerismo tissular requer fixação por paraformaldeído, fizemos uma avaliação da concentração de paraformaldeído utilizada na perfusão dos animais para estimar sua eventual interferência na preservação das moléculas IFN $\gamma \mathrm{R}$, e ainda para ver se interferia na fluorescência das células eGFP ${ }^{+}$. Para isso, células do baço de um animal eGFP foram expostas ao paraformaldeído pelo mesmo período que normalmente um animal sofre durante a perfusão e pós-perfusão (período de pós-fixação, 5 horas). Após esse período, as células foram analisadas utilizando as mesmas marcações de anticorpos citadas acima. A avaliação mostrou que nas concentrações utilizadas (1,6 e 4\%) o paraformaldeído não interfere no epítopo da molécula de IFN $\gamma$ R detectado pelo anticorpo monoclonal, mas diminui parcialmente a fluorescência eGFP (Figura 5).

\section{Avaliação da Concentração de Paraformaldeído}
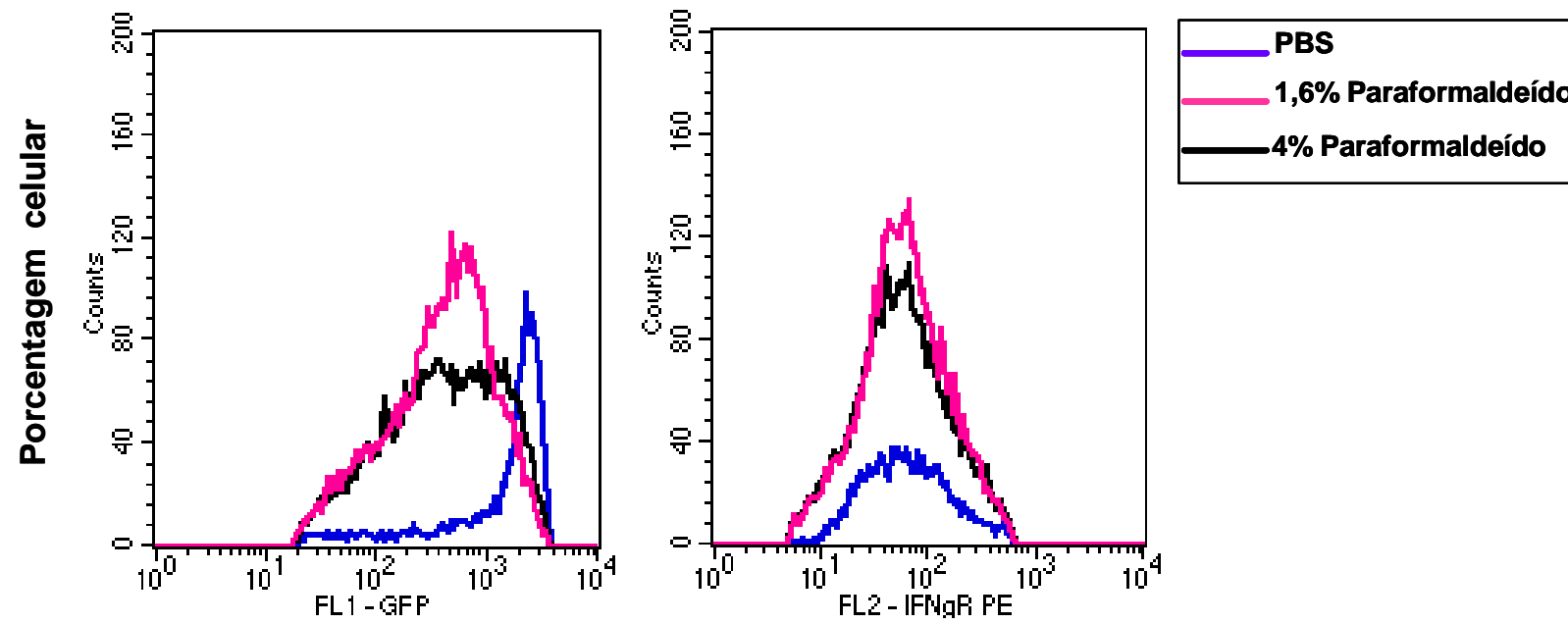

Figura 5. Análise por citometria de fluxo da presença de IFN $\gamma \mathrm{R}$ em leucócitos extraídos de baço de camundongo eGFP após fixação de 5 horas em solução de paraformaldeído nas concentrações de 1,6\% e 4\%. 


\subsubsection{IMUNOFLUORESCÊNCIA TISSULAR DE ANIMAIS EGFP}

Para padronização da técnica de imunofluorescência, animais eGFP, B6, IFN $\gamma$ RKO e dos grupos quiméricos eGFP/B6 e eGFP/IFN $\gamma R K O$ foram perfundidos com paraformaldeído à 1,6\%. Cabe enfatizar que esta dose de paraformaldeído, apesar de reduzir discretamente a fluorescência eGFP, não elimina esta (figura 5). Após a perfusão foram retirados o coração, o fígado e o músculo estriado (quadríceps) e emblocados com solução "anti-freezing" para realizar mais tarde cortes congelados. Foram feitas lâminas com cortes não seriados de $16 \mu$ de tecido cardíaco e levados imediatamente ao microscópio de fluorescência para padronização da emissão natural de fluorescência pelas células eGFP e ainda, verificar se houve reconstituição tecidual por parte das células transferidas de animais eGFP.

No animal eGFP podemos observar que o coração emite um nível elevado de fluorescência verde, que é facilmente visualizado nos diversos

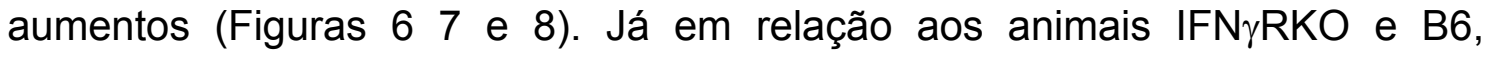
observa-se nos diferentes aumentos que o coração é totalmente negativo para fluorescência verde. Finalmente, nos animais quiméricos eGFP/B6 e eGFP/IFN $\gamma$ RKO analisados nos diferentes aumentos, não observamos nenhuma emissão de fluorescência. Assim, os resultados sugerem não haver reconstituição de células estruturais do tecido cardíaco a partir de células tronco presentes na medula de camundongos eGFP. 


\section{Expressão de eGFP - 20X}

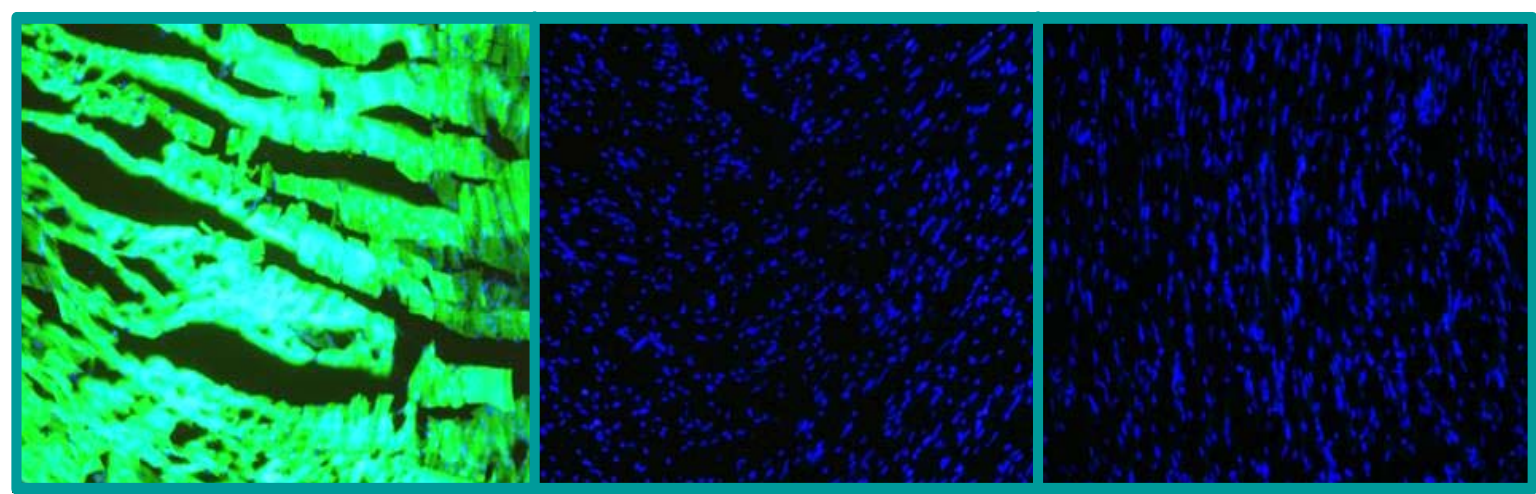

eGFP

B6

IFNyRKO

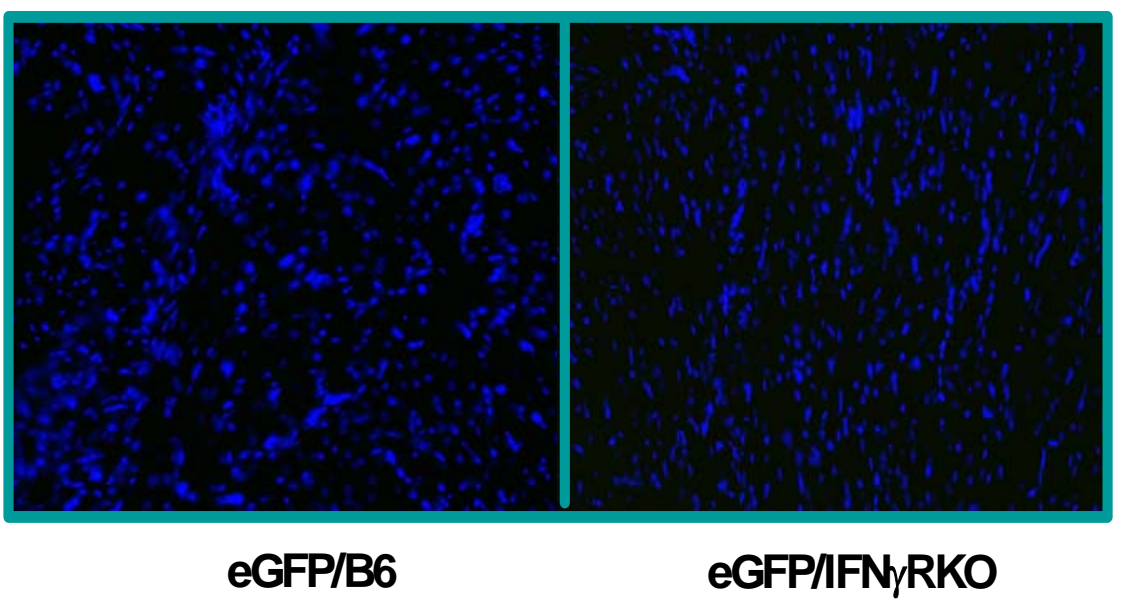

Figuras 6. Emissão de fluorescência eGFP do tecido cardíaco nos animais controles: eGFP, IFN $\gamma R K O$, B6 e nas quimeras eGFP/B6 e quimera eGFP/IFN $\gamma$ RKO em aumento de 20X. 


\section{Expressão de eGFP - 40X}
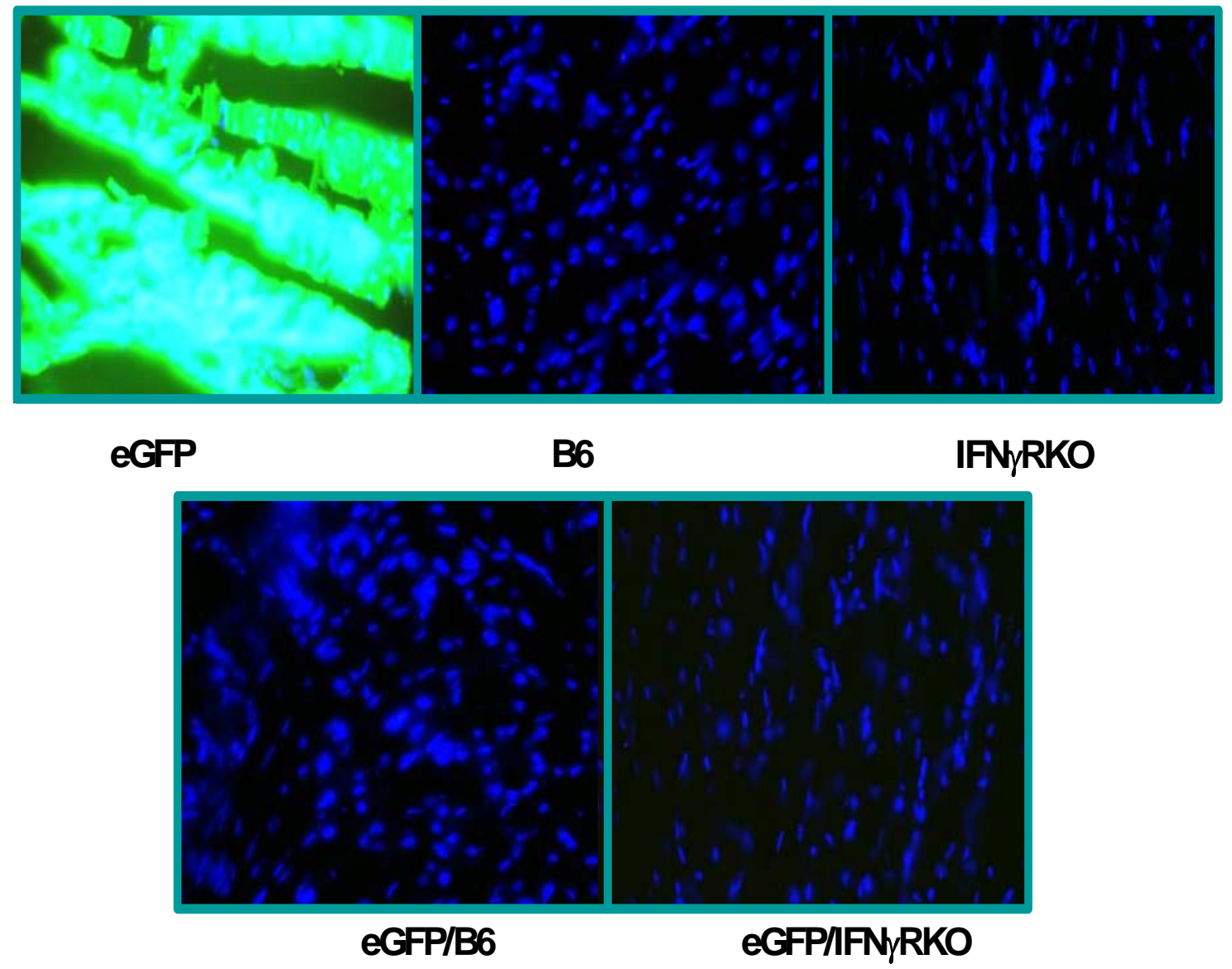

Figuras 7. Emissão de fluorescência eGFP do tecido cardíaco nos animais controles: eGFP, IFN $\gamma R K O$, B6 e nas quimeras eGFP/B6 e quimera eGFP/IFN $\gamma$ RKO em aumento de 40X. 


\section{Expressão de eGFP - 100X}

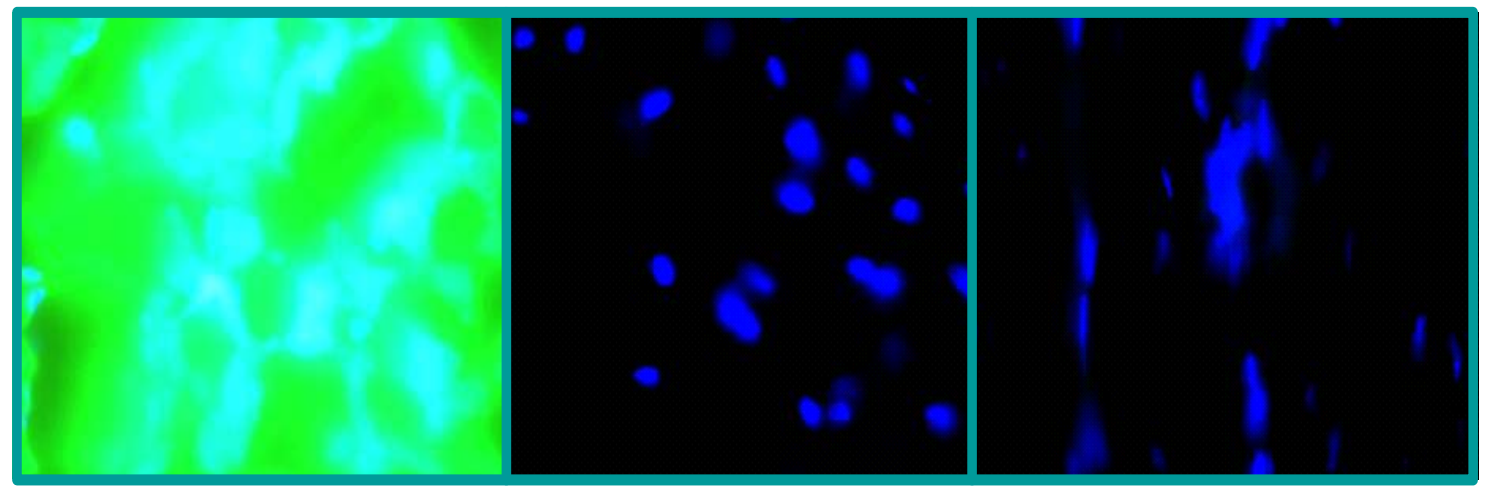

eGFP

B6

IFNyRKO

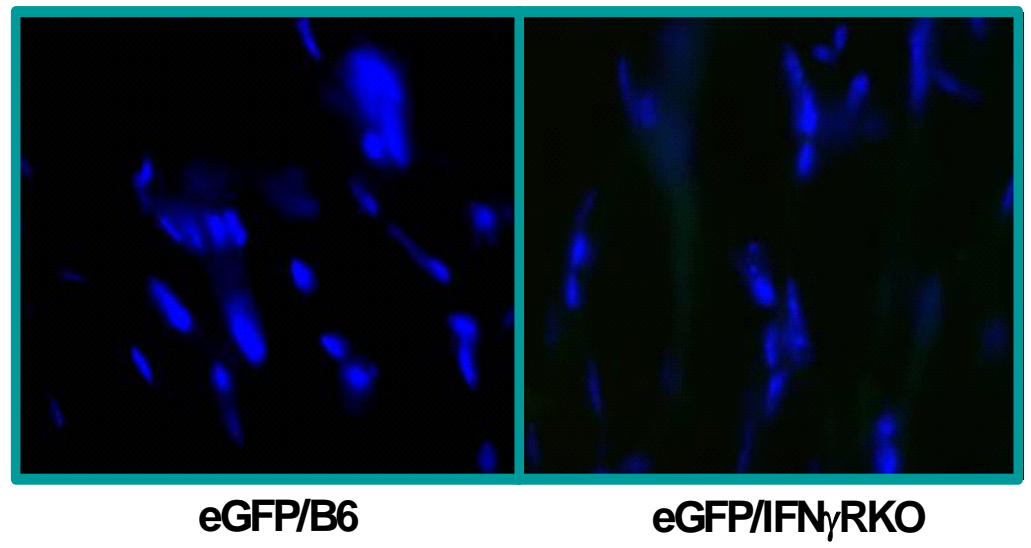

Figuras 8. Emissão de fluorescência eGFP do tecido cardíaco nos animais controles: eGFP, IFN $\gamma R K O, B 6$ e nas quimeras eGFP/B6 e quimera eGFP/IFN $\gamma$ RKO em aumento de 100X. 


\subsubsection{EXPRESSÂO DE IFN $\gamma$ R NO CORAÇÃO AVALIADA POR IMUNOFLUORESCÊNCIA}

Lâminas com cortes não seriados de $16 \mu$ de tecido cardíaco foram marcadas com anticorpo específico para o receptor de IFN $\gamma$ com o intuito de verificarmos se as células estruturais do coração realmente expressam esse receptor e ainda para padronização das concentrações do mesmo anticorpo. Após padronização da dose de anticorpo frente ao IFN $\gamma \mathrm{R}$ realizamos a avaliação da expressão do receptor nos diferentes animais. Nas figuras 9, 10 e 11 podemos observar nos animais eGFP, B6 e quimera eGFP/B6 intensa marcação vermelha de IFN $\gamma$ R. Isto era em certa forma esperado uma vez que todos estes animais tem íntegro o gene do IFN $\gamma$ R. Já em relação, aos animais quimera eGFP/IFN $\gamma$ RKO e IFN $\gamma$ RKO não apresentaram nenhuma marcação fluorescente vermelha. O fato do grupo quimérico eGFP/IFN $\gamma R K O$ não apresentar nenhuma fluorescência para esta marcação sugere que não houve nenhum tipo de reconstituição tecidual pelas células de medula transferidas, já que estas possuem o gene desse receptor intacto.

A conclusão destes experimentos é que o tecido cardíaco do animal normal expressa nível elevado do IFN $\gamma$ R. 


\section{Expressão de IFNyR - 20X}

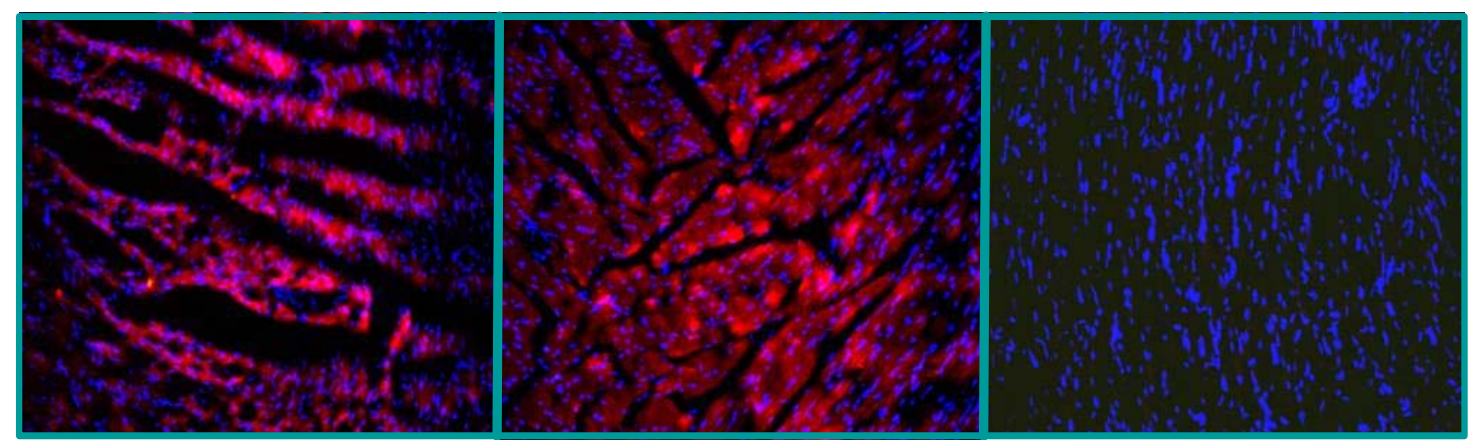

eGFP

B6

IFNyRKO
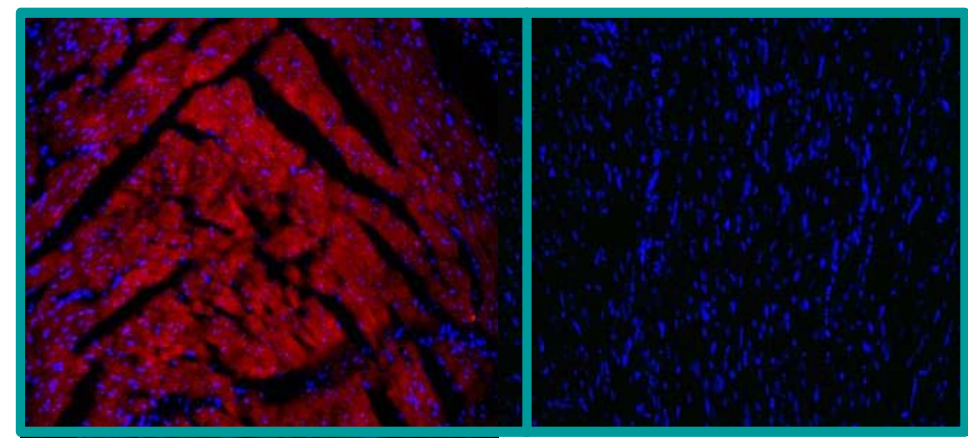

eGFP/B6

eGFPIIFNY̧RKO

Figuras 9. Análise da presença de IFN $\gamma \mathrm{R}$ no tecido cardíaco em animais controles: eGFP, B6, IFN $\gamma$ RKO e animais quimera eGFP/B6 e quimera eGFP/IFN $\gamma$ RKO em aumento de 20X. 


\section{Expressão de IFNyR - 40X}

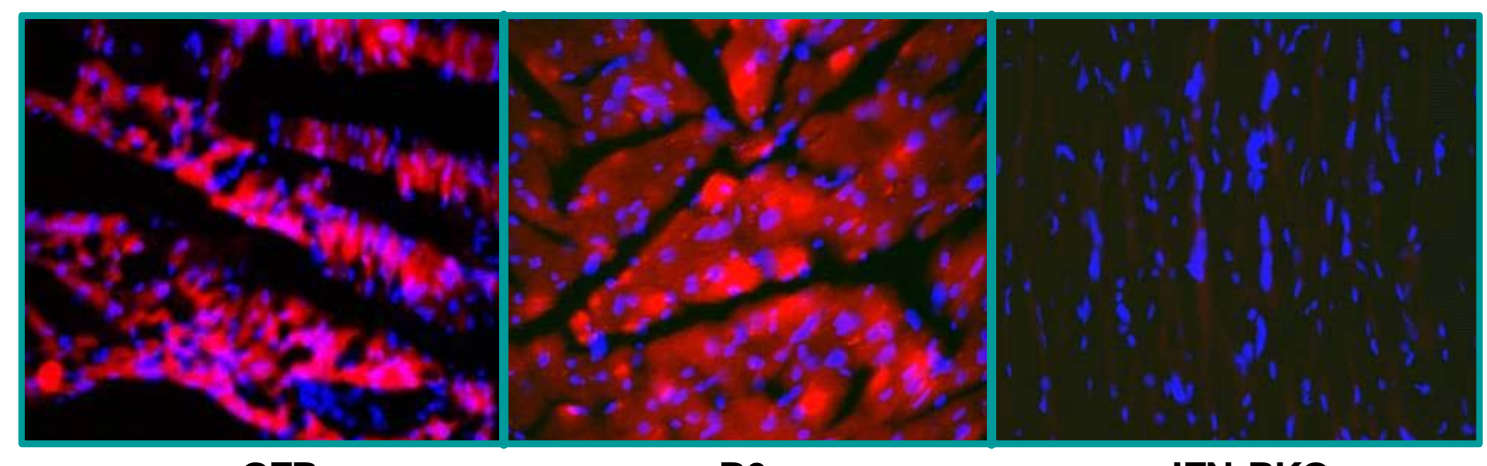

eGFP

B6

IFN $\gamma$ RKO

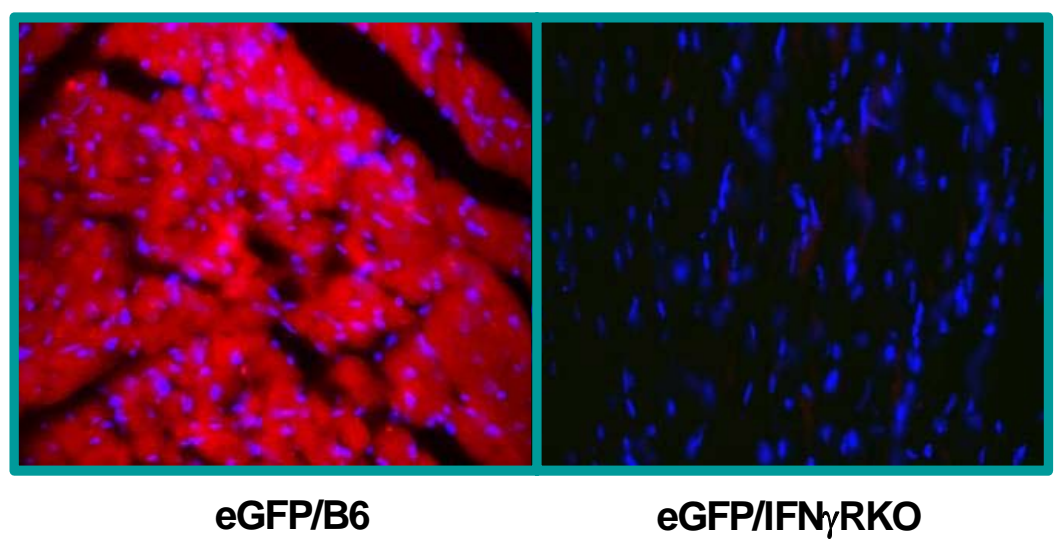

Figuras 10. Análise da presença de IFN $\gamma \mathrm{R}$ no tecido cardíaco em animais controles: eGFP, B6, IFN $\gamma$ RKO e animais quimera eGFP/B6 e quimera eGFP/IFN $\gamma$ RKO em aumento de $40 X$. 


\section{Expressão de IFNł̧R - 100X}
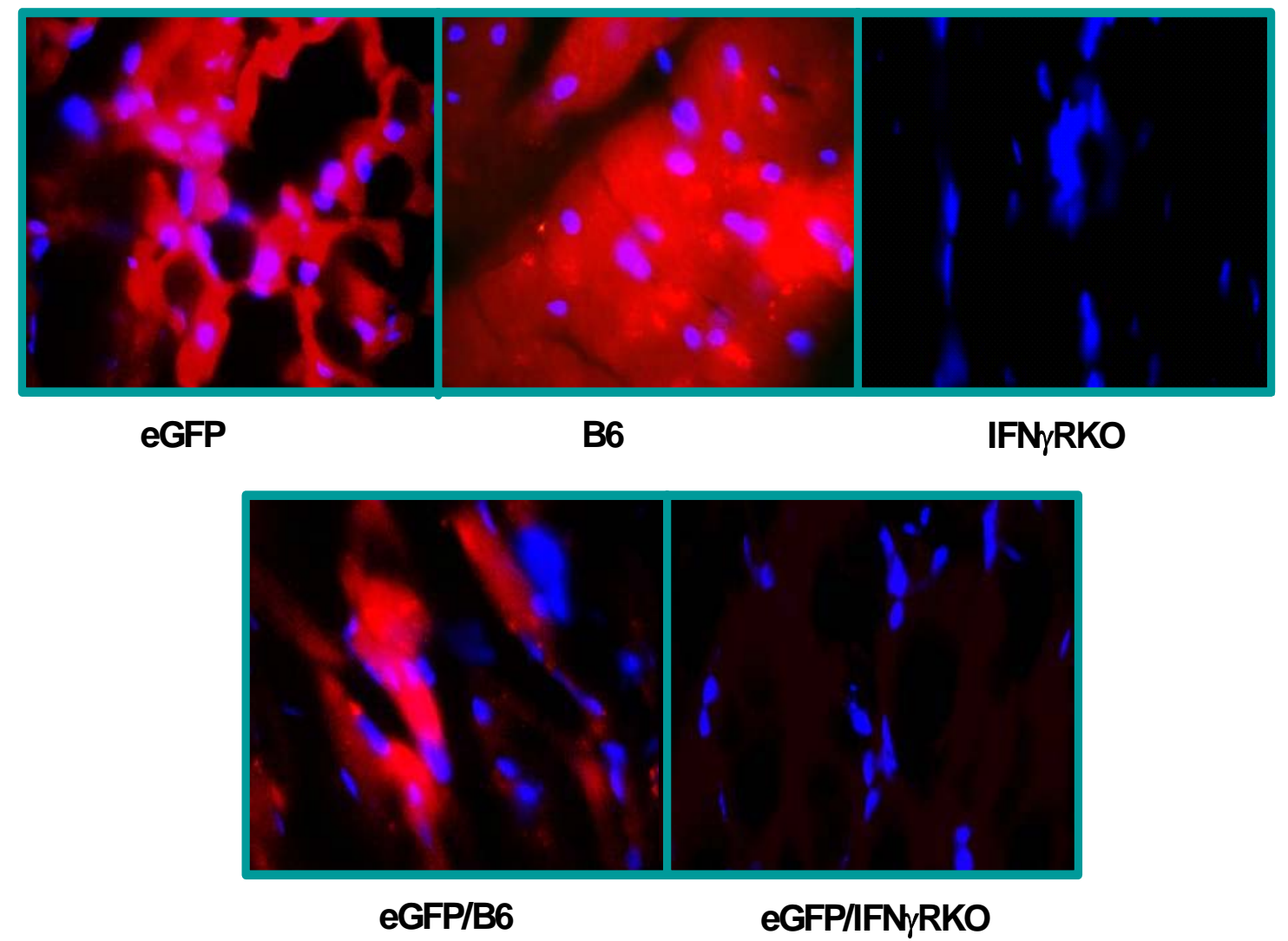

Figuras 11. Análise da presença de IFN $\gamma \mathrm{R}$ no tecido cardíaco em animais controles: eGFP, B6, IFN $\gamma$ RKO e animais quimera eGFP/B6 e quimera eGFP/IFN $\gamma$ RKO em aumento de 100X. 


\subsubsection{EXPRESSAO DE EGFP E IFN $\gamma R$ NO BAÇO DAS QUIMERAS EGFP/IFN $\gamma R$}

Seguindo as mesmas padronizações citadas anteriormente, foi realizada análise por imunofluorescência do baço dos animais dos grupos controles eGFP, B6, IFN $\gamma R K O$ e dos grupos quiméricos eGFP/B6 e

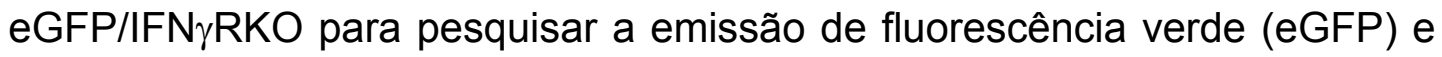
a presença do receptor de IFN $\gamma$ (em vermelho)

Com a objetiva 10X observamos que o baço do animal eGFP emite um nível muito elevado de fluorescência verde, que contrasta com a negatividade nos animais não transgênicos (B6 e IFN $\gamma$ RKO). Nos animais quiméricos eGFP/B6 e eGFP/IFN $\gamma$ RKO observamos também fluorescência, apesar de ser menos intensa que a dos animais eGFP. Assim, os resultados sugerem haver reconstituição de células leucocitárias do baço a partir de células tronco presentes na medula óssea de camundongos eGFP. (Figura12)

A análise por imunofluorescência da expressão do receptor para IFN $\gamma$ no baço destes mesmos animais mostrou nos animais eGFP, B6 e quimeras eGFP/B6 e eGFP/IFN $\gamma$ RKO uma intensa marcação. Isto era o esperado nos animais eGFP, B6 e quimeras eGFP/B6, uma vez que todos estes animais tem íntegro o gene do IFN $\gamma$ R. Já em relação aos animais quimera

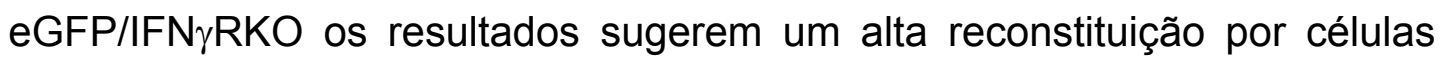
leucocitárias IFN $\gamma R^{+}$. Com relação ao grupo IFN $\gamma R K O$ não apresentaram nenhuma marcação fluorescente vermelha (Figura 12).

A conclusão destes experimentos é que o tecido esplênico do animal não deficiente expressa nível elevado do IFN $\gamma R$, assim como aquele dos animais dos grupos inoculados com medula óssea de animais eGFP. 


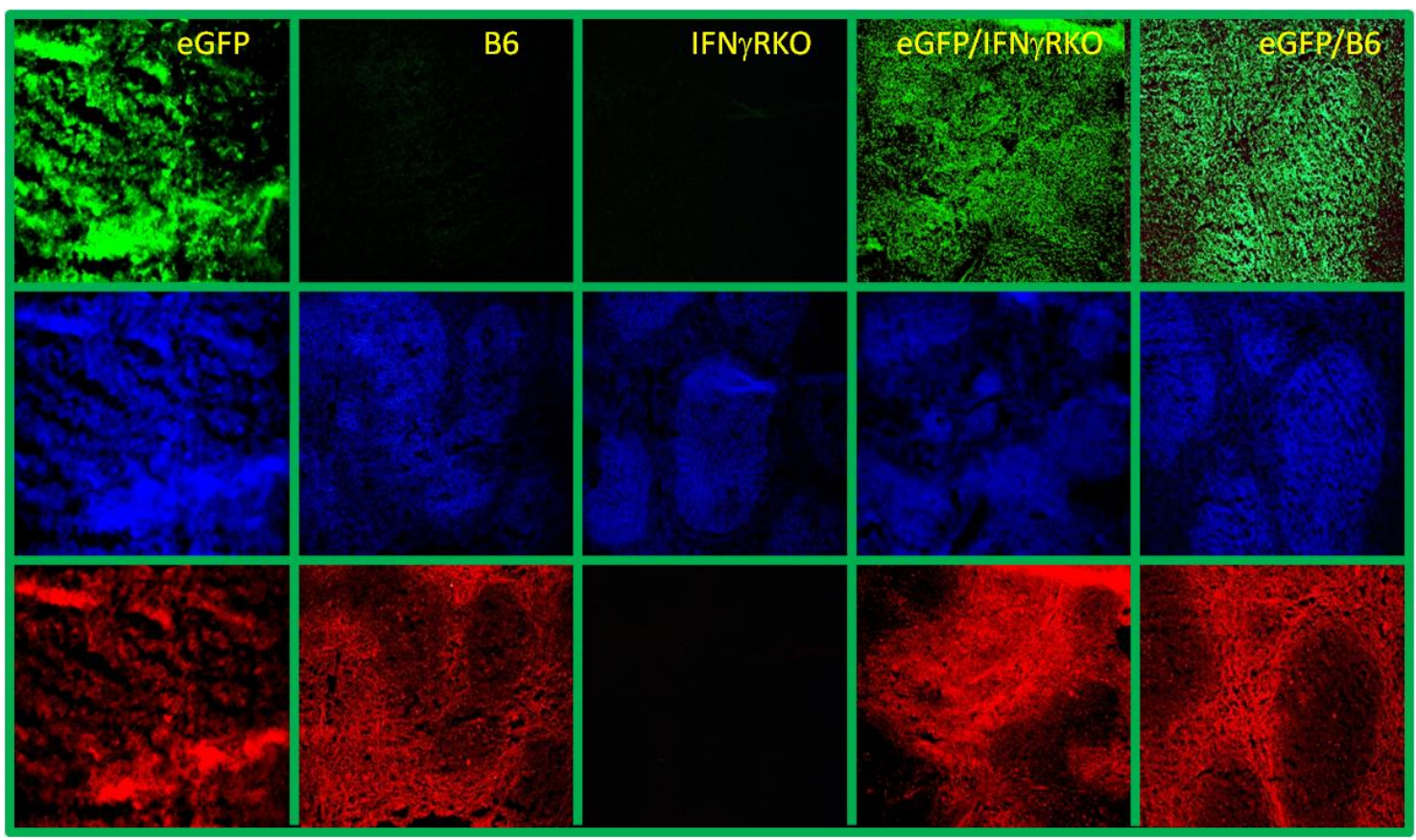

FIGURA 12. Emissão de fluorescência eGFP (verde), DAPI (marcador de núcleos celulares, azul) e IFN $\gamma R$ (vermelho) no baço de animais eGFP, IFN $\gamma$ RKO, B6 e quimeras eGFP/B6 e eGFP/IFN $\gamma$ RKO, observada com o objetivo de 10X. No círculo mostramos a expressão de IFN $\gamma R$ com o objetivo de 40X. 


\subsubsection{EXPRESSAO DE EGFP E IFN $\gamma R$ NO FÍGADO DAS QUIMERAS EGFP/IFN $\gamma R$}

Analogamente ao mostrado para o coração e o baço, foi realizada análise por imunofluorescência da expressão de eGFP e IFN $\gamma R$ no fígado dos animais eGFP, B6, IFN $\gamma R K O$ e grupos quiméricos eGFP/B6 e eGFP/IFN $\gamma$ RKO .

No animal eGFP observamos que o fígado emite um nível elevado de fluorescência verde, que contrasta com a absoluta negatividade nos animais

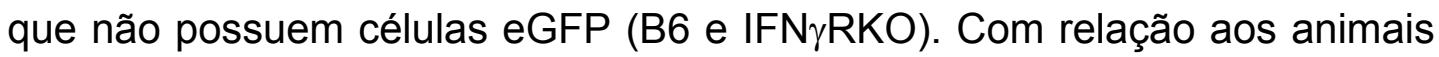
quiméricos eGFP/B6 e eGFP/IFN $\gamma R K O$, observamos a emissão de fluorescência verde, contudo de intensidade inferior à mostrada pelos animais eGFP. A marcação verde no fígado dos animais dos grupos quiméricos assume aparência radial ou de rede, com áreas de expressão mais intensa em volta dos vasos e em cordões ao longo do parênquima, que se soma a um pontilhado de marcação intensa superposto ao padrão de marcação radial. Assim, há espaços vazios eGFP' entre os cordões. Este quadro é mais facilmente observado no objetivo de 40X. Assim, os resultados sugerem haver reconstituição diferenciada das populações que compõem o tecido hepático a partir de células tronco presentes na medula óssea de camundongos eGFP (Figuras 13 e 14).

A expressão do receptor para IFN $\gamma$ nas lâminas destes mesmos animais permitiu observar que nos animais eGFP, B6, eGFP/B6 e

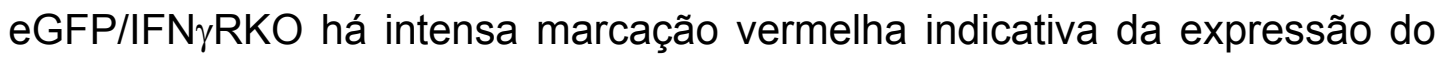
IFN $\gamma R$, enquanto que nos animais do grupo IFN $\gamma$ RKO não se observa nenhuma marcação. No entanto, a expressão do IFN $\gamma R$ é mais intensa nos animais eGFP, B6 e quimeras eGFP/B6 do que nos animais

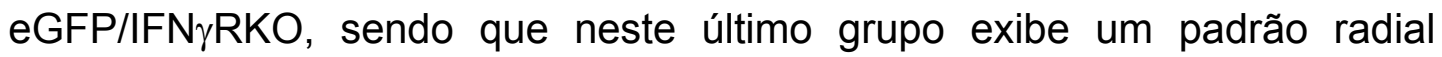
similar ao indicado na análise de eGFP (Figuras 13 e 15). 


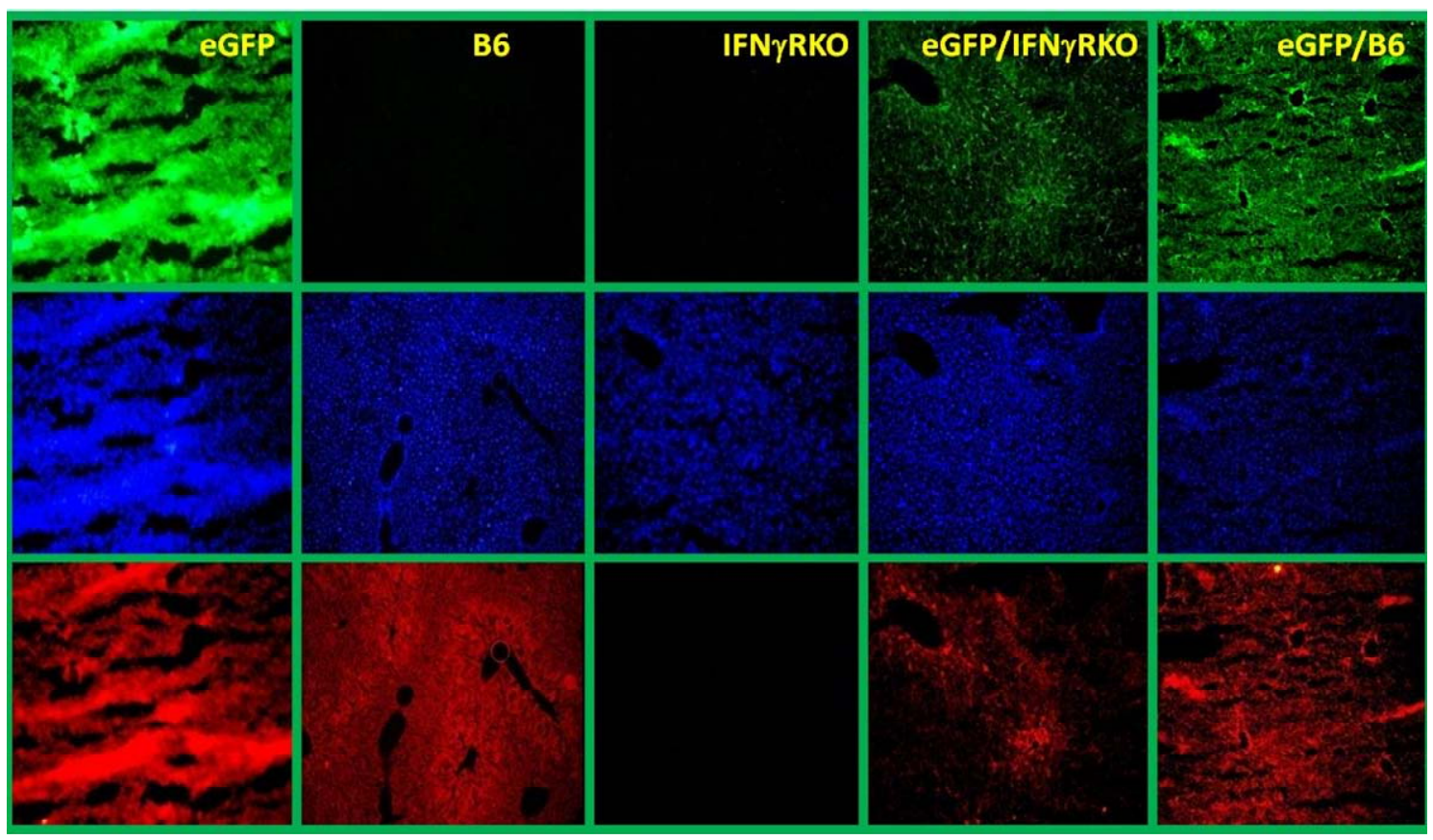

FIGURA 13. Emissão de fluorescência eGFP (verde), DAPI (marcador de núcleos celulares, azul) e IFN $\gamma \mathrm{R}$ (vermelho) no fígado de animais eGFP, IFN $\gamma \mathrm{RKO}$, B6 e quimeras eGFP/B6 e eGFPIIFN $\gamma$ RKO, observada com o objetivo de 10X. 


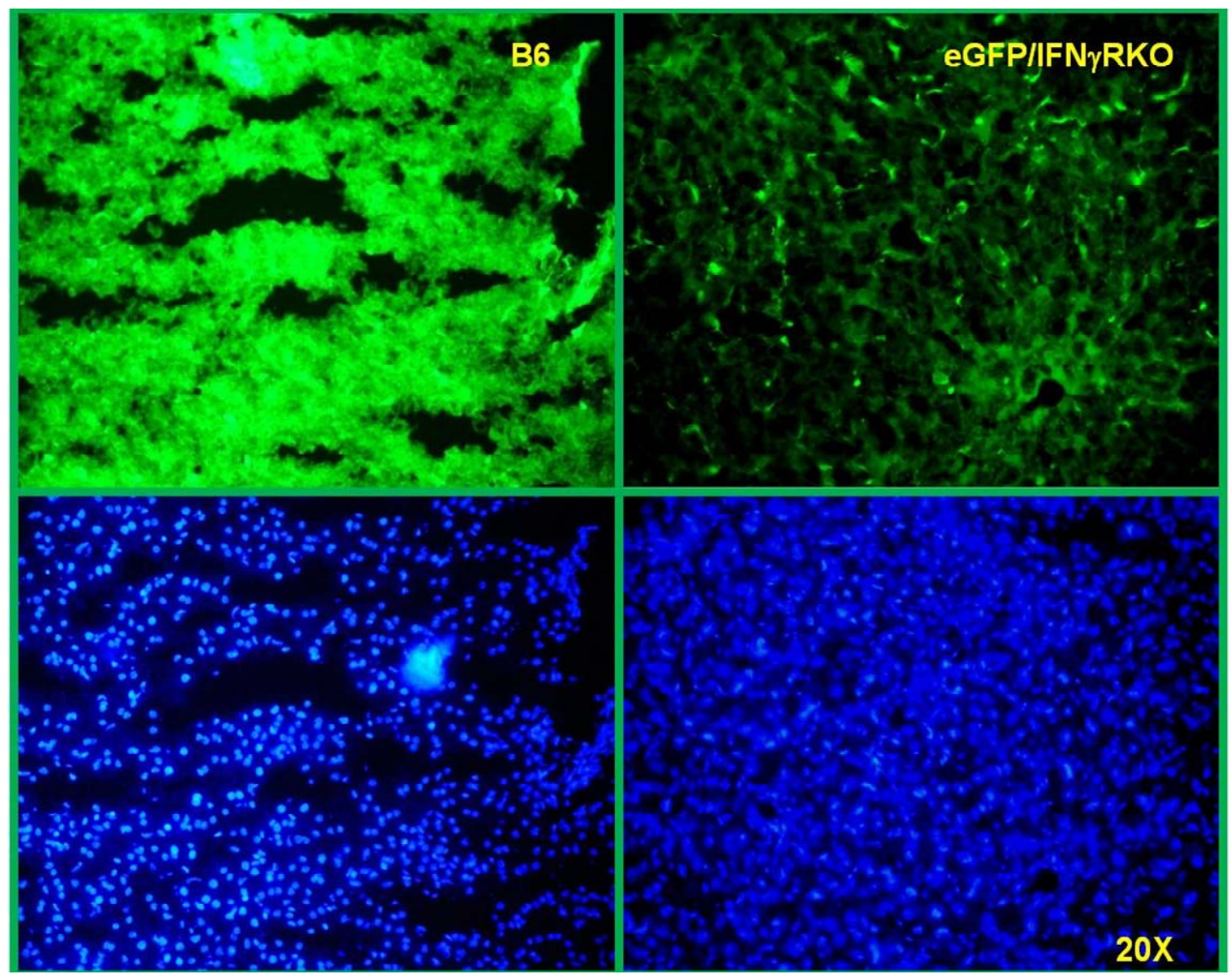

FIGURA 14. Emissão de fluorescência para eGFP e DAPI no tecido hepático dos animais B6 e quimera eGFP/IFN $\gamma$ RKO estimada com o objetivo de 20X. 


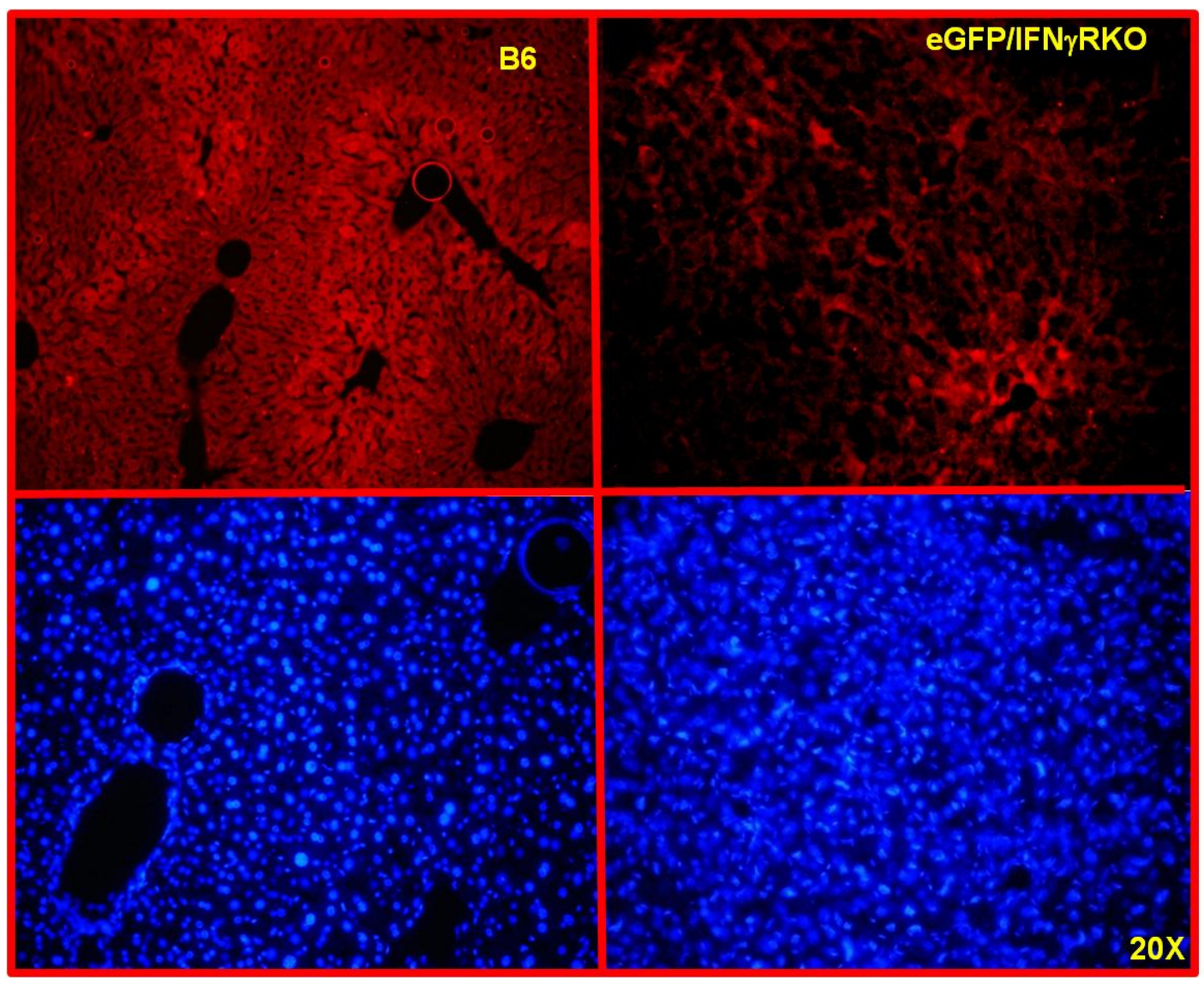

FIGURA 15. Emissão de fluorescência para a marcação do IFN $\gamma R$ (vermelho) e DAPI no tecido hepático de animais B6 e quimera eGFP/IFN $\gamma$ RKO, estimado com o objetivo de 20X. 


\subsection{INFECÇÃO POR TRYPANOSOMA CRUZI DE QUIMERAS B6/IFN $\gamma R$ E}

B6/B6

\subsubsection{ANÁLISE DA RECONSTITUIÇÃO DAS QUIMERAS}

Para a construção dos grupos quiméricos, experimental e controle, camundongos machos IFN $\gamma$ RKO e C57BL/6 (B6) foram irradiados com 1200rads e transferidos, via intraperitoneal, com $20 \times 10^{6}$ células de medula óssea proveniente de camundongos machos B6.

Três meses após a reconstituição, avaliamos se o estado quimérico havia sido atingido analisando por citometria de fluxo os leucócitos de sangue periférico da cauda de cada animal.

$A$ análise da freqüência de células $T\left(\mathrm{CD}^{+}\right)$e $B\left(B 220^{+}\right)$do sangue periférico que expressam IFN $\gamma R$ mostrou que os animais da quimera experimental B6/IFN $\gamma R K O$ foram parcialmente reconstituídos pela medula B6. Na Figura 16 ( $\mathrm{A}$ e B) mostramos a média de reconstituição das quimeras e grupos controle, assim como "dot-blots" de expressão de IFN $\gamma$ R em um animal de cada um dos diversos grupos, incluindo um animal quimérico B6/IFN $\gamma R$ onde a reconstituição foi quase completa. 


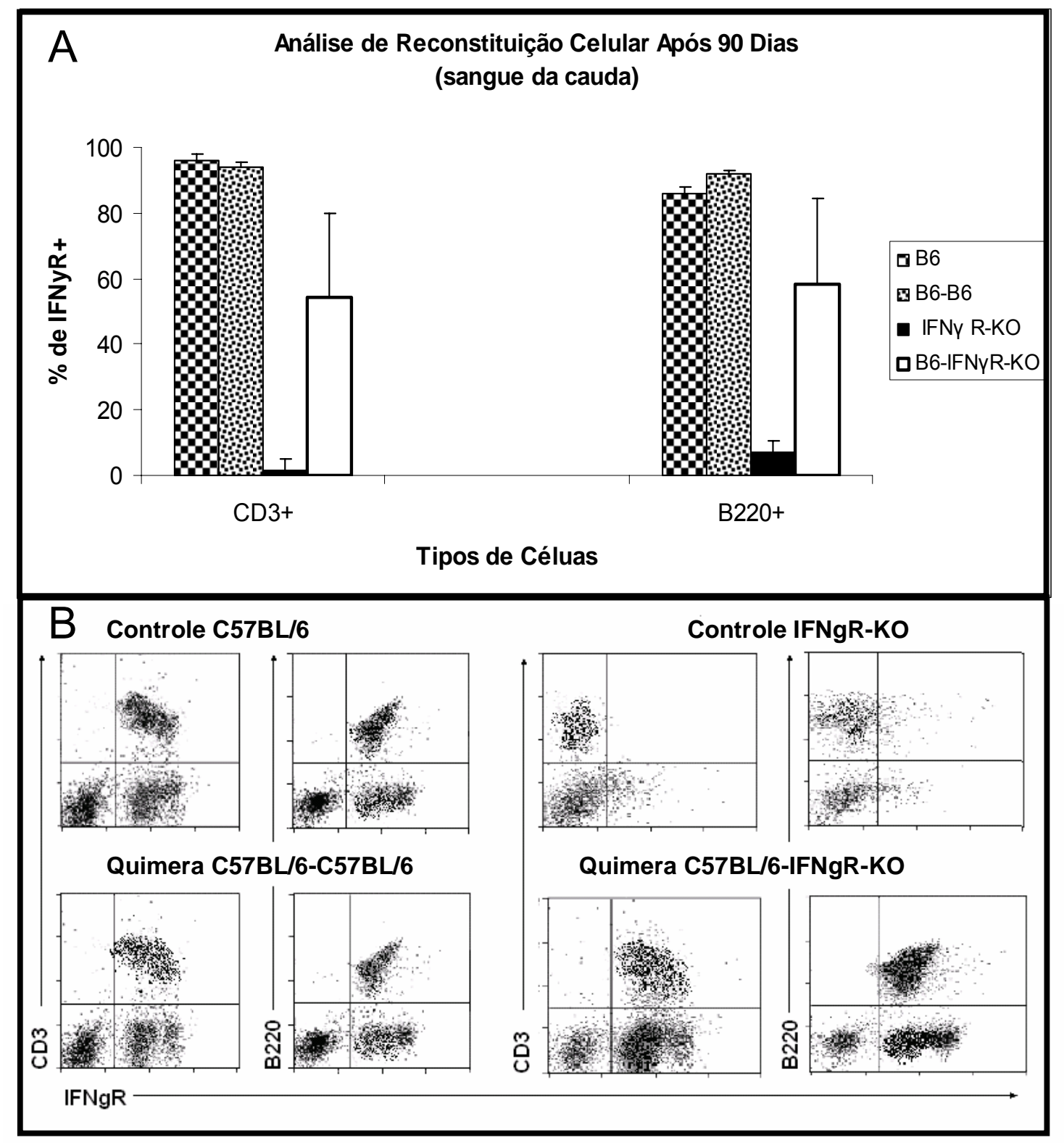

Figura 16. A. Análise por citometria de fluxo da reconstituição de animais quiméricos (B6/IFN $\gamma R-K O$ e B6/B6) por células IFN $\gamma R+$, nas populações CD3+ e B220+ do sangue periférico aos 90 dias da transferência de medula. B. Dot-blots representativos da expressão de IFN $\gamma \mathrm{R}$ versus CD3 ou B220 dos grupos controle e grupos quimera controle B6/B6 e quimera B6/IFN $\gamma$ RKO após 90 dias da transferência da medula. 


\subsubsection{INFECÇÃO PELO TRYPANOSOMA CRUZI DA CEPA SYLVIO X10/4.}

Confirmado o estado quimérico, os camundongos das quimeras experimental e controle, assim como os animais não quiméricos, foram infectados via intraperitoneal com $10^{6}$ parasitas do clone Sylvio X10/4 de $T$. cruzi.

Os animais foram avaliados em relação à parasitemia e sacrificados para exame histopatológico do coração, fígado e músculo estriado esquelético (quadríceps). Nesta experiência, o nosso objetivo era derivarmos uma idéia geral da infecção nos diferentes grupos e, principalmente, no grupo quimera B6/IFN $\gamma$ RKO em relação ao grupo quimera controle B6/B6. Assim, a infecção foi deixada evoluir e os animais foram sacrificados quando alguns dos membros de um determinado grupo começaram a morrer.

\subsubsection{PARASITEMIA}

Em relação à parasitemia nenhum dos animais dos grupos quimera B6/B6 e controle B6 mostrou parasitas no sangue até o dia de sacrifício. Dois dos sete animais quiméricos B6/IFN $\gamma$ RKO mostraram parasitemia muito baixa e os outros cinco animais nunca revelaram parasitemia positiva (média do grupo 0,28 parasitas/50 campos). Por outro lado, todos os animais do grupo controle IFN $\gamma$ R-KO apresentaram um nível elevado de parasitas circulantes no dia 13 de infecção (média do grupo 50 parasitas/50 campos). 


\subsubsection{ANÁLISE HISTOPATOLÓGICA DAS QUIMERAS INFECTADAS PELO T. CRUZI}

As análises histopatológicas foram realizadas nos diferentes órgãos (coração, fígado e músculo esquelético) de forma semi-quantitativa onde o infiltrado inflamatório foi classificado pela sua intensidade em: (0) nenhum, (1) suave, (2) moderado, (3) intenso, (4) severo e (5) muito severo.

\subsubsection{CORAÇÃO}

No dia 19 p.i., o infiltrado inflamatório cardíaco nos animais do grupo controle $\mathrm{B} 6$ e quimérico controle B6/B6 foi intenso, enquanto que no grupo quimérico experimental B6/IFN $\gamma$ RKO foi moderado ou estava ausente (Figura 17). Nos animais do grupo controle IFN $\gamma R K O$, a análise histopatológica mostrou infiltração linfo-monocitária suave, no dia 13-15 de infecção. Neste grupo, tempos posteriores não puderam ser avaliados uma vez que o mal estado geral dos animais tornou obrigatório o sacrifício de todo o grupo. O grupo controle B6 sofreu uma intensa patologia num período já mais avançado de infecção (Figura 18).

Em todos os grupos encontramos infiltrados inflamatórios focais e difusos evidenciando uma patologia intensa, formados predominantemente por células mononucleadas (Figuras 18 e 19).

Foram encontrados ninhos de parasitas no tecido cardíaco em todos os grupos em diferentes dias de infecção (Figuras 18, 19 e 20). No grupo de camundongos controle B6 o nível de parasitismo cardíaco foi baixo no dia 19 de infecção, evoluindo para um grau intenso nos dias 45 e 46 . No entanto, dois animais desse grupo não apresentaram parasitismo tissular. No grupo controle IFNyRKO os 2 animais sacrificados no dia 15 de infecção mostraram ninhos no coração (Figura 18). Já os animais do grupo quimérico experimental B6/IFN $\gamma$ RKO apresentaram um nível de parasitismo elevado no dia 19 de infecção, enquanto que nesta data o grupo quimérico controle B6/B6 
apresentou um nível de parasitismo tissular baixo. Nos grupos quiméricos a maior parte dos animais foi sacrificada no dia 19, não existindo animais B6/IFNyRKO avaliados em dias posteriores (Figura 18). 


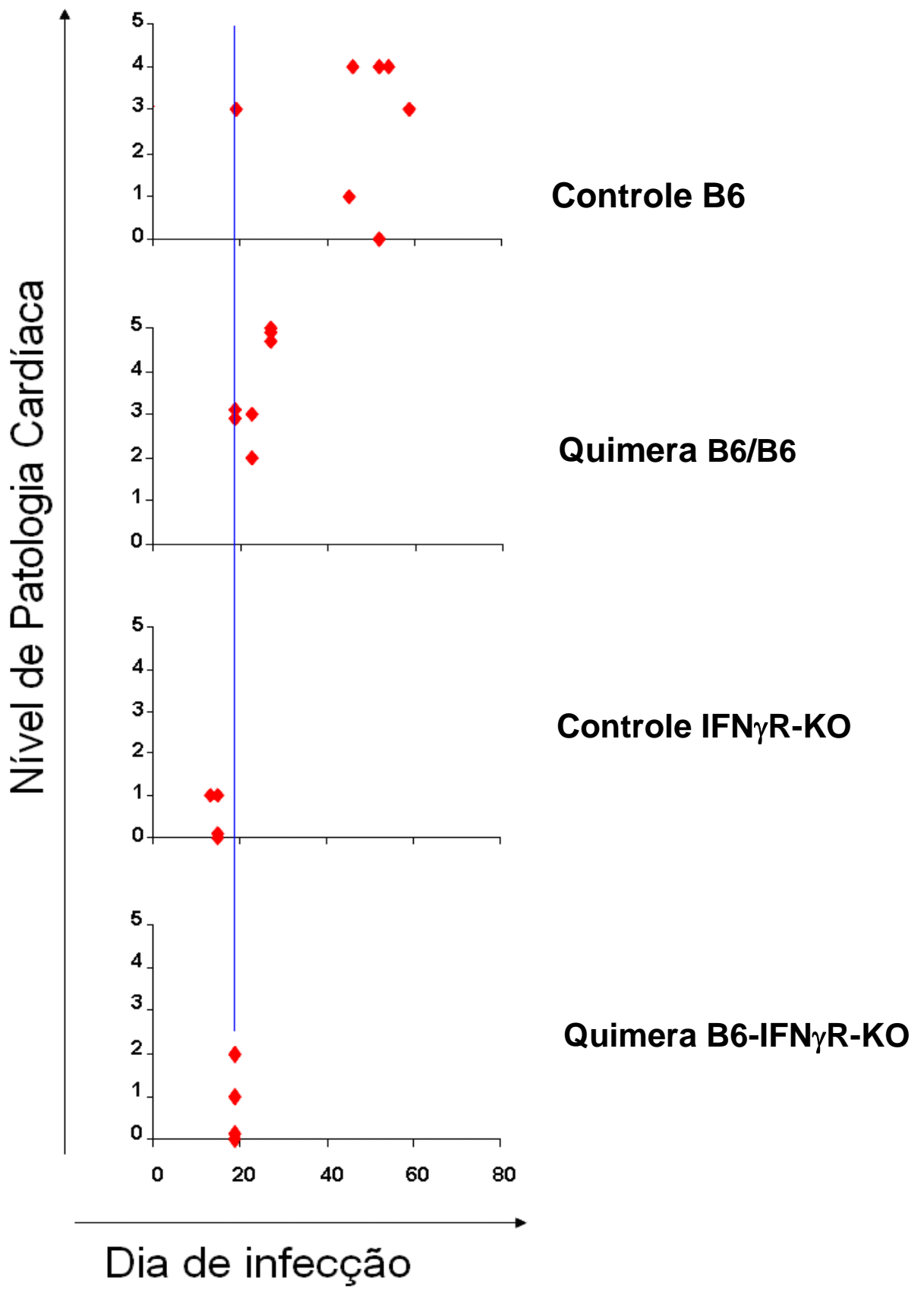

Figura 17. Análise comparativa da intensidade do infiltrado cardíaco em camundongos Controle B6, Quimera B6/B6, Controle IFN $\gamma$ RKO e Quimera B6/IFN $\gamma$ RKO. Os animais foram infectados via intraperitoneal com $10^{6}$ tripomastigotas da cepa Sylvio X10/4 de $T$. cruzi e sacrificados em diferentes dias de infecção para análise histopatológica. Intensidade do infiltrado: (0) nenhum, (1) suave, (2) moderado, (3) intenso, (4) severo e (5) muito severo. Uma atenção especial deve dar-se aos níveis observados no dia 19 p.i. 


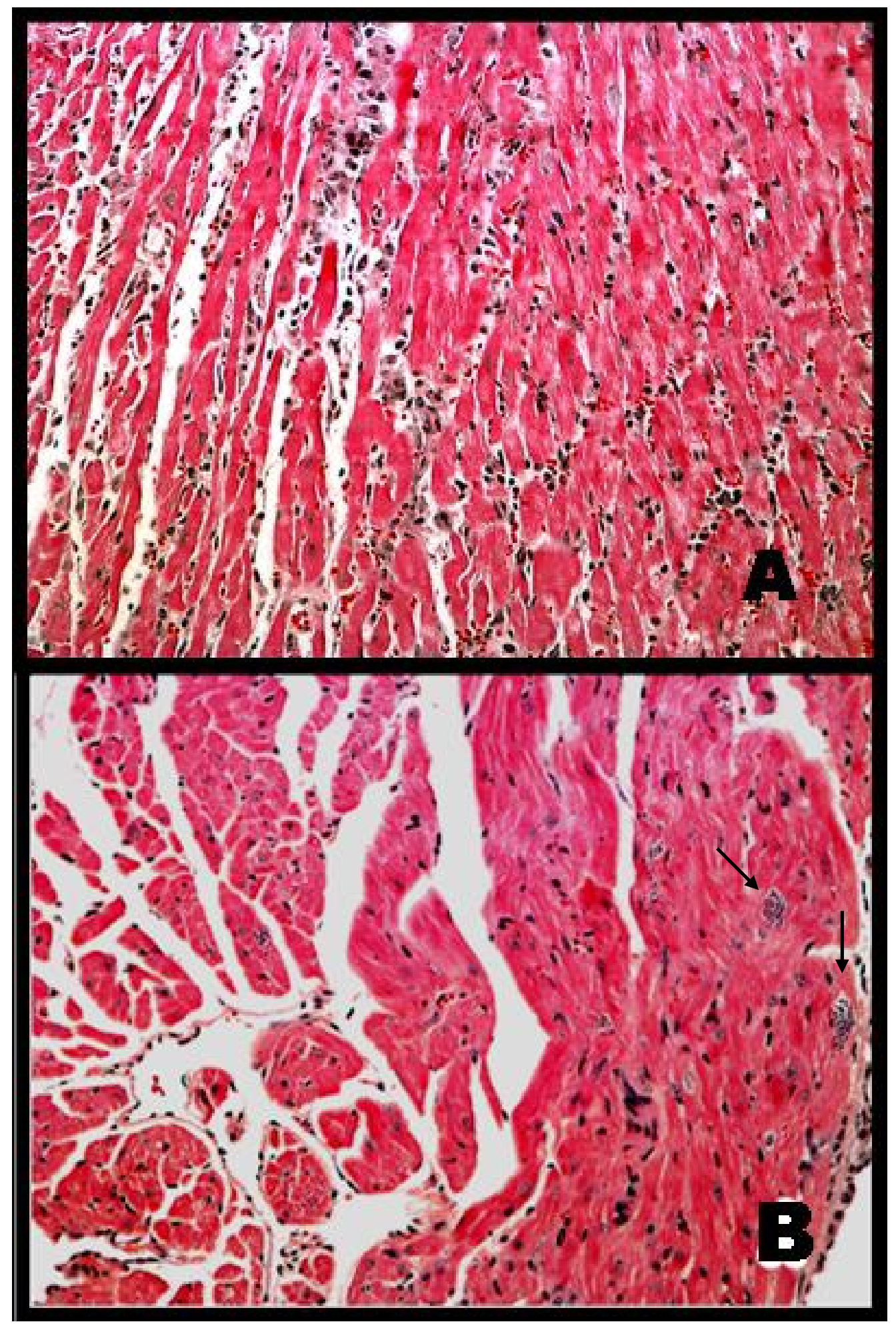

Figura 18. Tecido cardíaco dos animais controle B6 e IFN $\gamma$ RKO infectados por parasitas Sylvio X10/4 evidenciando a presença de infiltrados inflamatórios focais e difusos e presença de ninhos do parasita (setas) onde: A) B6 no dia 19 p.i; B)IFN $\gamma$ KO no dia 13 p.i. 


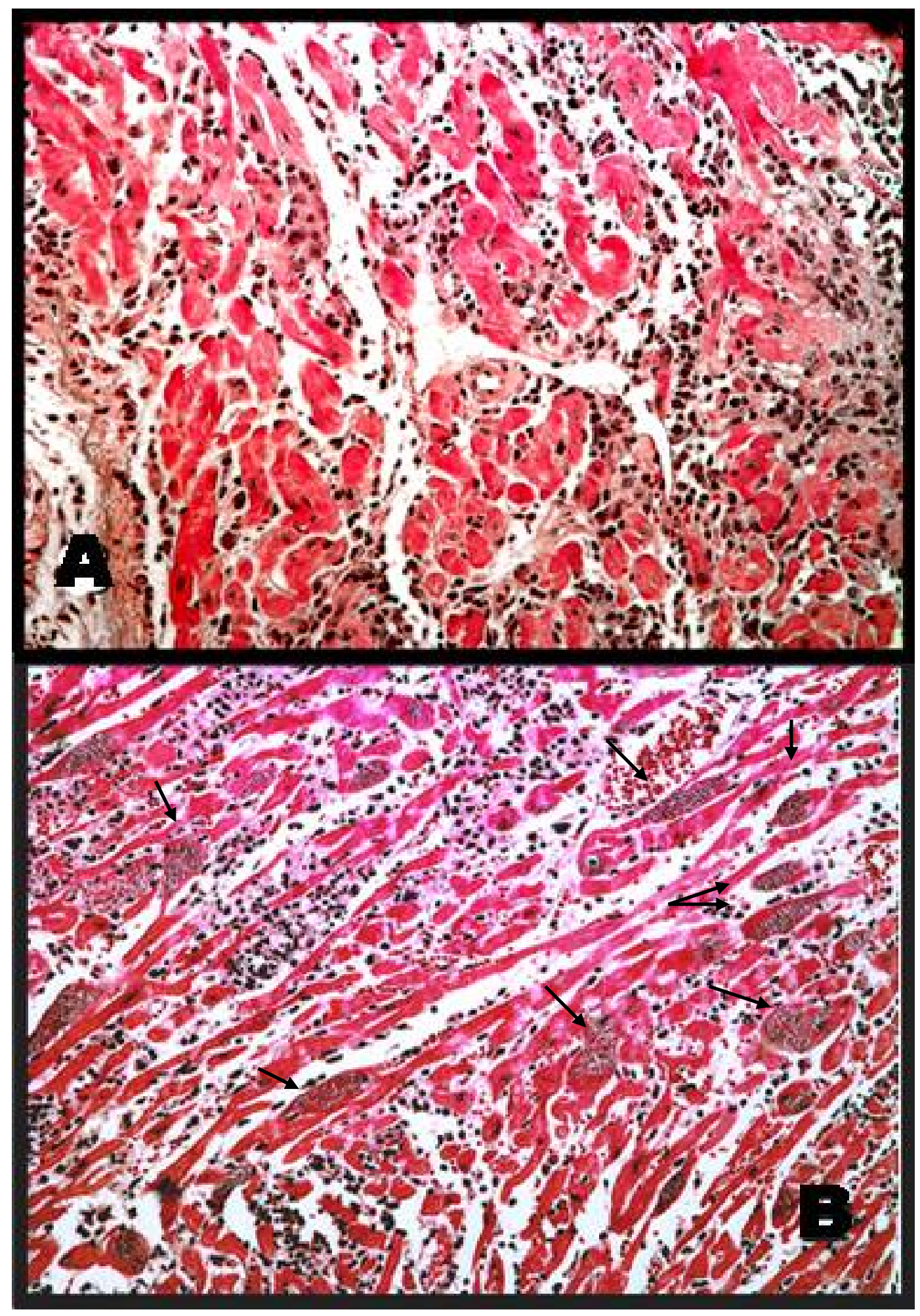

Figura 19. Tecido cardíaco dos animais das quimeras B6/B6 e quimeras B6/IFN $\gamma$ RKO infectados por parasitas Sylvio X10/4 evidenciando a presença de infiltrados inflamatórios focais e difusos e presença de ninhos do parasita (setas) no dia 19 p.i, onde A) quimera B6/B6, B) quimera B6/IFN $\gamma$ RKO. 


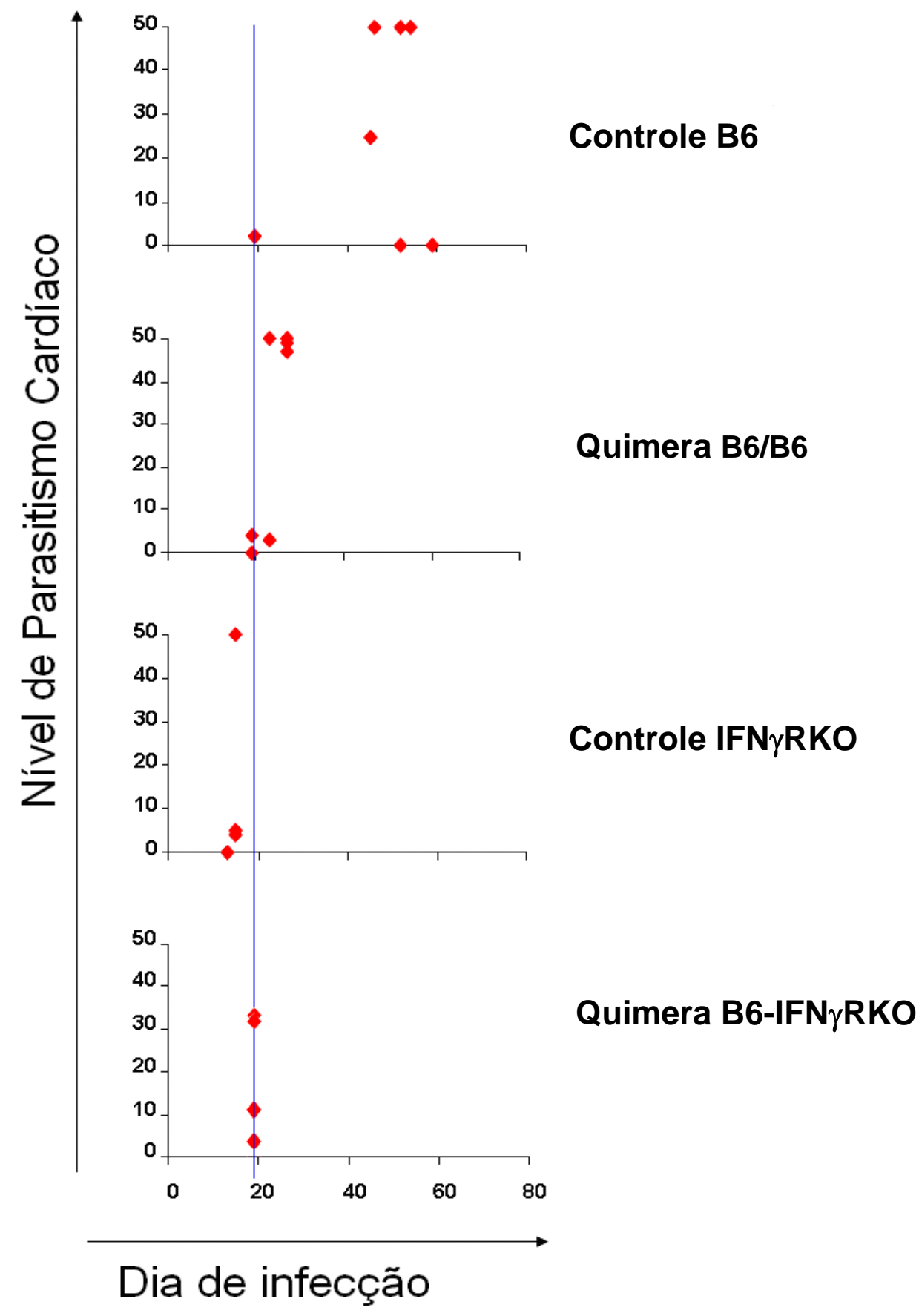

Figura 20. Análise comparativa do nível de parasitismo cardíaco em camundongos dos grupos B6, B6/B6, IFN $\gamma$ RKO e B6/IFN $\gamma$ RKO. Os animais foram infectados com $10^{6}$ tripomastigotas do clone Sylvio X10/4 de $T$. cruzi e analisados em diferentes dias de infecção. Foram analisados e quantificados números de ninhos de parasitas por microscopia óptica por corte de tecido. Uma atenção especial deve dar-se aos níveis observados no dia 19 p.i. 


\subsubsection{FÍGADO}

Com relação ao fígado, o grupo controle IFN $\gamma$ RKO desenvolveu uma hepatite muito severa no dia 15 p.i.. No dia 19 p.i., o infiltrado inflamatório dos animais do grupo quimera experimental B6/IFN $\gamma$ RKO foi intenso/severo, em níveis semelhantes ou até discretamente superiores aos dos animais dos grupos controle B6 e quimera B6/B6 (Figura 21). Em todos os grupos encontramos infiltrados inflamatórios focais, formados predominantemente por células mononucleadas (Figuras 22 e 23).

Com relação ao parasitismo tissular nenhum grupo apresentou índice considerável de parasitismo tissular com exceção de 1 animal do grupo controle IFN $\gamma$ RKO que apresentou um alto nível de parasitismo hepático no dia 13 p. i. (Figura 24). 


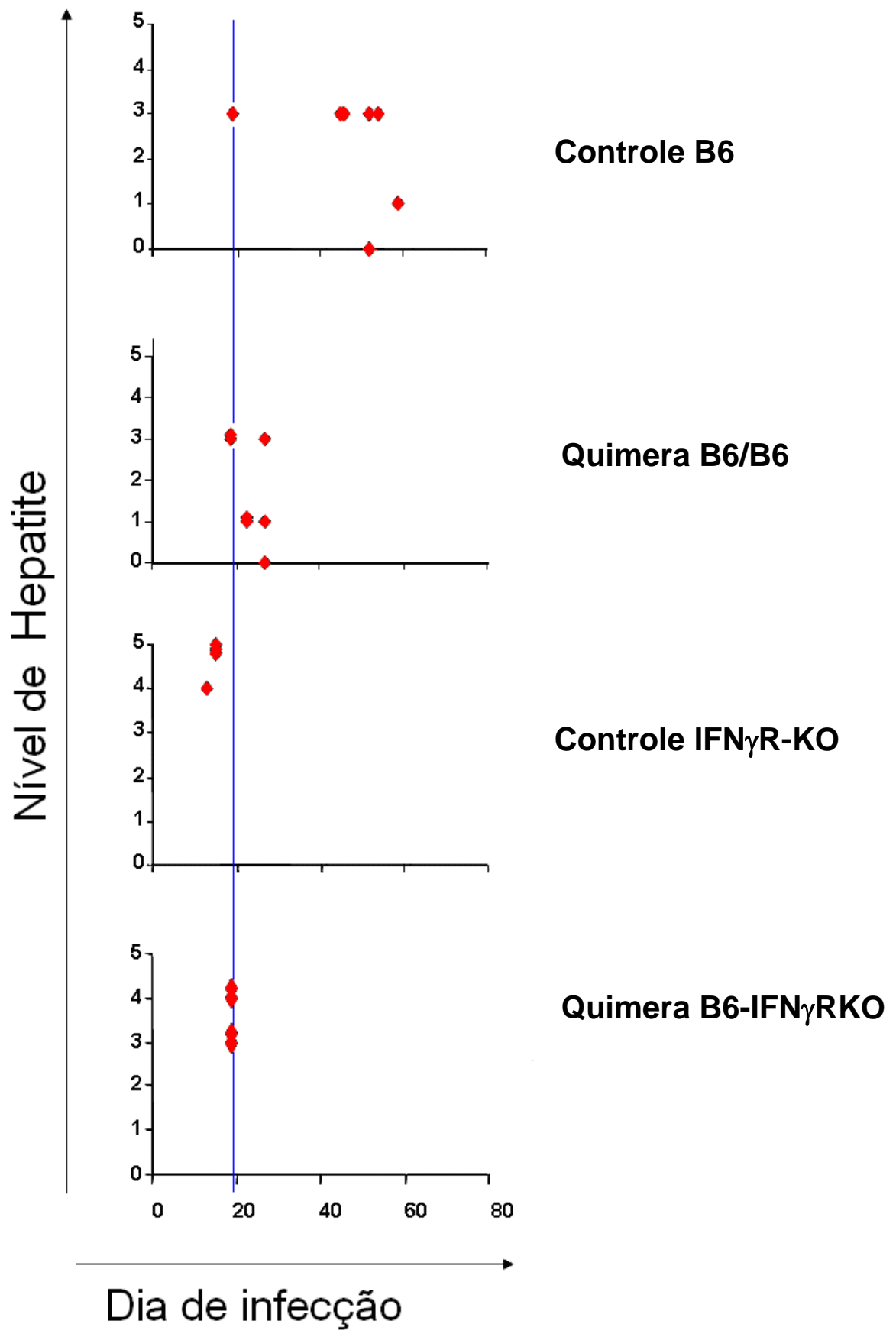

Figura 21. Análise comparativa da intensidade da hepatite em camundongos Controle B6, Quimera B6/B6, Controle IFN $\gamma$ RKO e Quimera B6/IFN $\gamma R K O$. Os animais foram infectados via intraperitoneal com $10^{6}$ tripomastigotas do clone Sylvio X10/4 de $T$. cruzi e sacrificados em diferentes dias de infecção para análise histopatológica. Intensidade do infiltrado: (0) nenhum, (1) suave, (2) moderado, (3) intenso, (4) severo e (5) muito severo. Uma atenção especial deve dar-se aos níveis observados no dia 19 p.i. 


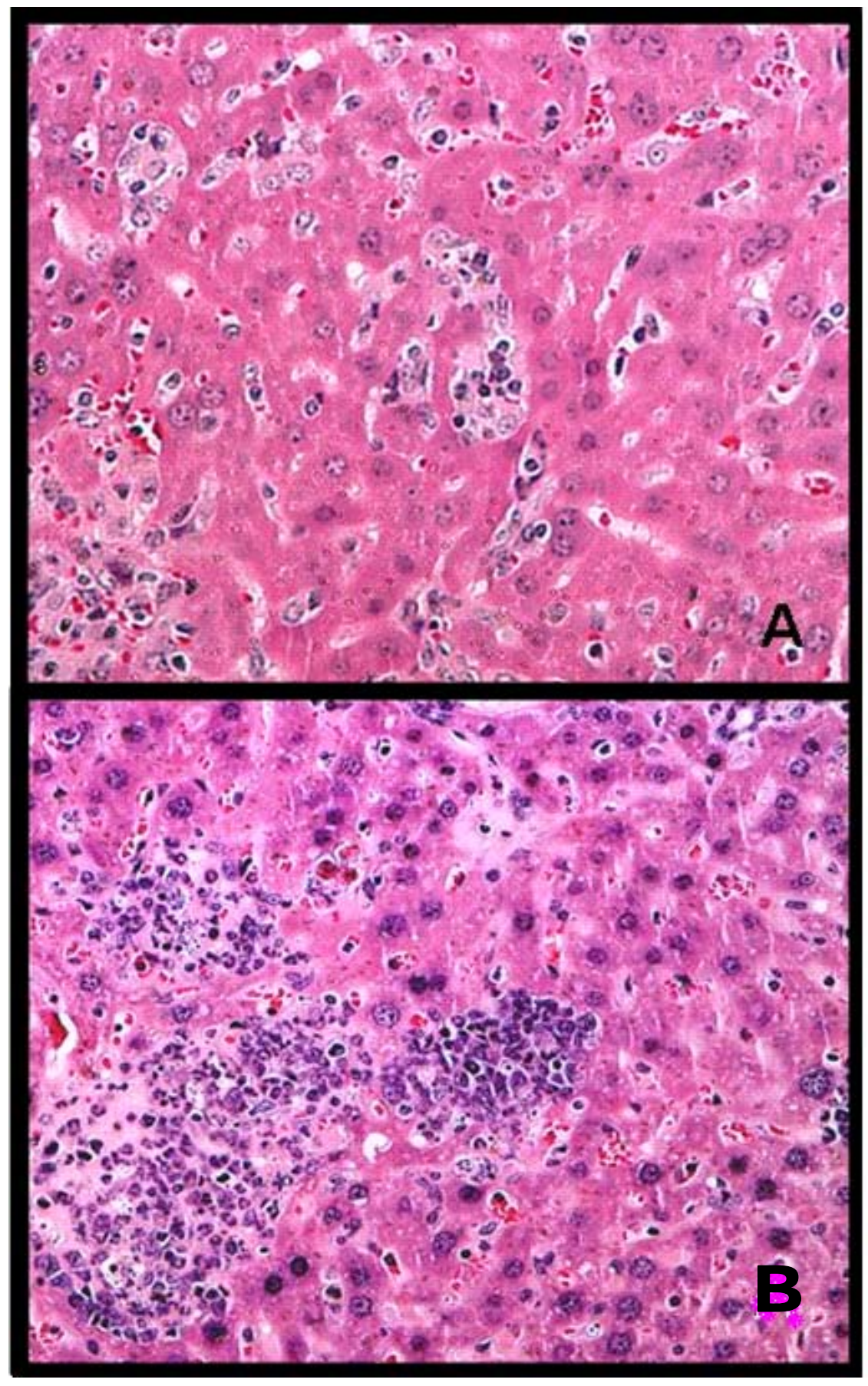

Figura 22. Tecido hepático dos animais dos grupos controle B6 e IFN $\gamma$ RKO infectados por $T$. cruzi Sylvio X10/4, evidenciando a presença de infiltrados inflamatórios focais, onde A) animal B6, no dia 19 p.i; B) animal IFN $\gamma$ RKO, no dia 13 p.i.. 


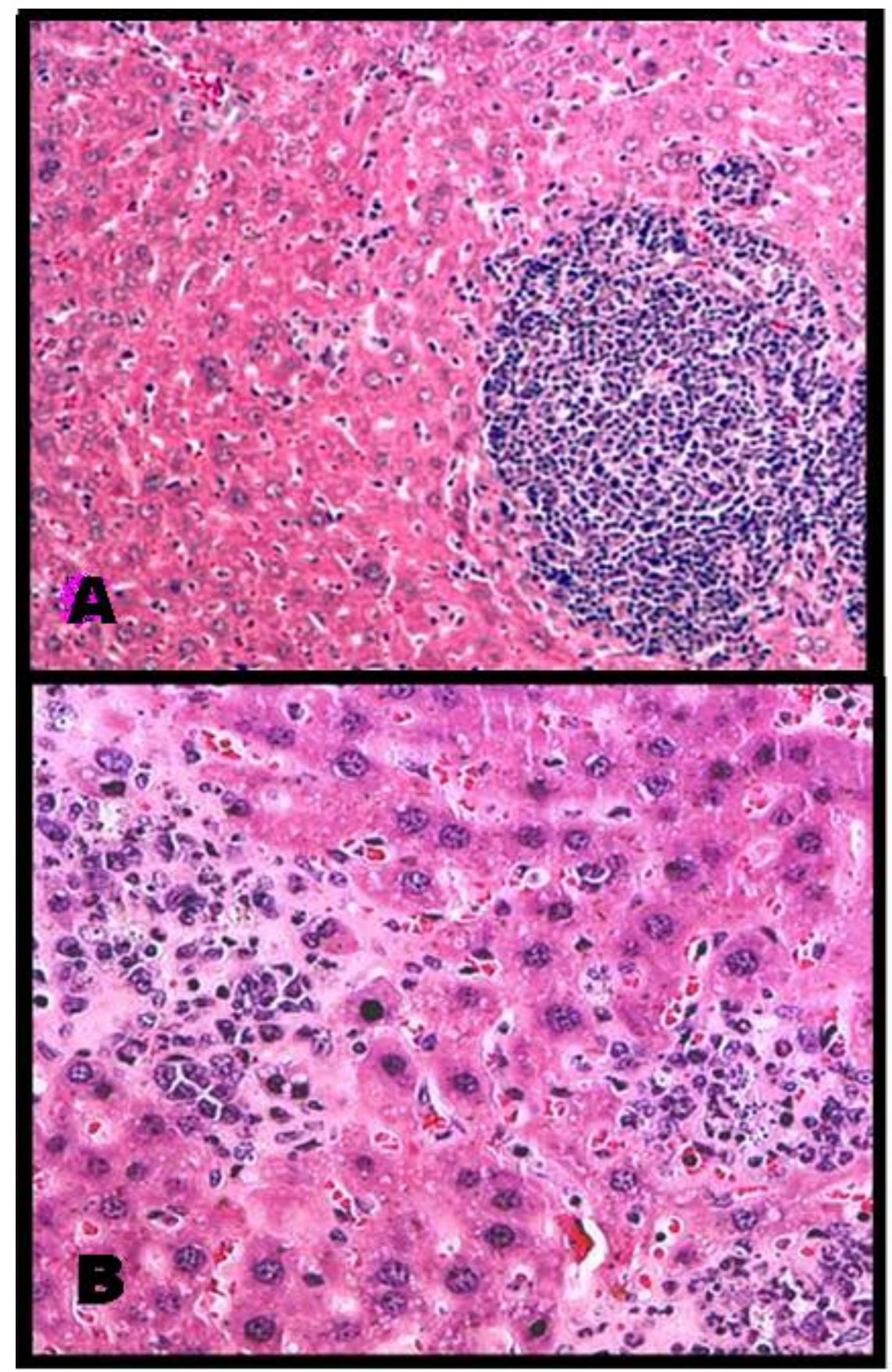

Figura 23. Tecido hepático dos animais dos grupos quimera B6/B6 e B6/IFN $\gamma$ RKO infectados por $T$. cruzi Sylvio X10/4, evidenciando a presença de infiltrados inflamatórios focais no dia 19 p.i, onde A) animal B6/B6 (aumento de $100 \mathrm{X}$ ), B) animal B6/IFN $\gamma$ RKO (aumento de $200 \mathrm{X}$ ) (o aumento é diferente em A e B). 


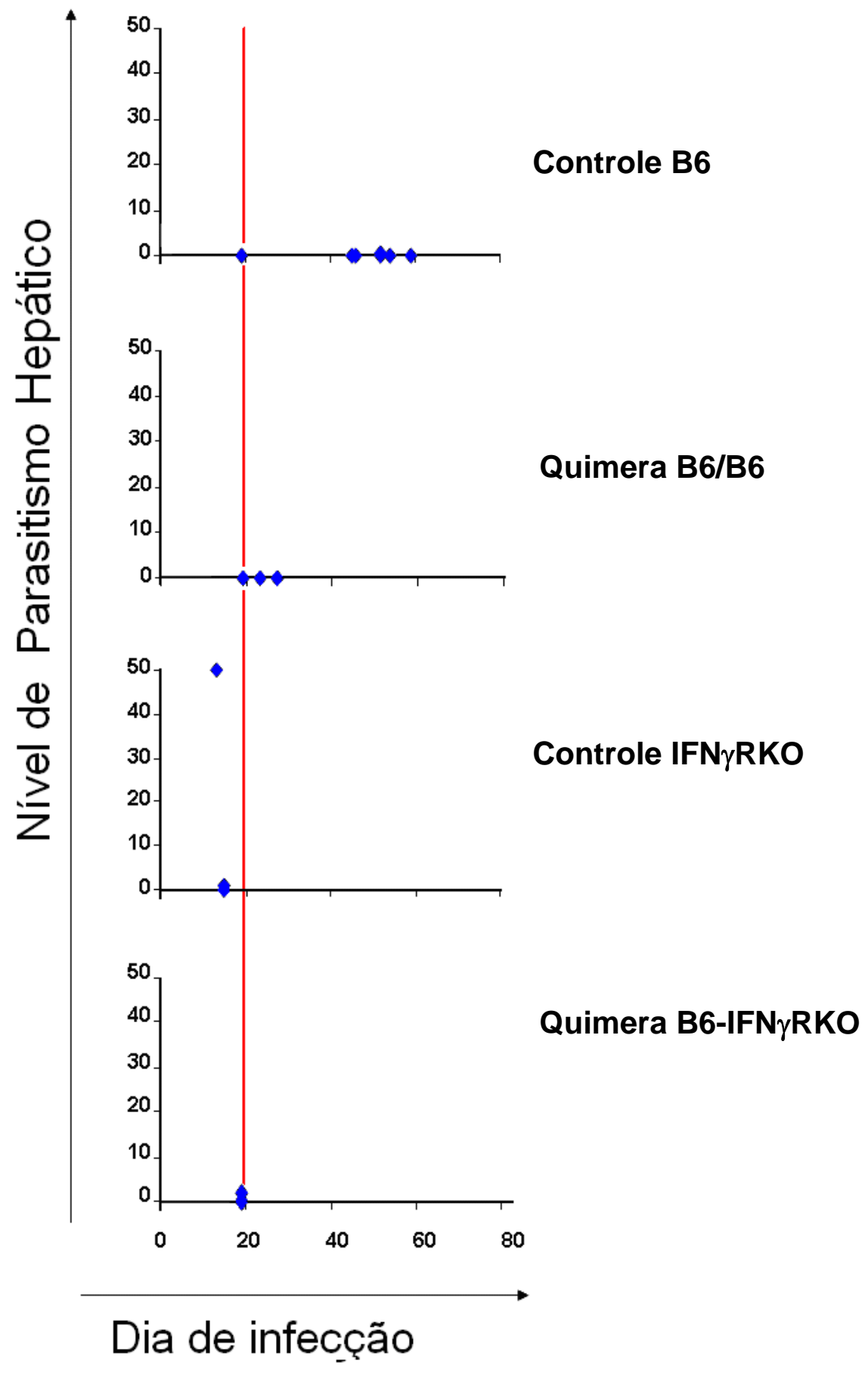

Figura 24. Análise comparativa do nível de parasitismo hepático em camundongos dos grupos B6, B6/B6, IFN $\gamma$ RKO e B6/IFN $\gamma$ RKO. Os animais foram infectados com $10^{6}$ tripomastigotas do clone Sylvio $\times 10 / 4$ de $T$. cruzi e analisados em diferentes dias de infecção. Foram analisados e quantificados números de ninhos de parasitas por microscopia óptica por corte de tecido. Uma atenção especial deve dar-se aos níveis observados no dia 19 p.i. 


\subsubsection{MÚSCULO ESQUELÉTICO}

No músculo estriado esquelético (quadríceps) dos animais do grupo controle B6 encontramos uma miosite intensa no dia 19 p.i., e dias subseqüentes, sendo que apenas um animal não apresentou patologia. $O$ mesmo quadro foi observado nos animais quiméricos B6/B6. (Figura 25).

No grupo controle IFN $\gamma$ RKO a miosite se desenvolveu de forma suave a moderada até o dia 15 de infecção. Já no grupo quimérico de B6/IFN $\gamma$ RKO observou-se ausência ou níveis muito discretos de patologia muscular no dia 19 p.i., em relação aos animais quiméricos B6/B6.

Em todos os grupos encontramos infiltrados inflamatórios focais, evidenciando uma miosite formada predominantemente por células mononucleadas (Figuras 26 e 27).

Com relação ao nível de parasitismo tissular no músculo estriado esquelético, os animais dos grupos controle B6 e quimera B6/B6 não mostraram ninhos no dia 19 p.i., enquanto que ninhos puderam ser observados em 2 dos 4 animais do grupo quimera B6/IFN $\gamma$ RKO (Figura 28). 


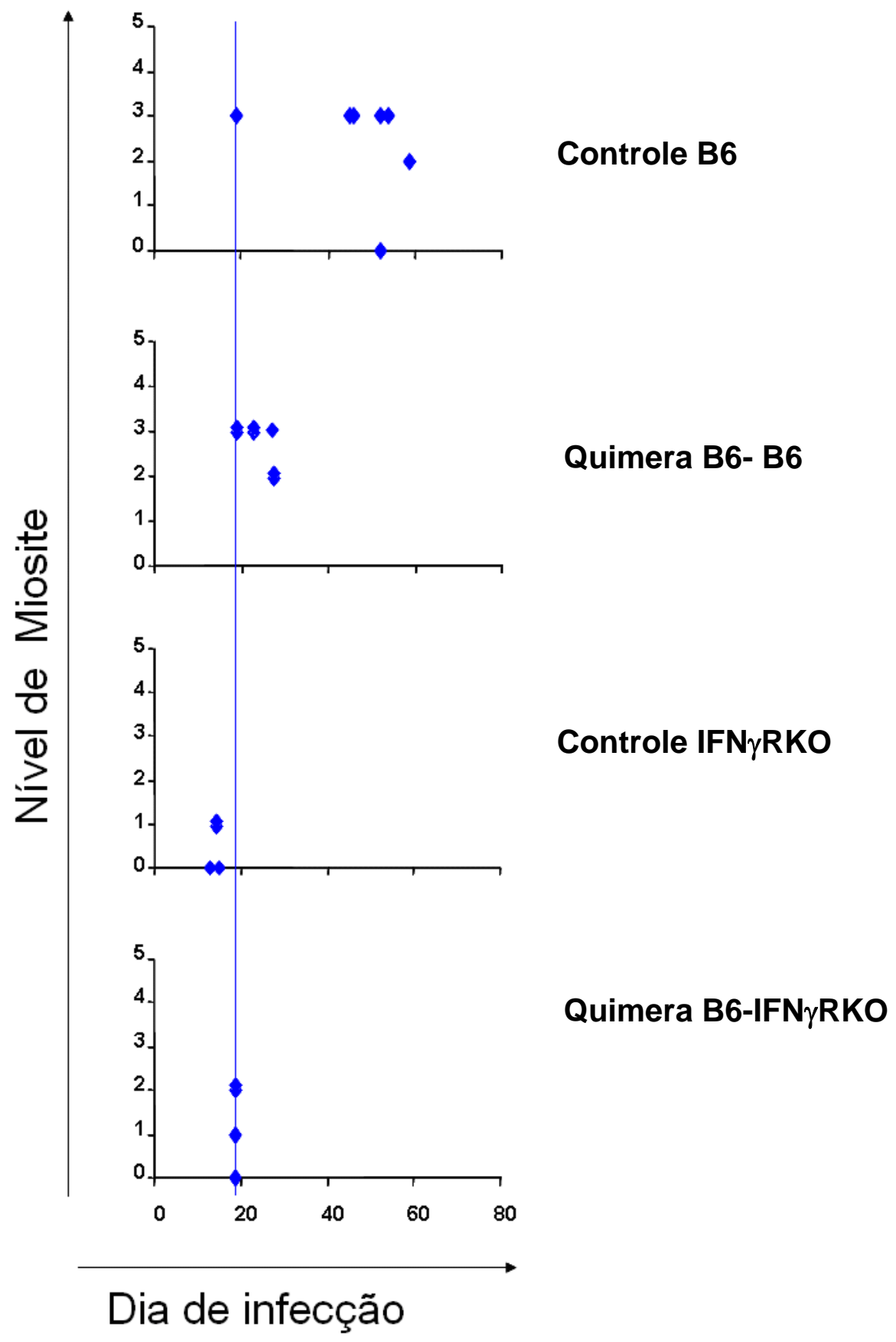

Figura 25: Análise comparativa do infiltrado inflamatório no quadríceps de camundongos dos grupos B6, B6/B6, IFN $\gamma$ RKO e B6/IFN $\gamma R K O$. Os animais foram infectados via intraperitonial com $10^{6}$ tripomastigotas da cepa Sylvio de $T$. cruzi e sacrificados em diferentes dias de infecção para exame histopatológico. Intensidade do infiltrado: (0) nenhum, (1) suave, (2) moderado, (3) intenso, (4) severo e (5) muito severo. Uma atenção especial deve dar-se aos níveis observados no dia 19 p.i. 


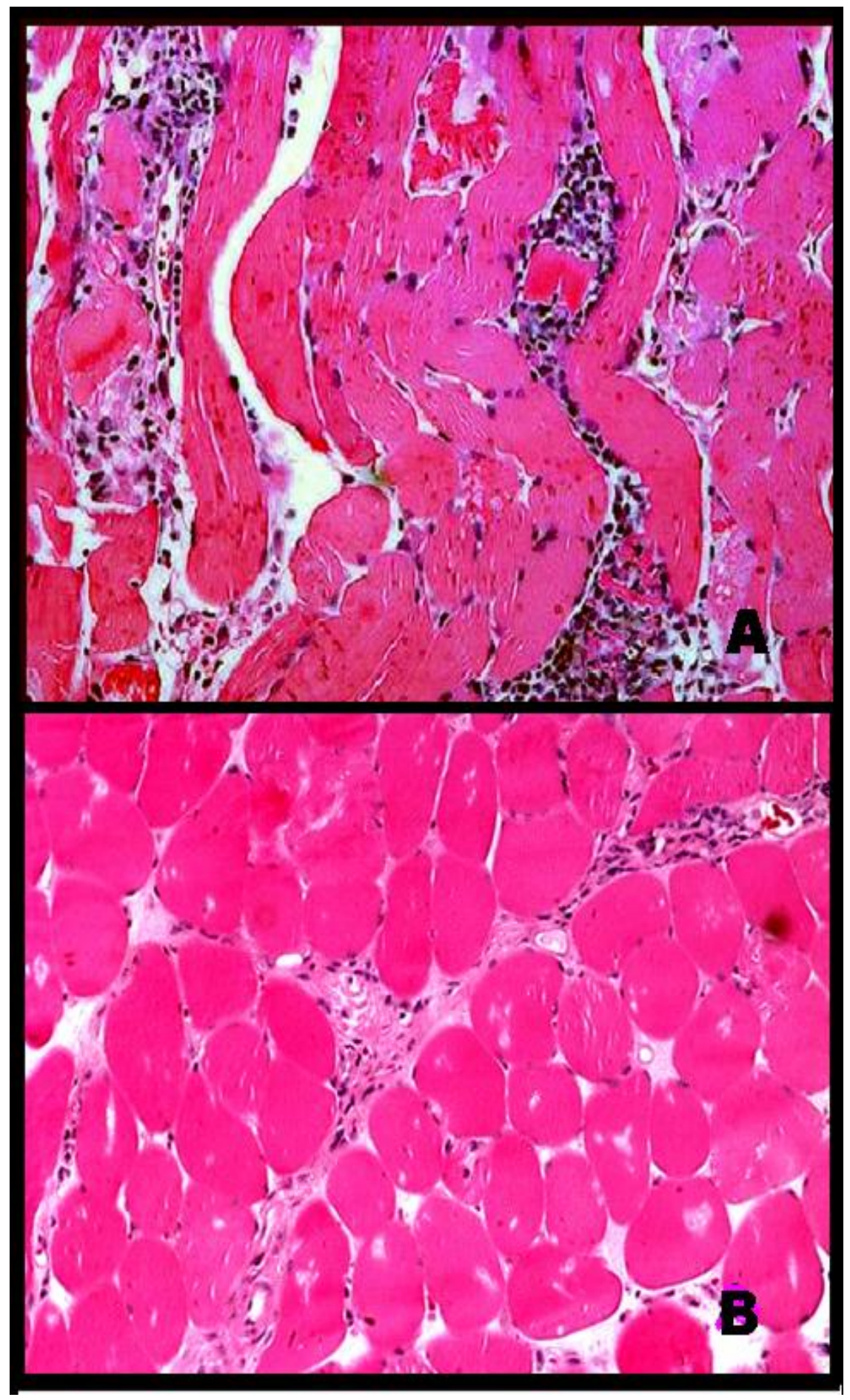

Figura 26: Tecido muscular esquelético (quadríceps) dos grupos controle B6 e IFN $\gamma$ RKO infectados por $T$. cruzi Sylvio X10/4, evidenciando a presença de infiltrados inflamatórios focais, onde A) animal B6, no dia 19 p.i.; B) animal IFN $\gamma$ RKO, no dia 13 p.i.. 


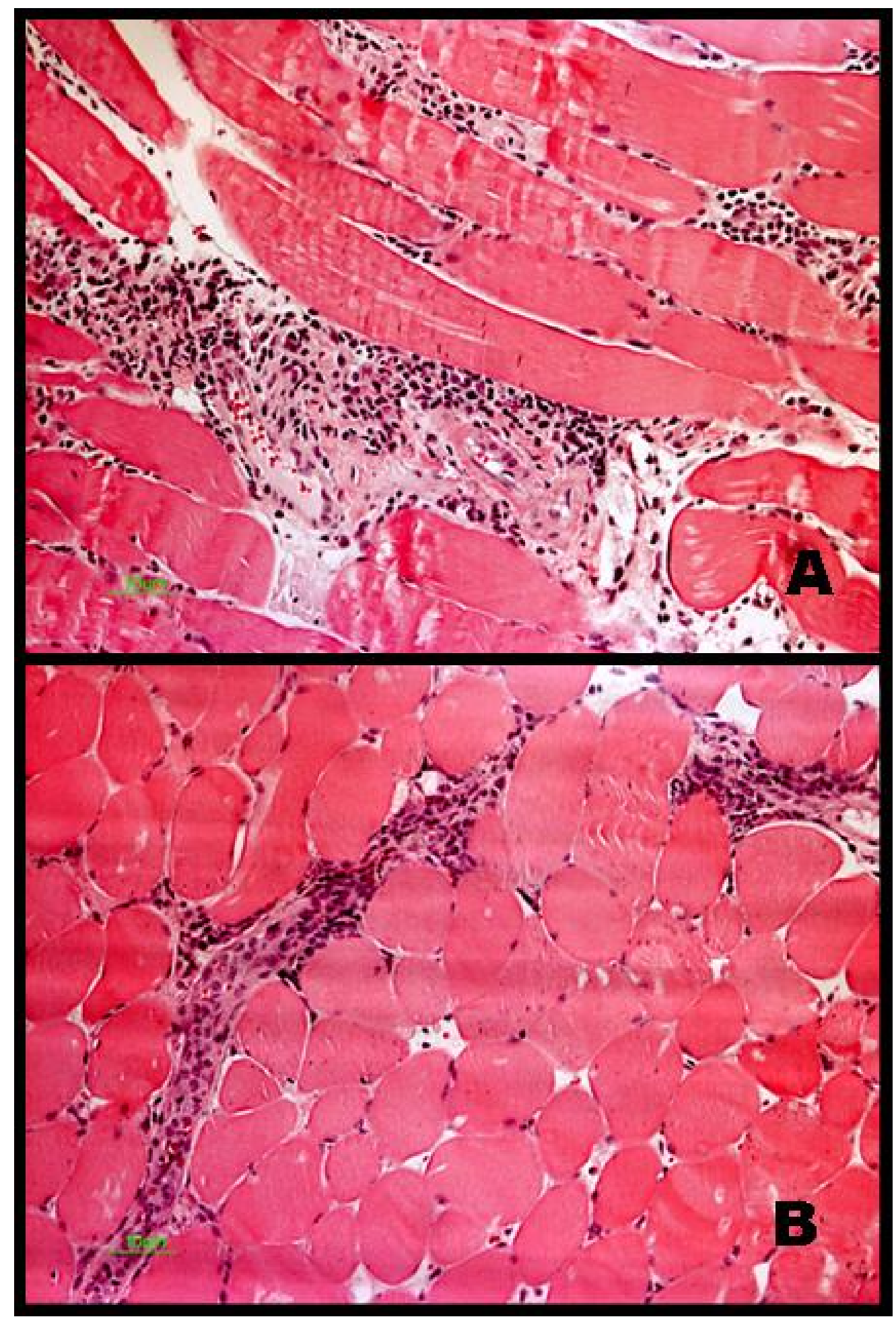

Figura 27: Tecido muscular esquelético (quadríceps) dos grupos B6/B6 e quimera experimental B6/IFN $\gamma$ RKO infectados por $T$. cruzi Sylvio X10/4, evidenciando a presença de infiltrados inflamatórios focais no dia 19 p.i, onde A) animal B6/B6, B) animal B6/IFN $\gamma$ RKO. 


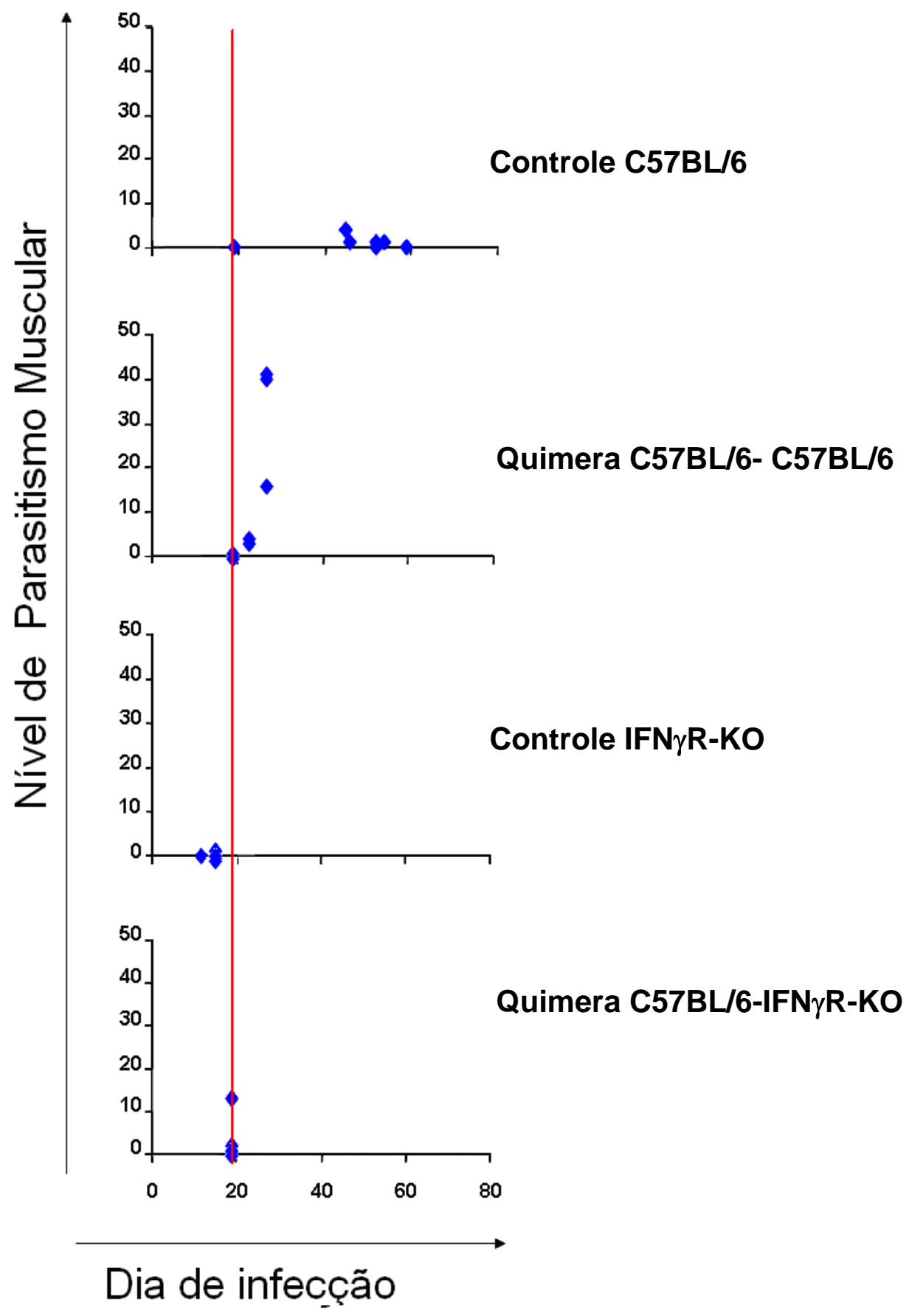

Figura 28. Análise comparativa do nível de parasitismo muscular (quadríceps) em camundongos dos grupos B6, B6/B6, IFN $\gamma$ RKO e B6/IFN $\gamma$ RKO. Os animais foram infectados com $10^{6}$ tripomastigotas do clone Sylvio X10/4 de T. cruzi e analisados em diferentes dias de infecção. Foram analisados e quantificados números de ninhos de parasitas por microscopia óptica por corte de tecido. Uma atenção especial deve dar-se aos níveis observados no dia 19 p.i. 


\subsection{INFECÇÃO PELO Plasmodium berghei ANKA GFP}

\subsubsection{AVALIAÇÃO DO ESTADO QUIMÉRICO: ANÁLISE POR CITOMETRIA DE FLUXO DA EXPRESSÃO DE IFN $\gamma R$ NOS LEUCÓCITOS DO SANGUE}

Antes de procedermos à infecção pelo $P$. berghei avaliamos o nível de reconstituição por células IFN $\gamma \mathrm{R}^{+}$nos animais quiméricos $\mathrm{B} 6 / \mathrm{IFN} \gamma \mathrm{RKO}$ e B6/B6, utilizando como controles negativo e positivo camundongos IFN $\gamma$ RKO e B6. Na figura 29 podemos observar que tanto no compartimento das células $B\left(B 220^{+}\right)$como das células $T\left(\mathrm{CD}^{+}\right)$, a totalidade dos animais $\mathrm{B} 6 / \mathrm{IFN} \gamma \mathrm{RKO}$ tiveram boa reconstituição por células $\operatorname{IFN} \gamma \mathrm{R}^{+}$. Isto é claramente observado pelas freqüências de células $B 220^{+}$e $\mathrm{CD}^{+}$que expressam IFN $\gamma$ R que atingem valores de $95 \%$ e $75 \%$ nos animais B6/IFN $\gamma$ RKO, muito superiores aos observados nos animais IFN $\gamma$ RKO $(3,0 \%$ e $2,8 \%)$ e próximos aos valores nas quimeras B6/B6 e controles B6. 


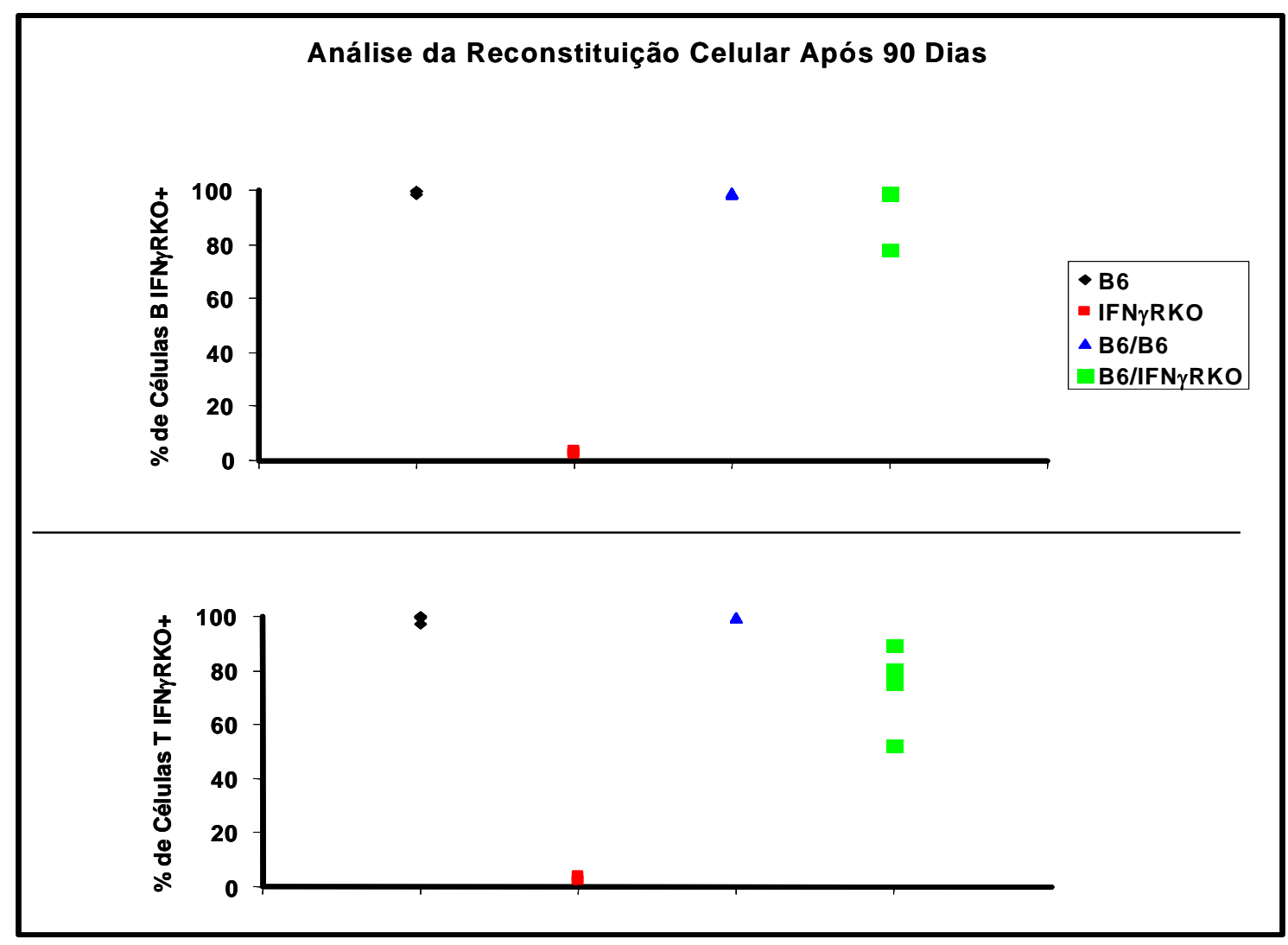

Figura 29. Reconstituição por células IFN $\gamma \mathrm{R}^{+}$no compartimento dos linfócitos $B\left(\mathrm{~B}^{2} 20^{+}\right)$, $T\left(\mathrm{CD}^{+}\right)$nos leucócitos do sangue de animais quiméricos B6/IFN $\gamma \mathrm{RKO}$. Animais IFN $\gamma$ RKO (controle negativo), assim como B6 e quimera B6/B6 (controles positivos) foram incluídos.

\subsubsection{MORTALIDADE APÓS INFECÇÃO PELO PLASMODIUM berghei} ANKA-GFP: DESENVOLVIMENTO DE MALÁRIA CEREBRAL

A infecção de camundongos com background C57BL/6 determina a morte precoce da totalidade dos animais que resulta do desenvolvimento de um quadro de malária cerebral. Experiências realizadas por outros pesquisadores mostraram que esta evolução desfavorável depende da produção de IFN $\gamma$.

Em consonância com os resultados da literatura, a totalidade dos camundongos do grupo controle B6 sucumbiu no dia 9 p.i. Analogamente, parte dos animais quimera controle B6/B6 faleceram no dia 9 p.i. e o 
restante do grupo veio a sucumbir até o dia 12 p.i... Já em relação ao grupo quimérico B6/IFN $\gamma$ RKO, 4 dos 5 animais faleceram até o dia 12 e um único animal sobreviveu até o dia 27 p.i. Em contraste com estes resultados, a totalidade dos animais do grupo controle IFN $\gamma$ RKO sobreviveu até os dias 27-28 p.i. (Figura 30). Os nossos dados confirmam a importante contribuição da resposta leucocitária ao IFN $\gamma$ no desenvolvimento da malária cerebral. Entretanto, os resultados sugerem que a resposta das células não leucocitárias a esta citocina em pouco contribui ao desenvolvimento deste quadro patológico.

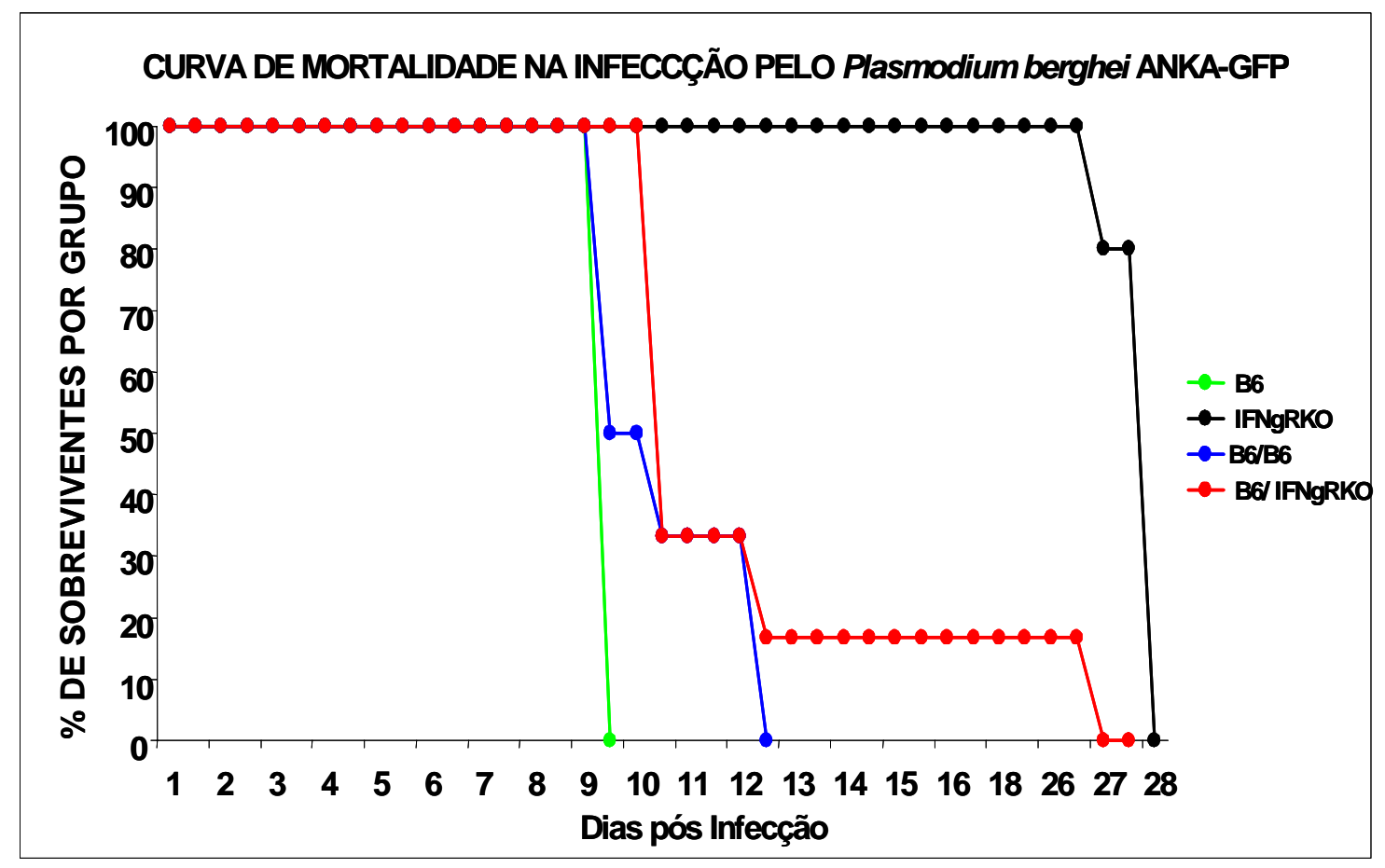

Figura 29 Curva de mortalidade na infecção pelo Plasmodium berghei ANKA-GFP em camundongos quiméricos B6/IFN $\gamma$ RKO e B6/B6, assim como em camundongos IFN $\gamma$ RKO e B6. Os animais foram inoculados com $10^{5}$ hemácias parasitadas pelo plasmódio e acompanhados até sua morte. 


\subsubsection{EVOLUÇÃO DAS PARASITEMIAS APÓS INFECÇÃO PELO $P$. berghei ANKA-GFP}

$\mathrm{Na}$ figura 30 podemos observar uma comparação bis-a-bis das médias de parasitemia dos diferentes grupos.

A análise comparativa das curvas de parasitemia dos grupos IFN $\gamma$ RKO e B6 não revelou diferenças no primeiro pico de parasitemia.

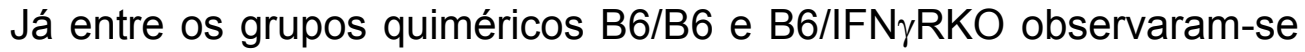
algumas diferenças, mas estas são de difícil interpretação. Assim, nos animais $\mathrm{B} 6 / \mathrm{IFN} \gamma \mathrm{RKO}$, o primeiro pico de parasitemia foi discretamente superior, mas a queda que segue após o primeiro pico foi mais intensa. Assim, acreditamos que a presença do IFN $\gamma \mathrm{R}$ nas células estruturais (presente nos animais B6/B6 e ausente nos animais B6/IFN $\gamma$ RKO) parece afetar de alguma forma a curva de parasitemia. Os resultados do primeiro pico na inf pelo $p$. berghei foram similares aos obtidos nos animais B6/B6 e B6/IFN $\gamma R K O$ após infecção pelo $P$. chabaudi, porém menos intensas. No momento é difícil considerarmos qual poderia ser a contribuição das células não leucocitárias ao controle do $P$. berghei. 

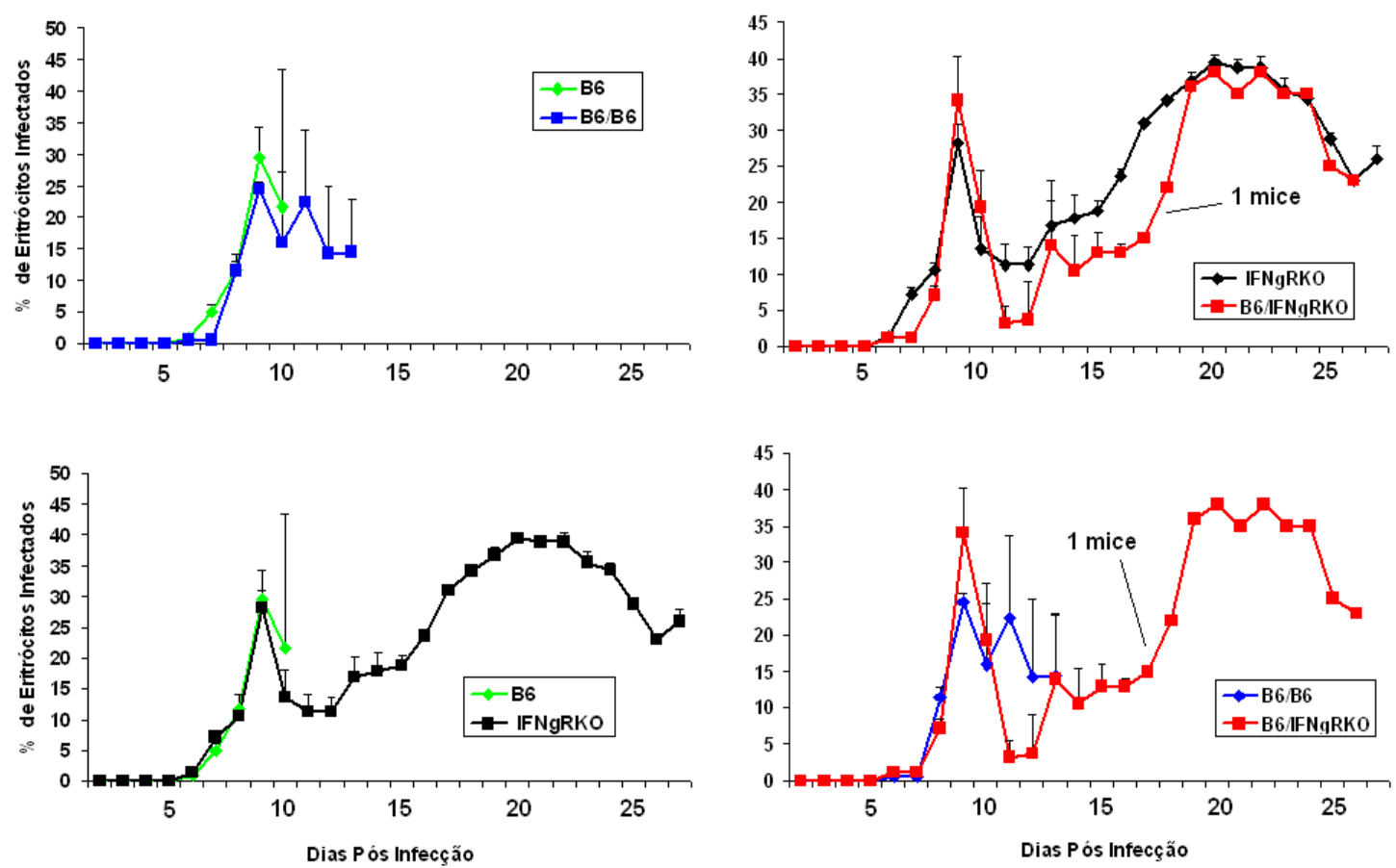

Figura 30. Comparação bis-a-bis da evolução das médias de parasitemia na infecção pelo Plasmodium berghei ANKA-GFP em camundongos quiméricos B6/IFN $\gamma R K O$ e B6/B6, assim como em camundongos IFN $\gamma$ RKO e B6. Os animais foram inoculados com $10^{5}$ hemácias parasitadas de plasmódio e a freqüência de hemácias infectadas avaliada dia a dia no sangue da cauda. 


\subsection{CONSTRUÇÃO DO GRUPO QUIMÉRICO E INFECÇÃO PELO Plasmodium chabaudi AS}

\subsubsection{ANÁLISE DA QUIMERA}

Duas experiências de quimeras foram realizadas com o objetivo de avaliar a ação do IFN $\gamma$ sobre as células não leucocitárias no decurso da infecção pelo Plasmodium chabaudi AS. Em forma análoga ao mostrado nas experiências acima, previamente à infecção avaliamos o nível de reconstituição por células IFN $\gamma \mathrm{R}^{+}$em grupos de animais quiméricos $\mathrm{B} 6 / \mathrm{IFN} \gamma \mathrm{RKO}$ e B6/B6, utilizando como controles negativo e positivo camundongos IFN $\gamma$ RKO e B6. Em ambas as experiências a reconstituição foi estimada nos leucócitos de sangue periférico, na forma indicada nos materiais e métodos. Mas ainda em uma dessas avaliamos também a reconstituição a nível do baço. Na figura 31 mostramos os resultados de uma das duas experiências, podendo-se observar que tanto no compartimento das células $\mathrm{B}\left(\mathrm{B} 220^{+}\right)$como das células $\mathrm{T} \mathrm{CD} 4^{+} \mathrm{e}$ $\mathrm{T} \mathrm{CD8}^{+}$, a totalidade dos animais B6/IFN $\gamma \mathrm{RKO}$ tiveram reconstituição por células IFN $\gamma \mathrm{R}^{+}$. Isto é claramente observado comparando a intensidade de fluorescência para este receptor nas células dos animais dos diferentes grupos, apreciando-se níveis similares nas quimeras B6/IFN $\gamma R K O$ e B6/B6 e nos animais B6, contudo, muito superiores aos das células dos animais IFN $\gamma$ RKO. Resultados de reconstituição análogos aos mostrados na figura 31 foram observados na segunda experiência acima citada (dados não mostrados). 


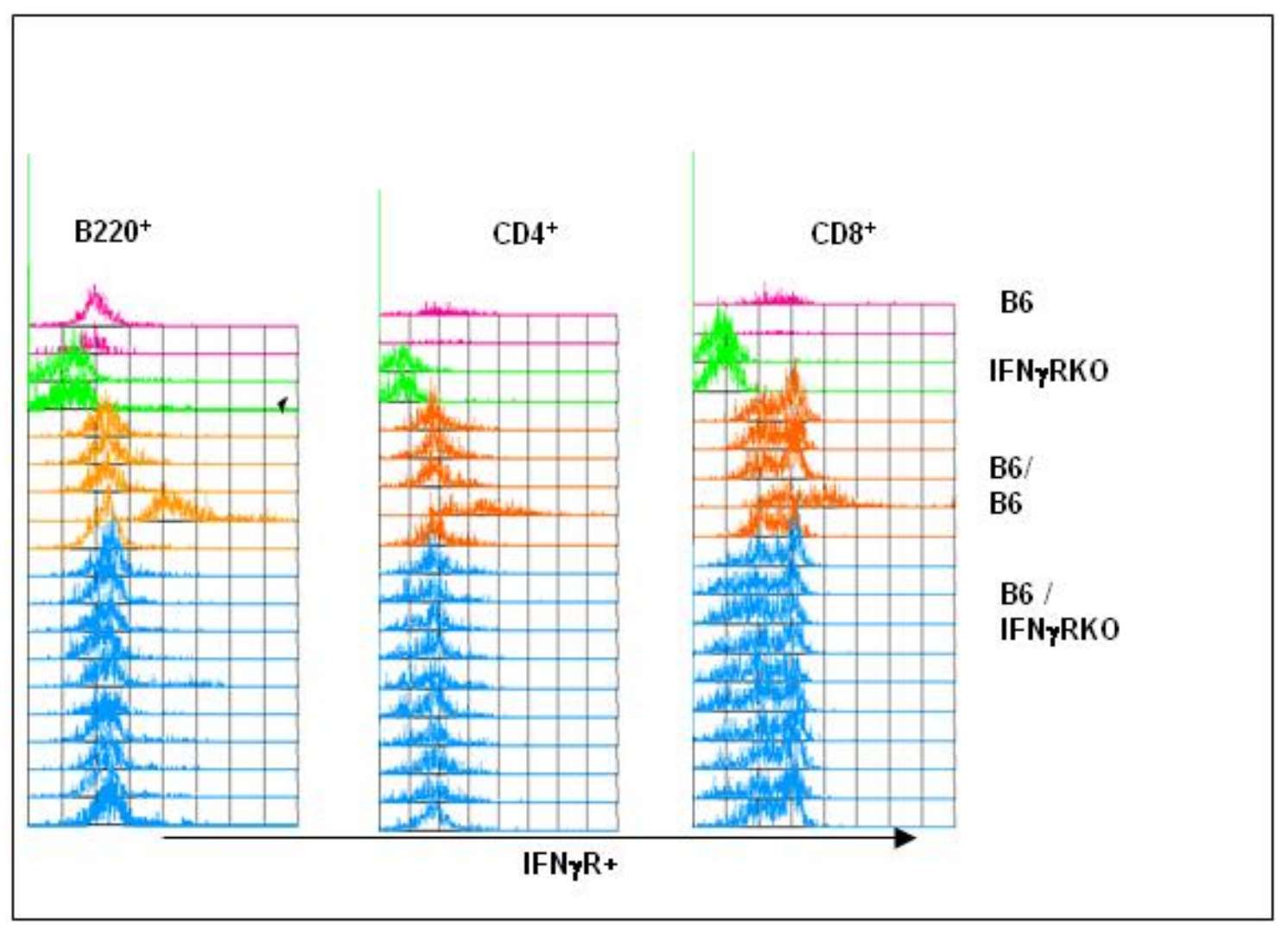

Figura 28. Reconstituição por células IFN $\gamma \mathrm{R}+$ procedentes da medula óssea no compartimento dos linfócitos B (B220+), T CD4+ e T CD8+ do sangue de animais quiméricos B6/IFN $\gamma R K O$, IFN $\gamma$ RKO (controle negativo), B6 e quimeras B6/B6 (controles positivos). (mudar a cor do gráfico)

\subsubsection{INFECÇÃO PELO Plasmodium chabaudi AS}

Uma vez confirmada a reconstituição por células $I F N \gamma R^{+}$e com o objetivo de avaliar se as células estruturais (não leucocitárias) teriam alguma participação na defesa contra o plasmódio, camundongos quiméricos B6/IFN $\gamma$ RKO e B6/B6, assim com camundongos controle IFN $\gamma$ RKO e B6, foram infectados via intraperitoneal com $10^{6}$ hemácias parasitadas pelo $P$. chabaudi AS. 


\subsubsection{PARASITEMIA}

Os animais foram analisados dia a dia em relação à parasitemia (\% de hemácias parasitadas em amostras de sangue da cauda) e mortalidade.

Na figura 32 podemos observar a parasitemia individual nos animais de cada um dos grupos da experiência mostrada na figura $31 \mathrm{e}$, para uma discussão mais fácil, na figura 33, uma comparação bis-a-bis das medias de parasitemia dos diferentes grupos.

A análise comparativa dos grupos IFN $\gamma R K O$ e quimera B6/IFN $\gamma$ RKO mostrou que a curva de parasitemia é idêntica até o dia 6 p.i. (Figura 33 esquerda). Isto sugere que até essa data a presença do IFN $\gamma \mathrm{R}$ nos leucócitos em pouco contribui na evolução da parasitemia. No entanto, nos dias 7-8, a parasitemia é maior nos animais IFN $\gamma$ RKO do que nos animais B6/IFN $\gamma$ RKO indicando que nesse período os leucócitos devem ter papel fundamental. Nesta experiência, a maior parte dos animais IFN $\gamma$ RKO vieram a morrer no dia 8 p.i e a maioria dos animais B6/IFN $\gamma$ RKO no dia 9 p.i., nos impedindo estudar tempos posteriores (Figura 34). Na segunda experiência de infecção por Plasmodium chabaudi, na qual os dados de parasitemia foram similares aos observados na primeira experiência, a totalidade dos animais IFN $\gamma$ RKO veio a falecer no dia 8 p.i., enquanto que nos do grupo B6/IFN $\gamma$ RKO isto aconteceu no dia 10 p.i. (dados não mostrados). Assim, o conjunto dos resultados de mortalidade sugere que, a partir do dia 7 p.i., os leucócitos passam a ter um papel importante no controle do plasmódio pela sua resposta ao IFN $\gamma$.

Já a análise comparativa dos grupos quimera B6/IFN $\gamma$ RKO e quimera B6/B6 mostrou níveis mais elevados de parasitemia nos animais B6/IFN $\gamma R K O$ (Figura 33 centro dados não mostrados da segunda experiência), ressaltando a importância do IFN $\gamma$ R nas células estruturais (não leucocitárias). Mais ainda, na figura 34 podemos observar que a mortalidade acumulativa dos animais $\mathrm{B} 6 / \mathrm{IFN} \gamma \mathrm{RKO}$ foi sensivelmente maior que a dos animais B6/B6. 
Por último, a análise comparativa dos grupos B6 e quimera B6/B6 mostrou níveis discretamente mais elevados de parasitemia nos animais B6/B6 (Figura 33, direita), mostrando que a irradiação não é um processo totalmente inócuo, mas determina uma desestabilização da resposta no animal quimérico. Na segunda experiência de infecção pelo $P$..chabaudi resultados análogos de parasitemia foram observados, mas a mortalidade dos animais B6/B6 foi superior à dos animais $\mathrm{B} 6$, os quais sobreviveram na sua totalidade.

\section{Parasitemia da Infecção por Plasmodium chabaudi AS}

IFNgR-KO

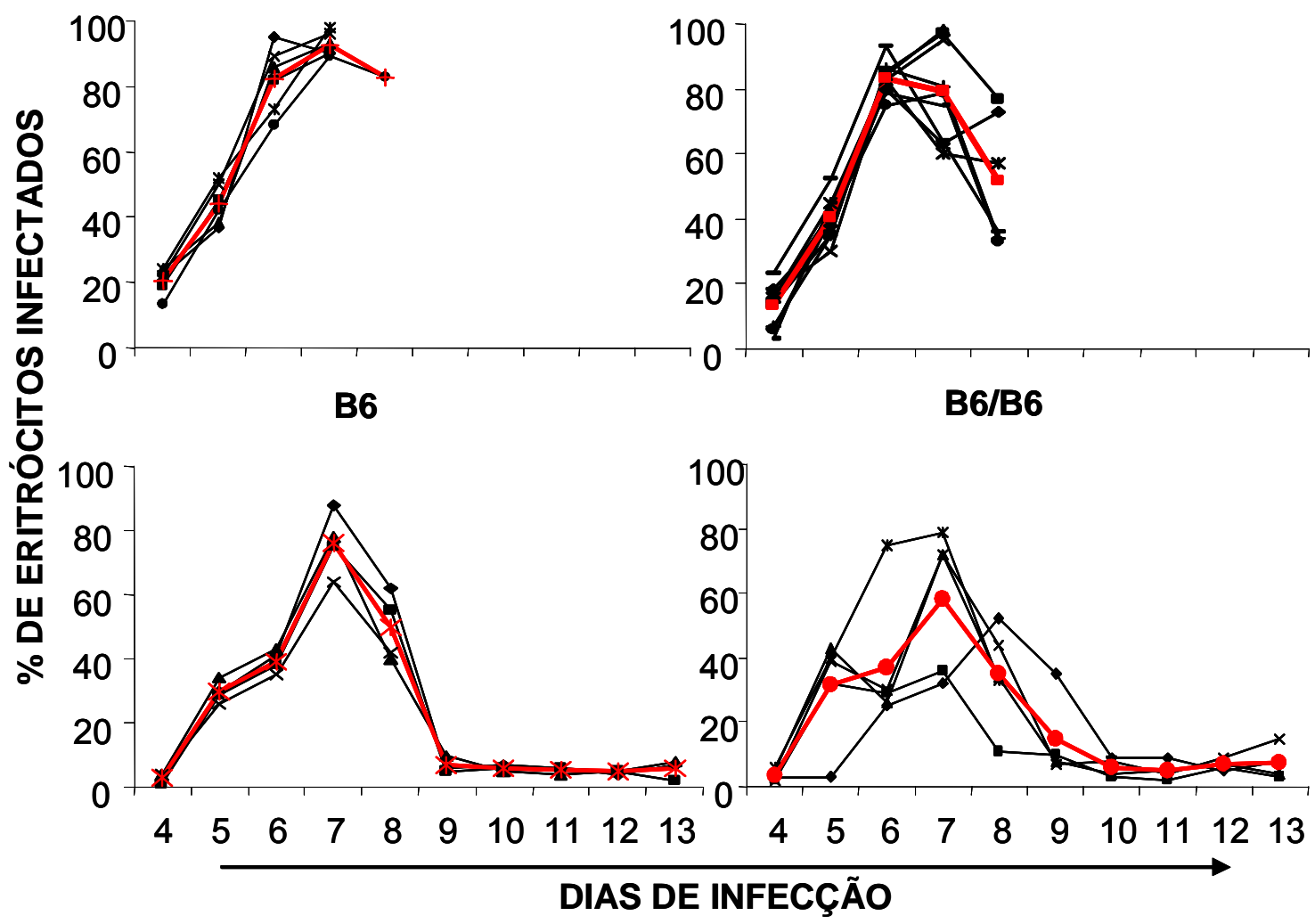

Figura 32. Evolução individual das parasitemias na infecção pelo Plasmodium chabaudi AS em camundongos quiméricos B6/IFN $\gamma$ RKO e B6/B6, assim como em camundongos IFN $\gamma$ RKO e B6. Os animais foram inoculados com $10^{6}$ hemácias parasitadas pelo plasmódio e a freqüência de hemácias infectadas avaliada dia a dia no sangue da cauda. A linha vermelha representa a média de parasitemia por grupo. 
Infecção pelo Plasmodium chabaudi AS de quimeras B6-IFNy̨KO

B6 -IFN RKO $_{0}$ vers us IFN $\mathrm{RK}_{0}$

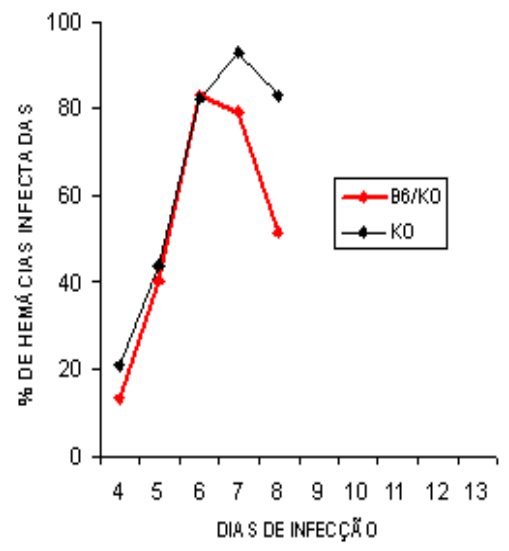

B6/IFNy̨RK0 versus B6/B6

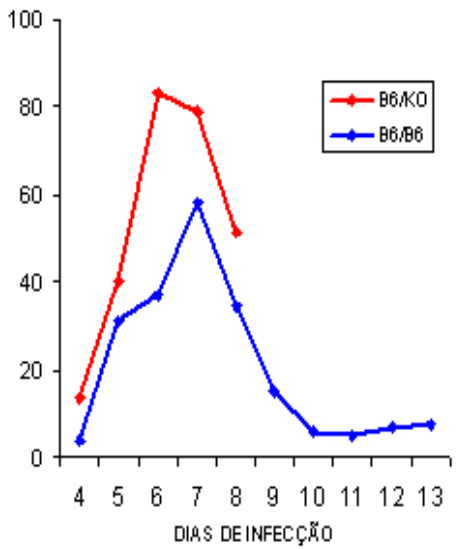

B6/B6 versus B6

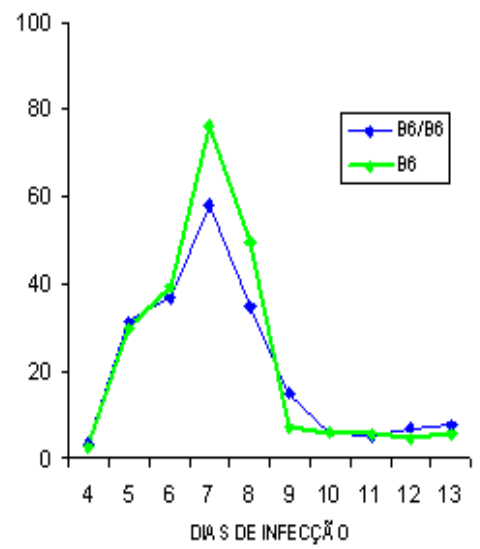

Figura 33. Evolução das médias de parasitemia na infecção pelo Plasmodium chabaudi AS em camundongos quiméricos B6/IFN $\gamma$ RKO e B6/B6, assim como em camundongos IFN $\gamma$ RKO e B6. Os animais foram inoculados com $10^{6}$ hemácias parasitadas pelo plasmódio e a freqüência de hemácias infectadas avaliada dia a dia no sangue da cauda. 


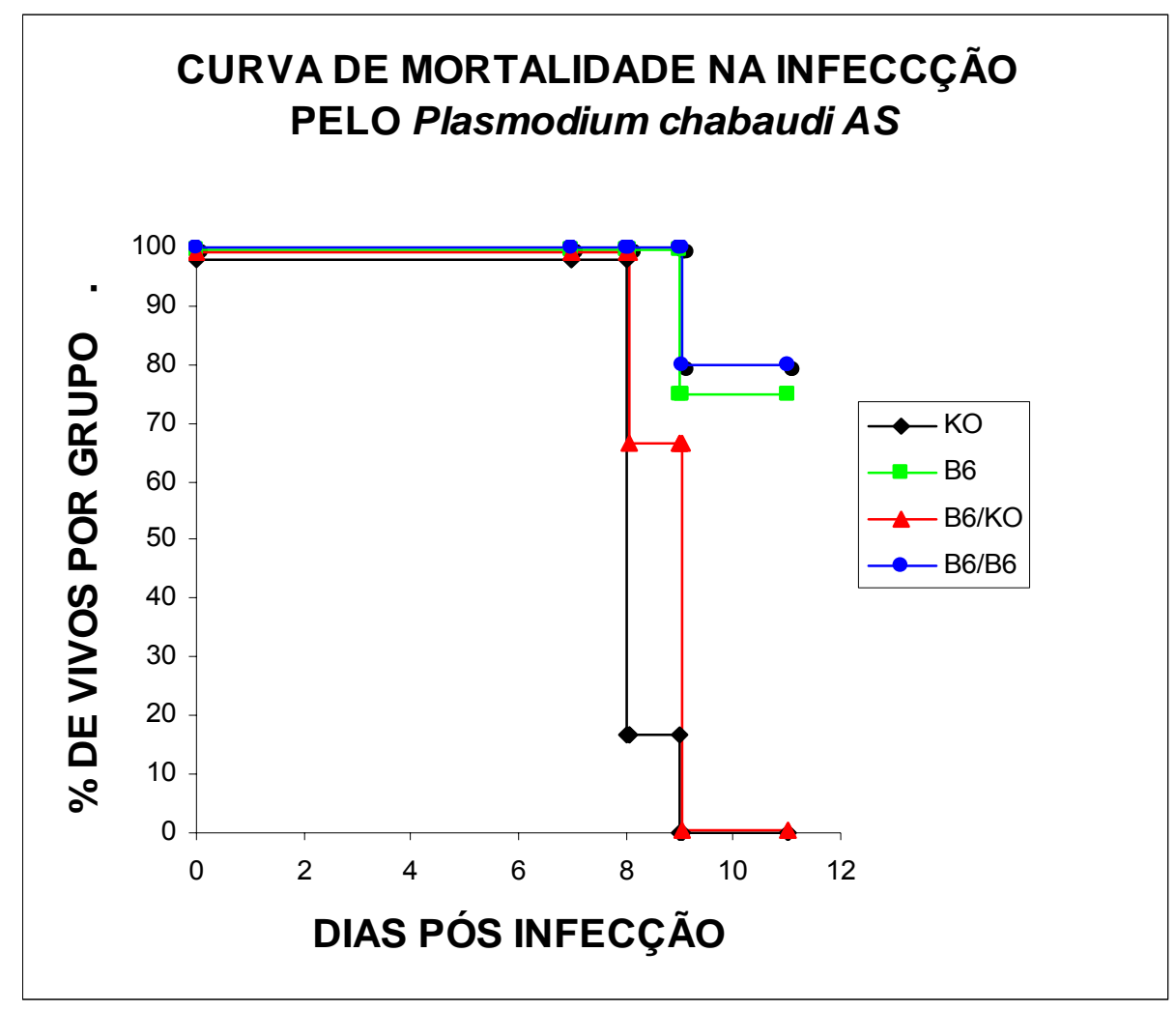

Figura 34. Curva de mortalidade na infecção pelo Plasmodium chabaudi AS em camundongos quiméricos B6/IFN $\gamma$ RKO e B6/B6, assim como em camundongos IFN $\gamma$ RKO e B6. Os animais foram inoculados com $10^{6}$ hemácias parasitadas pelo plasmódio e acompanhados até sua morte.

Para verificar, após infecção pelo $P$. chabaudi, o nível de reconstituição por células IFN $\gamma \mathrm{R}$ no baço das quimeras $\mathrm{B} 6 / \mathrm{IFN} \gamma \mathrm{RKO}$, realizamos análise por citometria de fluxo da expressão de IFN $\gamma R$ por diferentes populações esplênicas de animais dos grupos B6/B6, B6/IFN $\gamma$ RKO e IFN $\gamma$ RKO no dia 8 p.i. Realizamos marcações para CD11c, B220, CD3 e CD11b (FIGURAS 35 e 36). $\mathrm{Na}$ figura 35 podemos observar que nos compartimentos das células CD11c ${ }^{+}$, $\mathrm{B}^{2} 20^{+}$e $\mathrm{CD}^{+}$a totalidade dos animais B6/IFN $\gamma \mathrm{RKO}$ tiveram elevada reconstituição por células IFN $\gamma \mathrm{R}^{+}$. Isto é claramente observado comparando a intensidade de fluorescência para este receptor nas células dos animais dos diferentes grupos, apreciando-se níveis similares nas quimeras B6/IFN $\gamma \mathrm{RKO}$ e B6/B6, contudo, muito superiores à das células dos animais IFN $\gamma$ RKO. Em relação à expressão de CD11c (supostamente células dendríticas) resulta difícil afirmar se a reconstituição por células IFN $\gamma \mathrm{R}^{+}$foi parcial ou total. Isto deve-seo 
ao fato desta população ser minoritária e ter um alto grau de autofluorescência

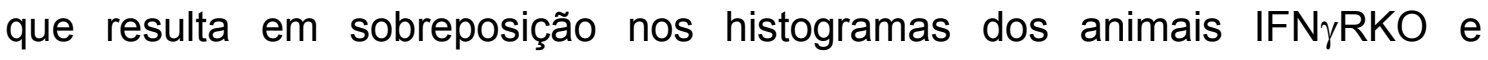
quimeras, sem separação clara de duas populações nos animais B6/IFN $\gamma$ RKO. Nesta experiência não foram analisadas as células dos baços dos animais B6.

CÉLULAS IFNYR + NO BAÇO DE ANIMAIS NO 8*DIA DE INFECÇ̄̉O PELO Plasmodium chabaudi AS

CD11c*

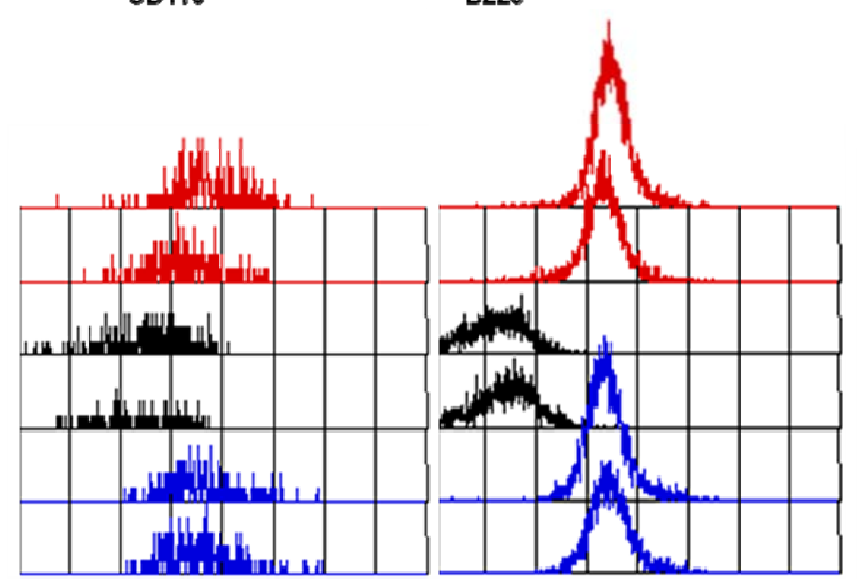

$\mathrm{CD}^{*}$

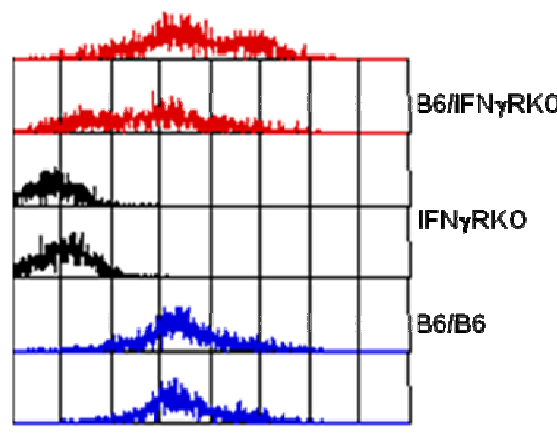

CÉLULAS IFNYr*

Figura 32. Expressão do IFN $\gamma \mathrm{R}$ nas células $\mathrm{CD} 11 \mathrm{c}+, \mathrm{B220}+\mathrm{e} C D 3+$ no baço de animais quiméricos B6/IFN $\gamma R K O$, B6/B6 e IFN $\gamma$ RKO (controle negativo) no $8^{\circ}$ dia de infecção pelo $P$. chabaudi AS. 


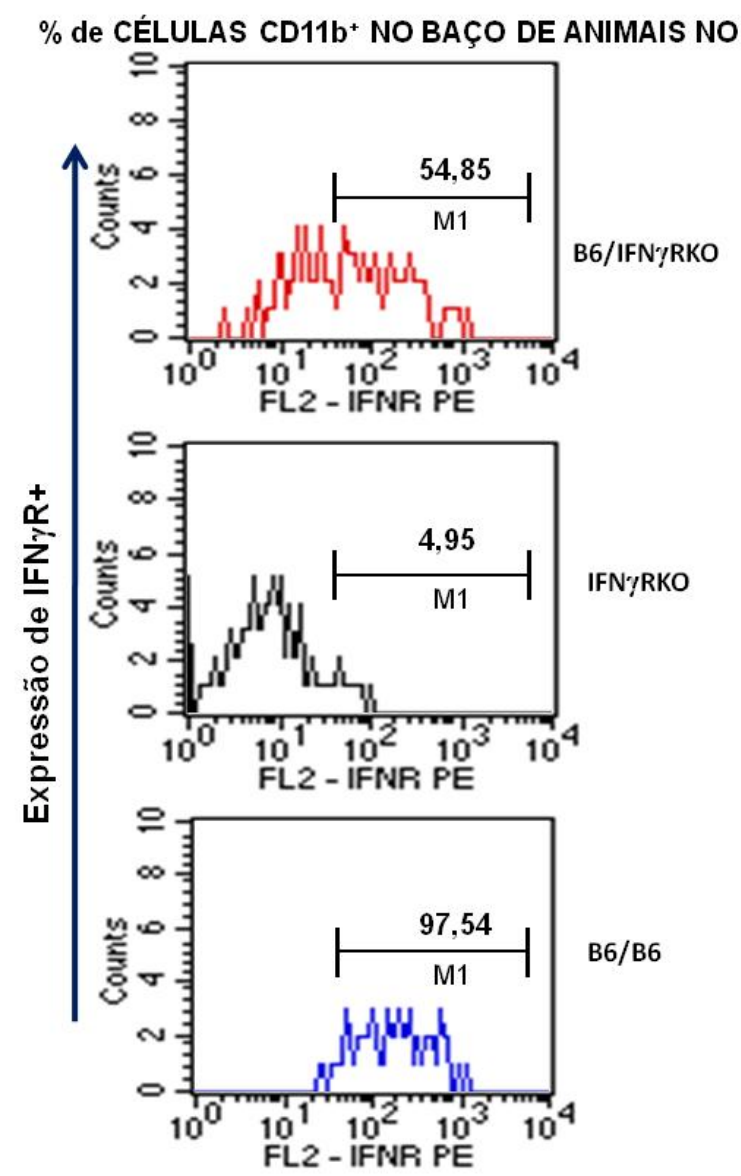

Figura 33. Expressão de IFNyR por células $C D 11 b+$ no baço de animais quiméricos B6/IFN $\gamma R K O, B 6 / B 6$ e IFN $\gamma R K O$ (controle negativo) no $8^{\circ}$ dia de infecção por P. chabaudi AS.

Como forma indireta de avaliar o nível de ativação do sistema imune dos animais infectados, estimamos o peso do baço por ocasião da morte/sacrificio. No dia 8 p.i. um aumento considerável do peso do baço foi observado nos animais do grupo controle IFN $\gamma$ RKO, muito superior ao dos animais B6/B6, enquanto que os animais do grupo quimérico B6/IFN $\gamma$ RKO apresentaram valores intermediários. Já no dia 9 p.i. observamos uma queda do peso do baço dos animais B6/IFN $\gamma R K O$, se igualando ao dos animais B6/B6. Finalmente, no dia 10 p.i. o processo se inverte e o peso do baço dos animais B6/B6 sofre um grande aumento, enquanto que o dos animais B6/IFN $\gamma$ RKO persiste em níveis baixos, similares aos do dia 9 p.i. (Figura 34). Estes resultados indicam uma cinética diferente de ativação do sistema imune, onde os animais do grupo B6/IFN $\gamma \mathrm{RKO}$ exibem uma resposta mais precoce que a do grupo B6/B6. 


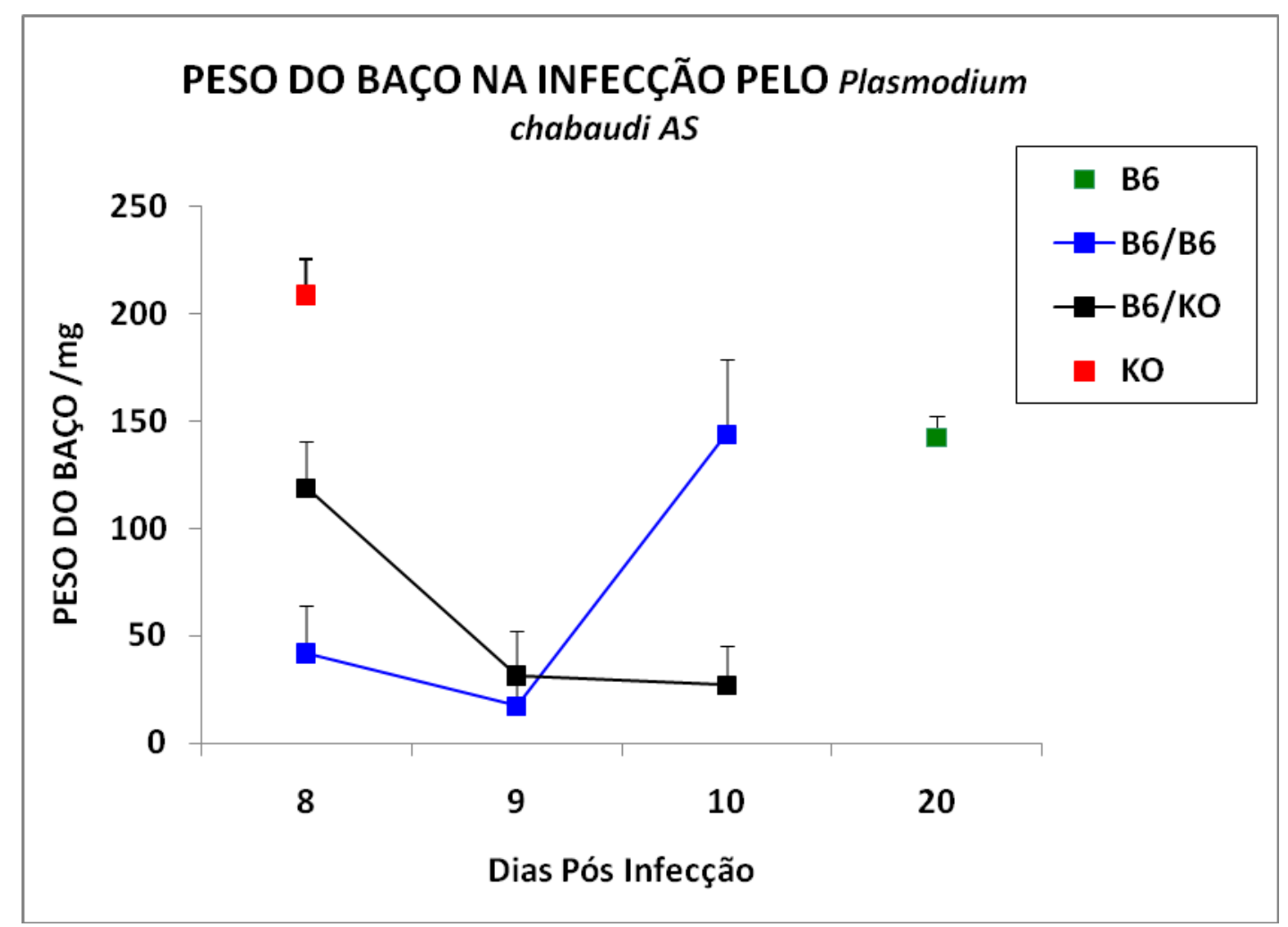

Figura 34. Peso do baço na infecção pelo Plasmodium chabaudi AS em camundongos quiméricos B6/IFN $\gamma$ RKO e B6/B6, assim como em camundongos IFN $\gamma R K O$ e B6. Os grupos foram infectados via intraperitoneal com 106 hemácias parasitadas pelo P. chabaudi AS, e nos dias 8, 9, 10 e 20 p.i. o peso dos baços foi estimado. Cada ponto representa a média \pm erro padrão dos valores individuais de cada grupo. 


\section{DISCUSSÃO}

Com o objetivo de avaliarmos a resposta das células estruturais (não leucocitárias) dos tecidos ao IFN $\gamma$ temos construído quimeras de medula óssea B6/IFN $\gamma$ RKO ou eGFP/IFN $\gamma R K O$, assim como quimeras controle B6/B6 e eGFP/B6. De pose destas ferramentas e após avaliarmos o grau de reconstituição das mesmas, temos realizado experiências preliminares para testar, em três modelos de infecção por protozoários, a contribuição da resposta ao IFN $\gamma$ pelas células estruturais.

O nível de reconstituição das quimeras B6/IFN $\gamma R K O$ e eGFP/IFN $\gamma$ RKO

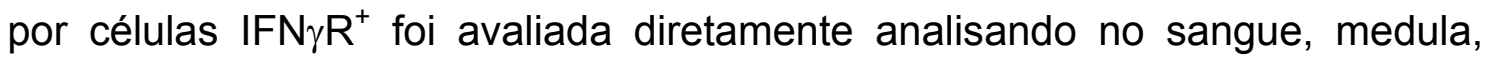
baço, placas de Peyer e fígado a expressão do receptor para IFN $\gamma$. Além disso, como forma indireta de avaliar a reconstituição, verificamos a presença de células eGFP ${ }^{+}$nos tecidos e sangue das quimeras eGFP/IFN $\gamma$ RKO.

Quanto à avaliação no sangue e medula óssea, realizada por citometria de fluxo, observamos que a reconstituição por células IFN $\gamma R^{+}$nos animais B6/IFN $\gamma$ RKO foi a regra, apesar de não ser completa. Contudo, foi geralmente superior a $50 \%$ e mais intensa para os linfócitos $B$ do que para os linfócitos $T$ $\left(C D 4^{+}\right.$ou $\left.\mathrm{CD}^{+}\right)$. Desconhecemos a causa da diferente reconstituição destas duas populações. No entanto, podemos conjeturar que a menor vida média dos linfócitos B naive requer um maior "turnover" e, em conseqüência, depende em maior grau da atividade proliferativa dos precursores B na medula óssea. Uma vez que os precursores medulares são mais sensíveis à irradiação (e consequentemente mais facilmente substituídos por precursores $\operatorname{IFN} \gamma R^{+}$) do que as células maduras, o compartimento das células $B$ deve ser mais eficientemente reposto do que o das células $\mathrm{T}$, que, por possuírem uma vida média mais longa, teriam uma menor necessidade de reposição (via diferenciação tímica) a partir dos precursores medulares.

Já na avaliação do coração por imuno-fluorescência, não constatamos, nos animais $B 6 / I F N \gamma R K O$ a presença de qualquer tipo de célula $I F N \gamma R^{+}$, ou de células eGFP ${ }^{+}$nos animais eGFP/IFN $\gamma$ RKO (ou eGFP/B6), sugerindo não ter acontecido substituição de células estruturais IFN $\gamma \mathrm{R}^{-}$nos animais quiméricos. Assim, se os cardiomiócitos, fibroblastos, adipócitos e as células endoteliais 
dos vasos possuem precursores na medula óssea do animal adulto, a sua reposição deve acontecer em ritmo muito lento, ou em uma freqüência muito baixa.

Diferentemente do coração, a análise por imuno-fluorescência do baço das quimeras eGFP/IFN $\gamma$ RKO mostrou uma expressão de IFN $\gamma$ R semelhante à dos camundongos eGFP/B6. Mais ainda, no aumento 40X, o padrão de expressão eGFP dos animais eGFP/IFN $\gamma$ RKO (ou eGFP/B6) foi semelhante ao dos animais trangênicos para eGFP. No entanto, no aumento 10X, o padrão de expressão eGFP dos animais eGFP foi muito mais intenso que o dos animais eGFP/IFN $\gamma$ RKO (ou eGFP/B6), o que poderia ser explicado pela ausência de células do estroma eGFP ${ }^{+}$no baço dos animais quiméricos, ou pela presença no animal eGFP de proteína fluorescente solúvel derivada dos tecidos estruturais. Apesar deste último achado, o conjunto dos resultados sugere ter acontecido substituição intensa das células do baço nos animais quiméricos. Resultados semelhantes foram obtidos para as placas de Peyer (dados não mostrados). Complemento destas avaliações, as diferentes populações leucocitárias no baço das quimeras B6/IFNyRKO e B6/B6 foram avaliadas por citometria de fluxo quanto à expressão de IFN $\gamma R$ no dia 8 de infecção pelo Plasmodium chabaudi AS. Os resultados confirmaram que nos animais B6/IFN $\gamma$ RKO a totalidade das células $B$ e a maior parte das células $T$ expressam este receptor, enquanto que nos macrófagos e células dendríticas a reconstituição parece ser parcial (por volta de 50\% destas células são IFN $\gamma \mathrm{R}+$ ).

No meio caminho entre a ausência de substituição tissular do coração e a intensa substituição celular no baço dos animais quiméricos eGFP/IFN $\gamma$ RKO, no fígado destes mesmos animais observamos por imuno-fluorescência substituição parcial de células, visível não somente pela expressão de IFN $\gamma R$, mas também pela presença de células eGFP ${ }^{+}$. Este resultado era esperado, uma vez que o fígado contém uma freqüência elevada de células derivadas da medula óssea, tais como células de Kuppfer e diversos tipos de linfócitos ( $B$, T $\alpha \beta$ e $\gamma \delta$, NK e NK-T) (Sardinha et al., 2006). Contudo, é da maior importância termos constatado um padrão reticular de marcação IFN $\gamma \mathrm{R}^{+} / \mathrm{eGFP}^{+}$no fígado das quimeras eGFP/IFN $\gamma R K O$, resultado compatível com a presença de células 
de Kuppfer IFN $\gamma \mathrm{R}^{+} / \mathrm{eGFP}{ }^{+}$derivadas da medula óssea do doador e hepatócitos IFN $\gamma \mathrm{R}^{-} / \mathrm{eGFP}{ }^{-}$derivados do animal receptor .

Para verificarmos a participação efetora frente ao $T$. cruzi das células estruturais (não leucocitárias), que através da sua resposta ao IFN $\gamma$ poderiam eventualmente contribuir ao controle tissular deste protozoário, quimeras B6/IFN $\gamma R K O$ e B6/B6, assim como animais controle B6 e IFN $\gamma R K O$, foram infectadas por tripomastigotas do clone Sylvio X10/4. Os animais do grupo quimérico B6/IFN $\gamma \mathrm{RKO}$ desenvolveram níveis de parasitemia muito baixos (não identificados em 5 dos 7 animais), muito inferiores aos do grupo IFN $\gamma$ RKO (que mostraram parasitemia muito elevada no dia 13 de infecção) e, no entanto, superiores aos dos grupos B6 e B6/B6, nos quais a parasitemia foi negativa em todos os animais. O maior parasitismo sistêmico dos animais B6/IFN $\gamma$ RKO (em relação ao dos animais $\mathrm{B} 6 / \mathrm{B} 6)$ já é compatível per se com a hipótese de trabalho desta dissertação, sugerindo que pela sua resposta ao IFN $\gamma$, as células estruturais participam no controle do T. cruzi.

Ao avaliarmos o coração no dia 19 p.i., observamos que os animais do grupo quimérico B6/IFN $\gamma \mathrm{RKO}$ mostraram maior número de ninhos que os animais quiméricos controle B6/B6. Resultados similares foram observados nestes mesmos animais em relação ao músculo estriado (quadríceps). Estes resultados são compatíveis com um menor controle do parasitismo cardíaco e muscular nos animais que carecem de receptor para IFN $\gamma$ nas células estruturais. Entretanto, o fato da colonização do tecido cardíaco (e da musculatura estriada) ser um evento relativamente tardio na infecção pelo $T$. cruzi, junto á nossa observação da parasitemia estar discretamente aumentada nos animais B6/IFN $\gamma$ RKO (em relação aos B6/B6), nos impede afirmar em forma categórica que o aumento dos ninhos de amastigotas no coração e músculo dos animais B6/IFN $\gamma$ RKO seja conseqüência do menor controle local do T. cruzi, uma vez que poderia ser também explicado por uma maior colonização dos tecidos cardíaco e muscular, secundária ao aumento do parasitismo sistêmico. Contudo, o achado do infiltrado leucocitário do coração e músculo estriado ser mais discreto nos animais B6/IFN $\gamma$ RKO do que nos animais B6/B6 (no dia 19 p.i.), sugere que pela sua resposta ao IFN $\gamma$ sistêmico ou local, as células estruturais estão envolvidas no recrutamento leucocitário. 
Com relação à patologia desenvolvida no fígado constatamos que o grupo quimérico B6/B6 apresentou menor grau de hepatite do que o grupo B6/IFN $\gamma R K O$. Este resultado, diferente ao encontrado no coração e músculo esquelético, sugere que o fígado é um local onde os mediadores produzidos pelas células estruturais (hepatócitos e células endoteliais) em pouco contribuem ao recrutamento leucocitário. Esta nos parece uma conclusão razoável, uma vez que o fígado tem um número muito elevado de leucócitos residentes (principalmente células de Kuppfer) que devem ser os grandes promotores do recrutamento leucocitário para este órgão.

Nos modelos de infecção pelo Plasmodium berghei e Plasmodium chabaudi AS, nosso objetivo era testarmos se as quimeras B6/IFN $\gamma$ RKO teriam níveis mais elevados de parasitemia do que as quimeras B6/B6 em decorrência da ausência do receptor para IFN $\gamma$ no baço. Na infecção por diversas espécies de plasmódio foi lançada a hipótese deste órgão sofrer modificações na arquitetura vascular da polpa vermelha que permitem uma remoção otimizada das hemácias infectadas e/ou merozoitas no início da infecção. Através das nossas experiências, avaliaríamos se estes eventuais processos dependem da resposta ao IFN $\gamma$ pelas células não leucocitárias (células do estroma, células endoteliais e células da musculatura vascular esplênica).

$\mathrm{Na}$ experiência preliminar realizada no modelo de infecção pelo Plasmodium berghei não constatamos em forma clara a participação do IFN $\gamma \mathrm{R}$ no suposto controle do parasita pelas células estruturais, uma vez que as curvas de parasitemia dos animais B6/IFN $\gamma R K O$ e B6/B6 mostraram uma evolução, que embora diferente, foi pouco coerente com a nossa hipótese de trabalho. Assim, apesar dos animais B6/IFN $\gamma$ RKO mostrarem um primeiro pico de parasitemia discretamente maior ao dos animais B6/B6, este pico foi seguido de queda mais pronunciada.

Já em relação à infecção pelo $P$. chabaudi, os grupos IFN $\gamma$ RKO e quimera B6/IFN $\gamma$ RKO mostraram curvas parasitemicas semelhantes até o dia 6 p.i, sugerindo que até essa data a presença do IFN $\gamma$ R nos leucócitos em pouco contribui ao controle do plasmódio. Nos dias 7-8, entretanto, e como esperado, a parasitemia passou a ser menor no grupo B6/IFN $\gamma$ RKO do que no grupo 
IFN $\gamma$ RKO. Por outro lado, a análise comparativa das parasitemias nos grupos B6/IFN $\gamma R K O$ e B6/B6 mostrou níveis mais elevados e precoces de parasitas no sangue nos animais B6/IFN $\gamma$ RKO. Mais ainda, a mortalidade dos animais B6/IFN $\gamma$ RKO foi maior que a dos animais B6/B6. Assim, no conjunto, os nossos resultados no modelo de infecção pelo $P$. chabaudi sugerem que a resposta ao IFN $\gamma$ pelas células estruturais (não leucocitárias) contribui em forma importante ao controle deste parasita. É difícil considerarmos qual pode ser a contribuição das células não leucocitárias ao controle do $P$. chabaudi. Podemos conjeturar que, além das supostas mudanças na arquitetura da polpa vermelha, o IFN $\gamma$ pode ter aumentado a expressão de moléculas de adesão nas células endoteliais, facilitando o processo de fagocitose pelos fagócitos residentes.

Além de permitir uma indagação sobre o participação do IFN $\gamma$ no controle do parasita (análise das curvas de parasitemia), o modelo de infecção pelo Plasmodium berghei ANKA permite avaliarmos se, pela sua resposta ao IFN $\gamma$, as células estruturais estão envolvidas no desenvolvimento do quadro de inflamação do sistema nervoso central conhecido como malária cerebral. Na literatura, já foi amplamente documentado o papel crucial do IFN $\gamma$ no estabelecimento deste quadro patológico. Resta saber, se além do seu papel sobre os leucócitos, o IFN $\gamma$ opera através das células não leucocitárias. Assim, poderia acontecer que, após sequestro (aderência) de hemácias parasitadas nos vasos do sistema nervoso central e produção de IFN $\gamma$ pelos leucócitos congregados no local, as células endoteliais dos vasos respondessem a esta citocina potenciando o extravasamento de líquido e o consequente edema cerebral.

Na experiência preliminar realizada observamos, em concordância com a literatura, que a totalidade dos camundongos B6 sucumbe rapidamente à infecção pelo $P$. berghei (dia 9 p.i.), enquanto os animais IFN $\gamma$ RKO sobrevivem por um tempo mais demorado (dias 27-28 p.i.). Já a análise comparativa dos grupos quiméricos mostrou que os animais B6 /B6 morrem entre os dias 9-12 p.i., enquanto que a maior parte dos animais B6/IFN $\gamma$ RKO falece entre os dias 10 e 12, apesar de um único animal deste grupo ter sobrevivido até o dia 27 p.i. Assim, os nossos dados confirmam o papel fundamental do IFN $\gamma$ no 
desenvolvimento da malária cerebral, mas sugerem que a resposta das células não leucocitárias a esta citocina em pouco contribui ao desenvolvimento do quadro patológico. Novos experimentos com um "n" maior serão necessários para descartar totalmente o envolvimento funcional do IFN $\gamma$ R nas células não leucocitárias.

Finalmente, em algumas das experiências realizadas neste mestrado observamos que os animais do grupo B6/B6 se comportam em forma discretamente diferente aos animais B6, indicando que a irradiação não é um processo inócuo, mas cobra um preço na resposta imune no animal quimérico. Neste sentido, animais irradiados mantém por vários meses níveis sistêmicos elevados de prostaglandinas (PETERS-GOLDEN, comunicação pessoal ${ }^{1}$ ), o que resulta em um ambiente anti-inflamatório. Desta forma, no modelo de quimeras de medula óssea, as análises comparativas devem ser sempre realizadas entre as quimeras experimental e controle.

\footnotetext{
${ }^{1}$ PETERS-GOLDEN dados que tiver... Local e ano.
} 


\section{CONCLUSÕES}

\section{- Reconstituição}

- a reconstituição por células eGFP de sangue periférico e medula óssea é maior nas células $B$ do que nas células $T$.

- não se observou qualquer reconstituição por células eGFP $^{+}$no tecido cardíaco dos animais quiméricos eGFP/B6 ou eGFP/IFN $\gamma R K O$.

- não se observou qualquer reconstituição por células $\operatorname{IFN} \gamma R^{+}$no tecido cardíaco dos animais quiméricos eGFP/IFN $\gamma$ RKO.

- Por imunofluorescência a expressão de IFN $\gamma R$ no baço dos animais eGFP/IFN $\gamma$ RKO foi semelhante à observada em camundongos eGFP/B6 e B6.

- Por imunofluorescência foi observada expressão pontual e difusa de IFN $\gamma R$ no fígado dos animais eGFP/IFN $\gamma$ RKO, contudo muito inferior à mostrada pelos camundongos eGFP/B6 e B6.

\section{- Infecção pelo T. cruzi Sylvio X10/4}

- O infiltrado inflamatório cardíaco nos animais B6 e B6/B6 foi intenso, enquanto que no grupo B6/IFN $\gamma$ RKO foi moderado ou ausente. Entretanto, o parasitismo tissular no coração dos animais do grupo B6/IFN $\gamma$ RKO foi mais intenso que o do grupo B6/B6.

- Em forma semelhante ao coração, no músculo estriado esquelético (quadríceps) os infiltrados inflamatórios dos animais do grupo B6/IFN $\gamma$ RKO foram mais discretos que os dos animais $\mathrm{B} 6$ e B6/B6. Além disso, nos animais B6 e B6/B6 não se observaram ninhos no quadríceps no dia 19 p.i., que foram observados em 2 dos 4 animais do grupo B6/IFN $\gamma$ RKO.

- Diferentemente do coração, no fígado dos animais do grupo B6/IFN $\gamma R K O$ o infiltrado inflamatório foi intenso/severo, semelhante ou até discretamente superior aoencontrado nos animais B6 e B6/B6. 


\section{- A infecção pelo Plasmodium berghei ANKA}

- Em concordância com os resultados da literatura, a totalidade dos camundongos B6 sucumbiu no dia 9 p.i., enquanto que os animais IFN $\gamma$ RKO sobreviveram até os dias 27-28 p.i.

- Os animais B6/B6 faleceram entre os dias 9-12 p.i., enquanto que os B6/IFN $\gamma$ RKO faleceram do dia 10 ao 12, e somente um sobreviveu até o dia 27 p.i. Os nossos dados confirmam o envolvimento da resposta leucocitária ao IFN $\gamma$ no desenvolvimento da malária cerebral, mas sugerem que a resposta das células não leucocitárias a esta citocina em pouco contribui ao desenvolvimento deste quadro patológico.

\section{- Infecção pelo Plasmodium chabaudi AS}

- Até o dia 6 p.i., a curva de parasitemia mostrou-se idêntica entre os animais

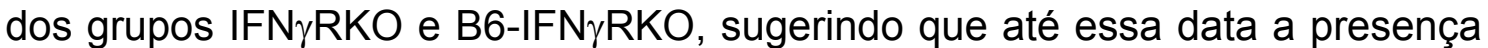
de leucócitos IFN $\gamma R^{+}$em pouco contribui na evolução da parasitemia. No entanto, a partir do dia 7 p.i. a parasitemia se torna maior nos animais IFN $\gamma R K O$ do que nos $\mathrm{B} 6 / / \mathrm{FN} \gamma \mathrm{RKO}$, sugerindo que a partir desta data os leucócitos passam a ter um papel importante no controle do plasmódio pela sua resposta ao IFN $\gamma$.

- A análise comparativa dos grupos B6/IFNyRKO e quimera B6/B6 mostrou níveis mais elevados de parasitemia e maior mortalidade nos animais B6/IFN $\gamma$ RKO, indicando que as células estruturais (não leucocitárias) participam no controle do plasmódio pela sua resposta ao IFN $\gamma$.

- Análise por citometria de fluxo da reconstituição por células IFN $\gamma R^{+}$no baço das quimeras infectadas por 8 dias com $P$. chabaudi revelou reconstituição total de células $B, T$, assim como uma reconstituição parcial de macrófagos e células dendríticas. 


\section{REFERÊNCIAS}

ABRAHAMSOHN, I.A.; COFFMAN, R.L. Trypanosoma cruzi: IL-10, TNF, IFNgamma, and $\mathrm{IL}-12$ regulate innate and acquired immunity to infection. Exp. Parasitol., v. 84, p. 231-244, 1996.

ABRAHAMSOHN, I.A.; SILVA, W.D. Antibody dependent cell-mediated cytotoxicity against Trypanosoma cruzi. Parasitology, v. 75, p. 317-323, 1977.

ALCANTARA, A.; BRENER, Z. The in vitro interaction of Trypanosoma cruzi bloodstream forms and mouse peritoneal macrophages. Acta Trop., v. 35, p. 209-219, 1978.

ALIBERTI, J.C.; SOUTO, J.T.; MARINO, A.P.; LANNES-VIEIRA, J.; TEIXEIRA, M.M.; FARBER, J.; GAZZINELLI, R.T.; SILVA, J.S. Modulation of chemokine production and inflammatory responses in interferon-gamma- and tumor necrosis factor-R1-deficient mice during Trypanosoma cruzi infection. Am. J. Pathol., v. 158, p. 1433-1440, 2001.

ALVES HJ; WEIDANZ W; WEISS L. The spleen in murine Plasmodium chabaudi adami malaria: stromal cells, T lymphocytes, and hematopoiesis. Am. J . Trop. Med. Hyg., 1996; 55:370-8.

AL-YAMAN F, GENTON B, KRAMER KJ, CHANG SP, HUI GS, BAISOR M et al. Assessment of the role of naturally acquired antibody levels to Plasmodium falciparum merozoite surface protein-1 in protecting Papua New Guinean children from malaria morbidity. Am. J. Trop. Med. Hyg., 1996; 54:443-8.

AMANI V, VIGÁRIO AM, BELNOUE E, MARUSSIG M, FONSECA L, MAZIER D, RÉNIA L. Involvement of IFN-gamma receptor-medicated signaling in pathology and anti-malarial immunity induced by Plasmodium berghei infection. Eur J Immunol. 2000 Jun;30(6):1646-55

ASAHARA T, MUROHARA T, SULLIVAN A, SILVER M, VAN DER ZEE R, LI T, WITZENBICHLER $B$, SCHATTEMAN G, ISNER JM. Isolation of putative progenitor endothelial cells for angiogenesis. Science. 1997;275:964-967.

\footnotetext{
De acordo com:

ASSOCIAÇÃO BRASILEIRA DE NORMAS TÉCNICAS. NBR 6023: Informação e documentação: referências: elaboração. Rio de Janeiro, 2002.
} 
ASAHARA T, MASUDA H, TAKAHASHI T, KALKA C, PASTORE C, SILVER M, KEARNE M, MAGNER M, ISNER JM Bone marrow origin of endothelial progenitor cells responsible for postnatal vasculogenesis in physiological and pathological neovascularization. Circ Res. 1999 Aug 6;85(3):221-8.

BACH O, BAIER $\mathrm{M}$, PULLWITT A, ET AL. Falciparum malaria after splenectomy: a prospective controlled study of 33 previously splenectomized Malawian adults. Trans R Soc Trop Med Hyg 2005;99(11):861-7.

BAGOT, M. IDRISSA BOUBOU, S. CAMPINO, C. BEHRSCHMIDT, O. GORGETTE, J.-L. GUÉNET, C. PENHA-GONÇALVES D. MAZIER, S. PIED, AND P.-A. CAZENAVE. Susceptibility to Experimental Cerebral Malaria Induced by Plasmodium berghei ANKA in Inbred Mouse Strains Recently Derived from Wild Stock. Infect. Immun., p. 2049-2056, Apr., 2002.

BAIRD JK, JONES TR, DANUDIRGO EW, ANNIS BA, BANGS MJ, BASKI H et al. Agedependent acquired protection against Plasmodium falciparum in people having two years exposure to hyperendemic malaria. Am J Trop Med Hyg. 1991; 45:65-76.

BAIRD JK, KRISIN, BARCUS MJ, ELYAZAR IR, BANGS MJ, MAGUIRE JD, FRYAUFF DJ, RICHIE TL, SEKARTUTI, KALALO W. Onset of clinical immunity to Plasmodium falciparum among Javanese migrants to Indonesian Papua. Ann Trop Med Parasitol. 2003; 97:557-64.

BEUCHER M, NORRIS KA. (2008). Sequence diversity of the Trypanosoma cruzi complement regulatory protein family. Infect Immun. Feb;76(2):750-8. Epub 2007 Dec 10.

BOGDAN, C., ROLLINGHOFF, M DIEFENBACH (2000) .A Reactive oxygen and reactive nitrogen intermediates in innate and specific immunity. Curr Opin Immunol, 12 (1): 64-76,

BRENER, Z.; ANDRADE, Z.A. (1987). Trypanosoma cruzi e Doença de Chagas. Rio de Janeiro: Guanabara Koogan, 1987. p. 6-10.

BUDZKO, D.B.; PIZZIMENTI, M.C.; KIERSZENBAUM, F. (1975). Effects of complement depletion in experimental chagas disease: immune lysis of virulent blood forms of Trypanosoma cruzi. Infect Immun, 11: 86-91.

BURLEIGH, B.A. e ANDREWS, N.W. (1995). The mechanisms of Trypanosoma cruzi invasion of mammalian cells. Annu Rev Microbiol, 49: 175-200. 
BURLEIGH, B.A., E.V. CALER, P. WEBSTER, AND N.W. ANDREWS. A cytosolic serine endopeptidase from Trypanosoma cruzi is required for the generation of Ca21 signaling in mammalian cells.. J. Cell Biol. 136:609-620, 1997.

C. BEKPEN, J.P. HUNN, C. ROHDE, I. PARVANOVA, L. GUETHLEIN, D.M. DUNN, E. GLOWALLA, M. LEPTIN, J.C. HOWARD, The interferon-inducible p47 (IRG) GTPases in vertebrates: loss of the cell autonomous resistance mechanism in the human lineage, Genome Biol. 6 (2005) R92.

CALER, E.V., S.V. DE AVALOS, P.A HAYNES, N.W. ANDREWS, AND B.A. BURLEIGH (1998). Oligopeptidase B-dependent signaling mediates host cell invasion by Trypanosoma cruzi. EMBO (Eur. Mol. Biol. Organ.) J. 17:49754986,

CARDILLO, F.; VOLTARELLI, J.C.; REED, S.G.; SILVA, J.S. (1996). Regulation of Trypanosoma cruzi infection in mice by gamma interferon and interleukin 10: role of NK cells. Infect Immun, 64: 128-134.

CAVINATO RA, BASTOS KRB, SARDINHA LR, ELIAS RM, ALVAREZ JM, D'IMPÉRIO LIMA MR. Susceptibility of the different blood forms of Plasmodium chabaudi chabaudi to hyperimmune serum, IgG1, IgG2a and F(ab')2 fragments. Parasite Immunol. 2001; 23:587-97.

CHAMBERS, T.J. 1978. Multinucleate giant cells. J. Pathol.126:125-148.

CHANDRASEKAR B, MELBY PC, TROYER DA, FREEMAN GL. Differential regulation of nitric oxide synthase isoforms in experimental acute chagasic cardiomyopathy. Clin Exp Immunol 2000;121(1):112-9.

CHANDRASEKAR B, MELBY PC, PENNICA D, FREEMAN GL. Overexpression of cardiotrophin-1 and gp130 during experimental acute Chagasic cardiomyopathy. Immunol Lett 1998;61(2-3):89-95.

CHU, C.Q., WITTMER, S. ALTON D.K. (2000). Failure to suppres the expansion of the activated CD4 T cell population in interferon gamma-deficient mice leads to exacerbation of experimental autoimmune encephalomyetitis. $J$ Exp Med, 192 (1): 123-128,. 
CLARK IA, HUNT NH, BUTCHER GA, COWDEN WB. Inhibition of murine malaria (Plasmodium chabaudi) in vivo by recombinant interferon-gamma or tumor necrosis factor, and its enhancement by butylated hydroxyanisole. J Immunol. 1987 Nov 15;139(10):3493-6.

COHEN S, MACGREGOR IA, CARRINGTON S. Gamma-globulin and acquired immunity to human malaria. Nature. 1961; 192:733-7.

COHN, Z.A. (1978). Activation of mononuclear phagocytes: fact, fancy, and future. J Immunol, 121: 813-816.

COLLI, W. (1993). Trans-sialidase: a unique enzyme activity discovered in the protozoan Trypanosoma cruzi. Faseb J, 7: 1257-1264.

COMBES V, COLTEL N, FAILLE D, WASSMER SC, GRAU GE.Cerebral malaria: role of microparticles and platelets in alterations of the blood-brain barrier. REVIW -Int J Parasitol. 2006 May 1;36(5):541-6. Epub 2006 Mar 10

CONTAMIN H, BEHR C, MERCEREAU-PUIJALON O, MICHEL J. Plasmodium falciparumin the squirrel monkey (Saimiri sciureus): infection of nonsplenectomised animals as a model for exploring clinical manifestations of malaria. Microbes Infect 2000;2(8):945-54.

DALTON, D.K, HAYNES, L. CHU, CQ. SWAIN, S. L. WITTMER, S. Interferon gamma responding CD4T cells during mycobacterial infection by inducing apoptosis of activated CD4T cells. J Exp Med 192:117-22, 2000.

DEMAR M, LEGRAND E, HOMMEL D, ESTERRE P, CARME B. Plasmodium falciparum malaria in splenectomized patients: two case reports in French Guiana and a literature review. Am J Trop Med Hyg 2004;71(3):290-3.

DEVELOPMENT of antimalaria immunity in mice lacking IFN-gamma receptor. J Immunol. 1995 May 15;154(10):5338-44.

DOCAMPO, R., AND S.N.J. MORENO.. The role of Ca21 in the process of cell invasion by intracellular parasites. Parasitol. Today. 12:61-65, 1996.

DOOLAN DL, HOFFMAN SL. Pre-erythrocytic stage immune effector mechanisms in Plasmodium spp. infections. Phi Fans Roy Sot Lond. 1997; 352:1361-7.

EGAN AF, MORRIS J, BARNISH G, ALLEN S, GREENWOOD BM, KASLOW $D C$ et al. Clinical immunity to Plasmodium falciparum malaria is associated with 
serum antibodies to the 19-kDa Cterminal fragment of the merozoite surface antigen, PfMSP-1. J Infect Dis. 1996; 173:765-9.

ELIAS RM, SARDINHA LR, BASTOS KRB, ZAGO CA, DA SILVA AP, ALVAREZ JM, LIMA MR. Role of CD28 in polyclonal and specific T and B cell responses required for protection against blood stage malaria. J Immunol. 2005; 174:790-9.

FALANGA PB, FRANCO DA SILVEIRA JF, PEREIRA DA SILVA L. Protective immune response to Plasmodium chabaudi, developed by mice after drug controlled infection or vaccination with parasite extracts: analysis of stage specific antigens from the asexual blood cycle. Parasite Immunol. 1984; 6:52943

FAVRE N, RYFFEL B, BORDMANN G, RUDIN W.The course of Plasmodium chabaudi chabaudi infections in interferon-gamma receptor deficient mice.Parasite Immunol. 1997 Aug;19(8):375-83.

FICHERA LE, ALBAREDA MC, LAUCELLA SA, POSTAN M. Intracellular growth of Trypanosoma cruzi in cardiac myocytes is inhibited by cytokineinduced nitric oxide release. Infect Immun 2004;72(1):359-63.

FRANCHIN, G.; PEREIRA-CHIOCCOLA, V.L.; SCHENKMAN, S.; RODRIGUES, M.M. (1997). Passive transfer of a monoclonal antibody specific for a sialic acid-dependent epitope on the surface of Trypanosoma cruzi trypomastigotes reduces infection in mice. Infect Immun, 65: 2548-2554.

FREEMAN RR, PARISH CRF. PLASMODIUM YOELII: antibody and the maintenance of immunity in balb/c mice. exp parasitol. 1981; 52:18-24.

G.A. TAYLOR, C.G. FENG, A. Sher, p47 GTPases: regulators of immunity to intracellular pathogens, Nat. Rev. Immunol. 4 (2004) 100e109.

G.R. STARK, I.M. KERR, B.R. WILLIAMS, R.H. SILVERMAN, R.D. SCHREIBER, How cells respond to interferons, Annu. Rev. Biochem. 67 (1998) $227 \mathrm{e} 264$.

GALVAO DA SILVA, A.P. e DE ALMEIDA ABRAHAMSOHN, I. (2001). Interleukin-12 stimulation of lymphoproliferative responses in Trypanosoma cruzi infection. Immunology, 104: 349-354. 
GAZZINELLI, R.T.; OSWALD, I.P.; HIENY, S.; JAMES, S.L.; SHER, A. (1992). The microbicidal activity of interferon-gamma-treated macrophages against Trypanosoma cruzi involves an L-arginine-dependent, nitrogen oxide-mediated mechanism inhibitable by interleukin-10 and transforming growth factor-beta. Eur J Immunol, 22: 2501-2506.

GENG L, IWABUCHI K, SAKAI S, OGASAWARA M, FUJITA M, OGASAWARA K, KAKINUMA M, GOOD RA, MORIKAWA K, ONOÉ K Analysis of synthetic sites of fourth and fifth components of serum complement system in allogeneic bone marrow chimaeras. Immunology. 1986 Jul;58(3):453-7.

GOOD MF, BERZOFSKY JA, MILLER LH. The T cell response to the malaria circumsporozoite protein: an immunological approach to vaccine development. Annu Rev Immunol. 1988, 6:663-88.

GRAU, G. E., H. HEREMANS, P. F. PIGUET, P. POINTAIRE, P. H. LAMBERT, A. BILLIAU, AND P. VASSALLI. 1989. Monoclonal antibody against interferon gamma can prevent experimental cerebral malaria and its associated overproduction of tumor necrosis factor. Proc. Natl. Acad. Sci. USA 86:55725574.

GREENWOOD MB, BRADLEY AK, GREENWOOD AM, BYASS P, JAMMEH K, MARSH K, TULLOCH S, OLDFIELD FS, HAYES R. Mortality and morbidity from malaria among children in rural area of The Gambia, West Africa. Trans Royal Soc Trop Med Hyg. 1987; 81:478-86.

GRUN JL, LONG CA, WEIDANZ WP. Effects of splenectomy on antibodyindependent immunity to Plasmodium chabaudi adami malaria. Infect Immun. 1985; 48:853-8.

HATCHER, F.M. e KUHN, R.E. (1982). Destruction of Trypanosoma cruzi by Natural killer cells. Science, 218: 295-296.

HENRIQUES-PONS, A.; OLIVEIRA, G.M.; PAIVA, M.M.; CORREA, A.F.; BATISTA, M.M.; BISAGGIO, R.C.; LIU, C.C.; COTTA-DE-ALMEIDA, V.; COUTINHO, C.M.; PERSECHINI, P.M.; ARAUJO-JORGE, T.C. (2002). Evidence for a perforin-mediated mechanism controlling cardiac inflammation in Trypanosoma cruzi infection. Int. J. Exp. Pathol., 83: 67-79.

HOFFMAN SL, CRUTCHER JM, PURI SK, ANSARI AA, VILLINGER F, FRANKE ED, SINGH PP, FINKELMAN F, GATELY MK, DUTTA GP, 
SEDEGAH M. Sterile protection of monkeys against malaria after administration of interleukin-12. Nat Med. 1997; 3:80-3.

HOFFMAN SL, FRANKE ED, HOLLINGDALE MR, DRUILHE P. Attacking the infected hepatocyte. In Malaria Vaccine Development: A Multi- immune Response Approach. Edited by Hoffman SL. Washington, DC: Am Soc Microbiol Press. 1996; 35-76.

HOFT, D.F.; LYNCH, R.G.; KIRCHHOFF, L.V. (1993). Kinetic analysis of antigen-specific immune responses in resistant and susceptible mice during infection with Trypanosoma cruzi. J Immunol, 151: 7038-7047.

HUNT NH, GOLENSER J, CHAN-LING T, PAREKH S, RAE C, POTTER S, MEDANA IM, MIU J, BALL HJ. Immunopathogenesis of cerebral malaria. Int J Parasitol. 2006 May 1;36(5):569-82.

IEZZI, G. KARJALAINEN, K. LANZAVECCHIA, A (1998). The duaration of antigenic stimulation determines the fate of naïve and effector Tcells. Immunity, 8 (1): 89-95,.

J.D. MACMICKING, IFN-inducible GTPases and immunity to intracellular pathogens, Trends Immunol. 25 (2004) 601e609.

J.D. MACMICKING, Immune control of phagosomal bacteria by p47 GTPases, Curr. Opin. Microbiol. 8 (2005) 74e82.

JACOBS P, RADZIOCH D, STEVENSON MM .In vivo regulation of nitric oxide production by tumor necrosis factor alpha and gamma interferon, but not by interleukin-4, during blood stage malaria in mice. Infect Immun. 1996 Jan;64(1):44-9.

JAMES, S.L.; KIPNIS, T.L.; SHER, A.; HOFF, R. (1982). Enhanced resistance to acute infection with Trypanosoma cruzi in mice treated with an interferon inducer. Infect Immun, 35: 588-593.

JAMIE R. SCHOENBORN* AND CHRISTOPHER B. WILSON (2007). Regulation of interferon-gamma during innate and adaptive immune responses.. Adv Immunol.;96:41-101. Review. † 
JARRA W, HILLS LA, MARCH JC, BROWN KN. Protective immunity to malaria. Studies with cloned lines of Plasmodium chabaudi chabaudi and $P$. berghei in CBA/Ca mice. II. The effectiveness and inter- or intra-species specificity of the passive transfer of immunity with serum. Parasite Immunol. 1986; 8:239-54.

KAUL DK, LIU XD, NAGEL RL, SHEAR HL. Microvascular hemodynamics and in vivo evidence for the role of intercellular adhesion molecule-1 in the sequestration of infected red blood cells in a mouse model of lethal malaria. Am J Trop Med Hyg. 1998 Feb;58(2):240-7.

KIERSZENBAUM, F. e HAYES, M.M. (1980). Mechanisms of resistance against experimental Trypanosoma cruzi infection. Requirements for cellular destruction of circulating forms of $\mathrm{T}$. cruzi in human and murine in vitro systems. Immunology, 40: 61-66.

KIERSZENBAUM, F. e LIMA, M.F. (1983). Susceptibility of insect-borne, metacyclic forms of Trypanosoma cruzi to antibody-mediated mechanisms of destruction. Am J Trop Med Hyg, 32: 1236-1241.

KIERSZENBAUM, F. (2003). Views on the autoimmunity hypothesis for Chagas disease pathogenesis. FEMS Immunol. Med. Microbiol., 37: 1-11.

KIPNIS, T.L.; JAMES, S.L.; SHER, A.; DAVID, J.R. (1981). Cell-mediated cytotoxicity to Trypanosoma cruzi. II. Antibody-dependent killing of bloodstream forms by mouse eosinophils and neutrophils. Am J Trop Med Hyg, 30: 47-53.

KIPNIS, T.L.; KRETTLI, A.U.; DIAS DA SILVA, W. (1985). Transformation of trypomastigote forms of Trypanosoma cruzi into activators of alternative complement pathway by immune IgG fragments. Scand J Immunol, 22: 217226.

KLEINSCHMIDT I, SHARP B. Patterns in age specific malaria incidence in a population exposed to low levels of malaria transmission intensity. Trop Med Int Health. 2001; 6:986-91.

KLOTZ FW, SCHELLER LF, SEGUIN MC, KUMAR N, MARLETTA MA, GREEN SJ, AZAD AF. Colocalization of inducible nitric oxide synthase and Plasmodium berghei in hepatocytes from rats immunized with irradiated sporozoites. J Immunol. 1995; 154:3391-5. 
KOS, F.J. e ENGLEMAN, E.G. (1996). Immune regulation: a critical link between NK cells and CTLs. Immunol Today, 17: 174-176.

KRETTLI, A.U. e PONTES DE CARVALHO, L.C. (1979). Membrane bound antibodies to bloodstream Trypanosoma cruzi in mice: strain differences in susceptibility to complement mediated lyses. Clin. Exp. Immunol., 37: 416-423.

KUBIN, M.; CHOW, J.M.; TRINCHIERI, G. (1994). Differential regulation of interleukin-12 (IL-12), tumor necrosis factor alpha, and IL-1 beta production in human myeloid leukemia cell lines and peripheral blood mononuclear cells. Blood, 83: 1847-1855.

LANGHORNE J, GILLARD S, SIMON B, SLADE S, EICHMANN K. Frequencies of CD4+ T cells reactive with Plasmodium chabaudi chabaudi: distinct response kinetics for cells with Th1 and Th2 characteristics during infection. Int Immunol. 1989; 1:416-24.

LEAVEY, J.K. e TARLETON, R.L. (2003). Cutting edge: dysfunctional CD8+ T cells reside in nonlymphoid tissues during chronic Trypanosoma cruzi infection. J Immunol, 170: 2264-2268.

LIMA, A.P.; ALMEIDA, P.C.; TERSARIOL, I.L.; SCHMITZ, V.; SCHMAIER, A.H.; JULIANO, L.; HIRATA, I.Y.; MULLER-ESTERL, W.; CHAGAS, J.R.; SCHARFSTEIN, J. (2002). Heparan sulfate modulates kinin release by Trypanosoma cruzi through the activity of cruzipain. J Biol Chem, 277: 58755881.

LONG CA, DALY TM, KIMA P, SRIVASTAVA I. Immunity To Erythrocytic Stages Of Malarial Parasites. Am J Trop Med Hyg. 1994;50(4 Suppl):27-32. Review.

MACHADO FS, MARTINS GA, ALIBERTI JC, MESTRINER FL, CUNHA FQ, SILVA JS. Trypanosoma cruzi-infected cardiomyocytes produce chemokines and cytokines that trigger potent nitric oxide-dependent trypanocidal activity. Circulation 2000;102(24):3003-8.

MAEGRAITH BG. In: Medicine in tropics. (ed) A. W. Woodruff, Edinburgh, Churchill Livingstone. 1974; p. 23-73. 
MAGGIO-PRICE L, BROOKOFF D, WEISS L. Changes in hematopoietic stem cells in bone marrow of mice with Plasmodium berghei malaria. Blood. 1985; 66:1080-5.

MARINHO CR, BUCCI DZ, DAGLI ML, BASTOS KR, GRISOTTO MG, SARDINHA LR, BAPTISTA CR, GONÇALVES CP, LIMA MR, ALVAREZ JM. Pathology affects different organs in two mouse strains chronically infected by a Trypanosoma cruzi clone: a model for genetic studies of Chagas' disease. Infect Immun. 2004 Apr;72(4):2350-7.

MARINHO CR, NUÑEZ-APAZA LN, MARTINS-SANTOS R, BASTOS KR, BOMBEIRO AL, BUCCI DZ, SARDINHA LR, LIMA MR, ALVAREZ JM (2007). IFN-gamma, but not nitric oxide or specific IgG, is essential for the in vivo control of low-virulence Sylvio X10/4 Trypanosoma cruzi parasites. Scand J Immunol. Aug-Sep;66(2-3):297-308.

MARINHO, C.R.; D'IMPERIO LIMA, M.R.; GRISOTTO, M.G.; ALVAREZ, J.M. (1999). Influence of acute-phase parasite load on pathology, parasitism, and activation of the immune system at the late chronic phase of Chagas' disease. Infect Immun, 67: 308-318.

MARSH K, OTOO L, HAYES RH, CARSON DC, GREENWOOD BM. Antibodies to blood stage antigens of Plasmodium falciparum in rural Gambians and their relation to protection against infection. Trans R Soc Trop Med Hyg. 1989; 83:293-303.

MARTINS, G. A., VIEIRA, L. Q., SILVA, SILVA, J.S. Gamma interferon modulates CD95 (Fas) and CD95 ligand (FasL) expression and nitric oxideinduced apoptosis during the acute phase of Trypanosoma cruzi infection: a possible role in immune response control. Infect Immun, 67: 3864-71, 1999.

MEDANA IM, TURNER GD. Human cerebral malaria and the blood-brain barrier. REVIW-Int J Parasitol. 2006 May 1;36(5):555-68.

MEDING SJ, CHENG SC, SIMON-HAARHAUS B, LANGHORNE J Role of gamma interferon during infection with Plasmodium chabaudi chabaudi. Infect Immun. 1990 Nov;58(11):3671-8

MING, M., M.E. EWEN, AND M.E. PEREIRA. 1995. Trypanosoma invasion of mammalian cells requires activation of the TGF-b signaling pathway. Cell. 82:287-296 
MINOPRIO, P.; EL CHEIKH, M.C.; MURPHY, E.; HONTEBEYRIEJOSKOWICZ, M.; COFFMAN, R.; COUTINHO, A.; O'GARRA, A. (1993). Xidassociated resistance to experimental Chagas' disease is IFN-gamma dependent. J Immunol, 151: 4200-4208.

MORTARA RA, ANDREOLI WK, FERNANDES MC, DA SILVA CV, FERNANDES AB, L'ABBATE C, DA SILVA S (2008). Host cell actin remodeling in response to Trypanosoma cruzi: trypomastigote versus amastigote entry. Subcell Biochem.;47:101-9. Review.

MUNOZ-FERNANDEZ, M.A.; FERNANDEZ, M.A.; FRESNO, M. (1992). Synergism between tumor necrosis factor-alpha and interferon-gamma on macrophage activation for the killing of intracellular Trypanosoma cruzi through a nitric oxide-dependent mechanism. Eur J Immunol, 22: 301-307.

NABORS, G.S. e TARLETON, R.L. (1991). Differential control of IFN-gamma and IL-2 production during Trypanosoma cruzi infection. J Immunol, 146: 35913598.

NOGUEIRA, N.; CHAPLAN, S.; REESINK, M.; TYDINGS, J.; COHN, Z.A. (1982). Trypanosoma cruzi: induction of microbicidal activity in human mononuclear phagocytes. J Immunol, 128: 2142-2146.

ONOÉ K, ARASE N, ARASE H, TAKAYANAGI T, NISHIHORI H, IWABUCHI K, OGASAWARA K, GOOD RA. Influence of graft versus host reaction on the T cell repertoire differentiating from bone marrow precursors following allogeneic bone marrow transplantation. : Transpl Immunol. 1997 Jun;5(2):75-82

ONOÉ K, FERNANDES G, GOOD RA. Humoral and cell-mediated immune responses in fully allogeneic bone marrow chimera in mice. J Exp Med. 1980 Jan 1;151(1):115-32

OSTER CN, KOONTZ LC, WYTER DI. Malaria in asplenic mice: effect of splenectomy, congenital asplenia, and splenic reconstitution on the course of infection. Am J Trop Med Hyg. 1980; 29:1138-41.

PAUL, W.E. e SEDER, R.A. (1994). Lymphocyte responses and cytokines. Cell, 76: 241-251. 
PINO P, TAOUFIQ Z, NITCHEU J, VOULDOUKIS I, MAZIER D. Blood-brain barrier breakdown during cerebral malaria: suicide or murder? Thromb Haemost. 2005 Aug;94(2):336-40.

PLATA, F.; GARCIA-PONS, F.; WIETZERBIN, J. (1987). Immune resistance to Trypanosoma cruzi: synergy of specific antibodies and recombinant interferon gamma in vivo. Ann Inst Pasteur Immunol, 138: 397-415.

PLATA, F.; WIETZERBIN, J.; PONS, F.G.; FALCOFF, E.; EISEN, H. (1984). Synergistic protection by specific antibodies and interferon against infection by Trypanosoma cruzi in vitro. Eur J Immunol, 14: 930-935.

PROCKOP DJ. Marrow stromal cells as stem cells for nonhematopoietic tissues. Science 1997;276:71-74.

RAFAELI, Y., VAN PARIJS, L., ALEXADER, S.I., ABBAS, A.K. Interferon gamma is requerid for ativacion-induced death of lymphocytes. J Exp Med, 196 (7): 999-1005, 2002.

REED, S.G.; BROWNELL, C.E.; RUSSO, D.M.; SILVA, J.S.; GRABSTEIN, K.H.; MORRISSEY, P.J. (1994). IL-10 mediates susceptibility to Trypanosoma cruzi infection. J Immunol, 153: 3135-3140.

REY, L. (1991). Parasitologia - 2a edição. Rio de Janeiro. Guanabara Koogan , p. 104-12, 138-52.

ROMANHA, A.J.; ALVES, R.O.; MURTA, S.M.; SILVA, J.S.; ROPERT, C.; GAZZINELLI, R.T. (2002). Experimental chemotherapy against Trypanosoma cruzi infection: essential role of endogenous interferon-gamma in mediating parasitologic cure. J Infect Dis, 186: 823-828.

RUDIN W, FAVRE N, BORDMANN G, RYFFEL B. Interferon-gamma is essential for the development of cerebral malaria. Eur J Immunol. 1997 Apr;27(4):810-5.

RUPPERT, E.E. e BARNES, R.D. (1994). Invertebrate Zoology - 6th ed. New York: Saunders College Publishing, p. 10-67.

RUSSO, M.; MINOPRIO, P.; COUTINHO, A.; HONTEBEYRIE-JOSKOWICZ, M. (1988). Depletion of L3T4+ T lymphocytes during acute Trypanosoma cruzi 
infection abolish macrophage and B lymphocyte activation but not tissue inflammatory reaction. Mem Inst Oswaldo Cruz, 83: 527-538.

S. EHRT, D. SCHNAPPINGER, S. BEKIRANOV, J. DRENKOW, S. SHI, T.R. GINGERAS, T. GAASTERLAND, G. SCHOOLNIK, C. NATHAN, REPROGRAMMING OF THE MACROPHAGE transcriptome in response to interferon-gamma and Mycobacterium tuberculosis: signaling roles of nitric oxide synthase-2 and phagocyte oxidase, J. Exp. Med. 194 (2001) 1123e1140.

S. MARTENS, J. HOWARD, The interferon-inducible GTPases, Annu. Rev. Cell Dev. Biol. 22 (2006) 559e589.

SABCHAREON A, BURNOUF T, OUTTARA D, ATTANATH P, BOUHARON TAYOUN $\mathrm{H}$ et al. Parasitologic and clinical human response to immunoglobulin administration in falciparum malaria. Am J Trop Med Hyg. 1991; 45:297-308.

SALES PA JR, GOLGHER D, OLIVEIRA RV, VIEIRA V, ARANTES RM, LANNES-VIEIRA J, GAZZINELLI RT.The regulatory CD4+CD25+ T cells have a limited role on pathogenesis of infection with Trypanosoma cruzi. Microbes Infect. 2008 May;10(6):680-8. Epub 2008 Mar 29.

SARDINHA LR, ELIAS RM, MOSCA T, BASTOS KR, MARINHO CR, D'IMPÉRIO LIMA MR, ALVAREZ JM. Contribution of NK, NK T, gamma delta T, and alpha beta $T$ cells to the gamma interferon response required for liver protection against Trypanosoma cruzi. Infect Immun. 2006 Apr;74(4):2031-42

SAUL A. Kinetic constraints upon the development of a malaria vaccine. Parasite Immunol. 1987; 9:1-9.

SCHARFSTEIN J, LIMA AP. Roles of naturally occurring protease inhibitors in the modulation of host cell signaling and cellular invasion by Trypanosoma cruzi. Subcell Biochem.;47:140-54, 2008

SCHARFSTEIN, J., SCHMITZ, V., MORANDI, V., CAPELLA, M.M., LIMA, A.P., MORROT, A., JULIANO, L., MULLER-ESTERL, W., Host cell invasion by Trypanosoma cruzi is potentiated by activation of bradykinin $\mathrm{B}(2)$ receptors. $\mathrm{J}$. Exp. Med. 192, 1289-1300. 2000

SCHOFIELD L, VILLAQUIRAN J, FERREIRA A, SCHELLEKENS $\mathrm{H}$, NUSSENZWEIG RS, NUSSENZWEIG V. Gamma-interferon, CD8+ T cells and antibodies required for immunity to malaria sporozoites. Nature. 1987; 330:6646. 
SEDEGAH M, FINKELMAN F, HOFFMAN SL. Interleukin-12 induction of interferon gammadependent protection against malaria. Proc Nat/ Acad Sci USA. 1994; 91(22):10700-2.

SEGUIN MC, KLOTZ FW, SCHNEIDER I, WEIR JP, GOODBATY M, SLAYTER $M$ et al. Induction of nitric oxide synthase protects against malaria in mice exposed to irradiated Plasmodium berghei infected mosquitoes: involvement of interferon gamma and CD8+ T cells. J Exp Med. 1994; 180:353-8.

SILVA, J.S.; MACHADO, F.S.; MARTINS, G.A. (2003). The role of nitric oxide in the pathogenesis of Chagas disease. Front. Biosci., 8: s314-325.

SILVA, J.S.; MORRISSEY, P.J.; GRABSTEIN, K.H.; MOHLER, K.M.; ANDERSON, D.; REED, S.G. (1992). Interleukin 10 and interferon gamma regulation of experimental Trypanosoma cruzi infection. J Exp Med, 175: 169174.

SINGH RP, KASHIWAMURA $S$, RAO $P$, OKAMURA $H$, MUKHERJEE $A$, CHAUHAN VS The role of IL-18 in blood-stage immunity against murine malaria Plasmodium yoelii 265 and Plasmodium berghei ANKA. J Immunol. 2002 May $1 ; 168(9): 4674-81$.

SHI Q, RAFII S, WU MH, WIJELATH ES, YU C, ISHIDA A, FUJITA $Y$, KOTHARI S, MOHLE R, SAUVAGE LR, MOORE MA, STORB RF, HAMMOND WP. Evidence for circulating bone marrow-derived endothelial cells. Blood. 1998;92:362-367.

SNAPPER, C.M. e PAUL, W.E. (1987). B cell stimulatory factor-1 (interleukin 4) prepares resting murine $B$ cells to secrete IgG1 upon subsequent stimulation with bacterial lipopolysaccharide. J Immunol, 139: 10-17.

SNAPPER, C.M.; MCINTYRE, T.M.; MANDLER, R.; PECANHA, L.M.; FINKELMAN, F.D.; LEES, A.; MOND, J.J. (1992). Induction of IgG3 secretion by interferon gamma: a model for $\mathrm{T}$ cell-independent class switching in response to T cell-independent type 2 antigens. J Exp Med, 175: 1367-1371.

SOBEK, V. BALKOW, S., KORNER, H., SIMON, M. M.. Antigen-induced cell death of $T$ effector cells in vitro proceeds via Fas patway, requires endogenous interferon-gamma and is independent of perforin and granzymes. Eur $\mathrm{J}$ Immunol, 32 ( 9): 2490-2499, 2002. 
STEVENSON MM, TAM MF, BELOSEVIC M, VAN DER MEIDE PH, PODOBA JE. ROLE OF endogenous gamma interferon in host response to infection with blood-stage Plasmodium chabaudi AS. Infect Immun. 1990 Oct;58(10):3225-32.

STEVENSON MM, TAM MF, WOLF SF, SHER A. IL-12-induced protection against blood-stage Plasmodium chabaudi AS requires IFN-gamma and TNFalpha and occurs via a nitric oxide-dependent mechanism. J Immunol. 1995 Sep 1;155(5):2545-56.

SU Z, STEVENSON M. Central role of endogenous gamma interferon in protective immunity against blood-stage Plasmodium chabaudi AS infection. Infect Immun. 2000; 68:4399-406.

TAMBOURGI, D.V.; KIPNIS, T.L.; DIAS DA SILVA, W. (1989). Trypanosoma cruzi: antibody-dependent killing of bloodstream trypomastigotes by mouse bone marrow-derived mast cells and by mastocytoma cells. Exp Parasitol, 68: 192-201.

TANOWITZ, H.B.; KIRCHHOFF, L.V.; SIMON, D.; MORRIS, S.A.; WEISS, L.M.; WITTNER, M. (1992). Chagas' disease. Clin Microbiol Rev, 5: 400-419.

TARDIEUX, I., M.H. NATHANSON, and N.W. ANDREWS. Role in host cell invasion of Trypanosoma cruzi-induced cytosolic free Ca21 transients. J. Exp. Med. 179:1017-1022, 1994

TARLETON, R.L. (1990). Depletion of CD8+ T cells increases susceptibility and reverses vaccine-induced immunity in mice infected with Trypanosoma cruzi. J Immunol, 144: 717-724.

TARLETON, R.L. (1991). Regulation of immunity in Trypanosoma cruzi infection. Exp Parasitol, 73: 106-109.

TARLETON, R.L.; KOLLER, B.H.; LATOUR, A.; POSTAN, M. (1992). Susceptibility of beta 2-microglobulin-deficient mice to Trypanosoma cruzi infection. Nature, 356: 338-340.

TAYLOR-ROBINSON AW, PHILLIPS RS, SEVERN A, MONCADA S, LIEW FY. The role of TH1 and TH2 cells in a rodent malaria infection. Science. 1993 Jun 25;260(5116):1931-4. 
TONGREN JE, ZAVALA F, ROOS DS, RILEY EM. Malaria vaccines: if at first you don't succeed... Trends Parasitol. 2004; 20(12):604-10.

TSUJI M, MIYAHIRA Y, NUSSENZWEIG RS, AGUET M, REICHEL M, ZAVALA F.

TZELEPIS F, DE ALENCAR BC, PENIDO ML, CLASER C, MACHADO AV, BRUNA-ROMERO O, GAZZINELLI RT, RODRIGUES MM. Infection with Trypanosoma cruzi restricts the repertoire of parasite-specific CD8+ $T$ cells leading to immunodominance.J Immunol. 2008 Feb 1;180(3)

BOEHM, T. KLAMP, M. GROOT, J.C. HOWARD, Cellular responses to interferon- gamma, Annu. Rev. Immunol. 15 (1997) 749e795.

UMEKITA, L.F. e MOTA, I. (1989). In-vitro lysis of sensitized Trypanosoma cruzi by platelets: role of $\mathrm{C} 3 \mathrm{~b}$ receptors. Parasite Immunol, 11: 561-566.

UNE, C.; ANDERSSON, J.; ELORANTA, M.L.; SUNNEMARK, D.; HARRIS, R.A.; ORN, A. (2000). Enhancement of natural killer (NK) cell cytotoxicity and induction of NK cell-derived interferon-gamma (IFN-gamma) display different kinetics during experimental infection with Trypanosoma cruzi. Clin. Exp. Immunol., 121: 499-505.

van der HEYDE HC, PEPPER B, BATCHELDER J, CIGEL F, WEIDANZ WP The time course of selected malarial infections in cytokine-deficient mice. Exp Parasitol. 1997 Feb;85(2):206-13.

VARMA, T.K., C.Y., TOLIVER, T.E, SHERWOOD, E. R.. Endotoxin induced gamma interferon production: contributing cell types and key regulatory factors. Clin Diagn Lab Immunol, 9 (3): 530-43, 2002.

VESPA, G.N.; CUNHA, F.Q.; SILVA, J.S. (1994). Nitric oxide is involved in control of Trypanosoma cruzi-induced parasitemia and directly kills the parasite in vitro. Infect Immun, 62: 5177-5182.

VILLEVAL JL, LEW A, METCALF D. Changes in hematopoietic and regulator levels in mice during fatal or nonfatal malarial infections. 1. Erythropoietic populations. Exp Parasitol. 1990; 71: 364-74.

VITELLI-AVELAR DM, SATHLER-AVELAR R, MASSARA RL, BORGES JD, LAGE PS, LANA M, TEIXEIRA-CARVALHO A, DIAS JC, ELÓI-SANTOS SM, MARTINS-FILHO OA Are increased frequency of macrophage-like and natural killer (NK) cells, together with high levels of NKT and CD4+CD25high T cells 
balancing activated CD8+ T cells, the key to control Clin Exp Immunol. 2006 Jul;145(1):81-92.

von der Weid T, Langhorne $\mathrm{J}$. The roles of cytokines produced in the immune response to the erythrocytic stages of mouse malarias. Immunobiology 1993;189(3-4):397-418.

WASSMER SC, COMBES $V$, CANDAL FJ, JUHAN-VAGUE I, GRAU GE Platelets potentiate brain endothelial alterations induced by Plasmodium falciparum. Infect Immun. 2006 Jan;74(1):645-53

WEISS, L. Mechanism of splenic control of murine malaria: cellular reactions of the spleen in lethal (strain 17XL) Plasmodium yoelli malaria in BALB/c mice, and the consequences of pro-infective splenectomy. Am J Trop Med Hyg. 1989. 41:144-60.

WHO,2008 (http://www.who.int/ctd/chagas/disease.htm).

WILSON, K.C. e FINBLOOM, D.S. (1992). Interferon gamma rapidly induces in human monocytes a DNA-binding factor that recognizes the gamma response region within the promoter of the gene for the high-affinity Fc gamma receptor. Proc Natl Acad Sci U S A, 89: 11964-11968.

WIRTH, J.J.; KIERSZENBAUM, F.; SONNENFELD, G.; ZLOTNIK, A. (1985). Enhancing effects of gamma interferon on phagocytic cell association with and killing of Trypanosoma cruzi. Infect Immun, 49: 61-66.

YADAVA A, KUMAR S, DVORAK JA, MILON G, MILLER LH. Trafficking of Plasmodium chabaudi adami-infected erythrocytes within the mouse spleen. Proc Natl Acad Sci USA. 1996; 93:4595-9.

YAP GS, STEVENSON MM. Plasmodium chabaudi AS: erythropoietic responses during infection in resistant and susceptible mice. Exp Parasitol. 1992; 75:340-52.

YONETO T, YOSHIMOTO T, WANG CR, TAKAHAMA Y, TSUJI M, WAKI S, NARIUCHI H. Gamma interferon production is critical for protective immunity to infection with blood-stage Plasmodium berghei XAT but neither NO production nor NK cell activation is critical. Infect Immun. 1999 May;67(5):2349-56. 
ZHANG, L. , TARLETON, R.L. (1996). Persistent production of inflammatory and anti-inflammatory cytokines and associated MHC and adhesion molecule expression at the site of infection and disease in experimental Trypanosoma cruzi infections. Exp Parasitol, 84: 203-213.

ZIEGELHOEFFER T, FERNANDEZ B, KOSTIN S, HEIL M, VOSWINCKEL R, HELISCH A, SCHAPER W. Bone marrow-derived cells do not incorporate into the adult growing vasculature. Circ Res. 2004 Apr 30;94(8):e71. 